\title{
Development of instrumentation for the investigation of surface regeneration for candle filters
}

\author{
Sean Patrick Gregory \\ West Virginia University
}

Follow this and additional works at: https://researchrepository.wvu.edu/etd

\section{Recommended Citation}

Gregory, Sean Patrick, "Development of instrumentation for the investigation of surface regeneration for candle filters" (2001). Graduate Theses, Dissertations, and Problem Reports. 1192.

https://researchrepository.wvu.edu/etd/1192

This Thesis is protected by copyright and/or related rights. It has been brought to you by the The Research Repository @ WVU with permission from the rights-holder(s). You are free to use this Thesis in any way that is permitted by the copyright and related rights legislation that applies to your use. For other uses you must obtain permission from the rights-holder(s) directly, unless additional rights are indicated by a Creative Commons license in the record and/ or on the work itself. This Thesis has been accepted for inclusion in WVU Graduate Theses, Dissertations, and Problem Reports collection by an authorized administrator of The Research Repository @ WVU. For more information, please contact researchrepository@mail.wvu.edu. 


\title{
Development of Instrumentation for the Investigation of Surface Regeneration for Candle Filters
}

\author{
Sean Gregory \\ Thesis submitted to the College of Engineering and Mineral Resources \\ at West Virginia University in partial fulfillment of the \\ requirements for the degree of \\ Master of Science \\ in \\ Mechanical Engineering \\ Eric K. Johnson, Ph.D., Chair \\ Bruce Kang, Ph.D., Co-Chair \\ Department of Mechanical and Aerospace Engineering \\ Richard A. Dennis \\ National Energy Technology Laboratory
}

Morgantown, West Virginia

2001

Keywords: Candle Filter, Surface Regeneration, Pressure Histories 


\author{
ABSTRACT \\ Development of Instrumentation for the Investigation of \\ Surface Regeneration for Candle Filters \\ Sean Gregory
}

Two methods of improving efficiency of coal based power generation are integrated gasification combined-cycle (IGCC) and pressurized fluidized-bed combustion (PFBC). Both of these options require high-temperature gas stream particle cleanup for optimum efficiency. Candle filters in a pressurized vessel have received the greatest amount of attention in dealing with this topic, but problems still persist and there does not seem to be clear-cut answer to the problem. This research is an investigation of the candle filter cleaning process, a process known as surface regeneration.

The objective of this research program has been to develop the instrumentation necessary to investigate the surface regeneration process in a room temperature test facility (RTTF).

For this project a room temperature chamber was built to observe the candle filter cleaning process, denoted as surface regeneration. Instrumentation was installed so that pressure histories could be obtained. The pressure histories were timed with digital photographs taken so that an approximation could be made of the pressure drop across the filter required for filter ash crack initiation. 


\section{Acknowledgements}

I would like to express my appreciation to my research advisor and committee chairman, Dr. Eric K. Johnson, for his patience and guidance towards the completion of this research and thesis. I would also like to express my appreciation to my other research advisor and committee co-chairman, Dr. Bruce Kang, for his advice and guidance. I would also like to extend thanks to Mr. Richard A. Dennis for his suggestions made toward the project.

I would like to thank Venkatesh Vasudevan and Tanner Johnson for their advice and help on the project.

I would like to thank my officemates Dennis Kamil, and Roxana and Cezar Cisloiu for their support during the completion of this thesis.

I would like to thank my parents and family for their emotional support and encouragement throughout the research project. 


\section{Table of Contents}

Title Page

$\begin{array}{ll}\text { Abstract } & \text { ii }\end{array}$

Acknowledgements

Table of Contents $\quad$ iv

List of Figures vii

List of Tables $\quad$ xii

Chapter 1 Introduction

1.1 Introduction 1

$\begin{array}{ll}1.2 \text { Background } & 3\end{array}$

Chapter 2 Description of Problem

$\begin{array}{ll}2.1 \text { Introduction } & 7\end{array}$

$\begin{array}{ll}\text { 2.2 Filtration Devices } & 7\end{array}$

$\begin{array}{lr}\text { 2.3 Barrier Filters } & 8\end{array}$

2.3.1 Bag Filters $\quad 8$

2.3.2 Ceramic Cross Flow Filters $\quad 8$

2.3.3 Candle Filters 9

2.3.4 Pressures Histories Found in Literature $\quad 11$

$\begin{array}{ll}\text { 2.3.5 Efficiencies } & 13\end{array}$

2.3.5.1 Mass Removal Efficiency 13

2.3.5.2 Pressure Drop Efficiency $\quad 15$

2.4 Candle Filter Systems $\quad 16$ 
Chapter 3 Experimental System

3.1 Introduction 22

3.2 Chamber History 22

3.2.1 System $1 \quad 22$

3.2.2 System $2 \quad 24$

$\begin{array}{ll}\text { 3.2.3 System } 3 & 27\end{array}$

3.3 Instrumentation and Noise 32

3.3.1 History $\quad 32$

3.3.2 Discussion of Problems 33

3.4 Employed Instrumentation 36

3.4.1 Transducers 36

3.4.2 Signal Conditioning 38

3.5 Test Procedure 46

Chapter 4 Experimental Results

4.1 Introduction 49

4.2 Test Matrix 49

4.3 Reference Curve 49

4.4 Pressure Histories $\quad 52$

$\begin{array}{ll}4.5 \text { Pictures } & 66\end{array}$ 
Chapter 5 Conclusions and Recommendations

5.1 Conclusions

5.2 Recommendations for the Future

References

Appendix A

82

Appendix B

86

Appendix C

90

Appendix D

100

Appendix E

101

VITA

102 
Figure

Number

$\underline{\text { Title }}$

$\underline{\text { Page }}$

$\begin{array}{lll}\text { Figure 1.2.1 Simple PFBC Process } & 4\end{array}$

Figure 1.2.2 Schematic of IGCC Power Plant 5

Figure 1.2.3 Schematic of Possible PFBC-Gasification

Combined Cycle Layout

Figure 2.3.1 Schematic of a Ceramic Cross Flow Filter 9

Figure 2.3.2 Simple Schematic of Candle Filter Operation 10

Figure 2.3.3 Pressure Drop Across Candle Filter for Different Back Pulse Pressures 12

$\begin{array}{lll}\text { Figure 2.3.4 Pressure Drop Across Filter } & 12\end{array}$

Figure 2.3.5 The Effect of the Growth of the Residual Ash on The Performance of the Filter 13

$\begin{array}{lll}\text { Figure 2.3.6 Graph of Efficiency Across Filter } & 14\end{array}$

$\begin{array}{lll}\text { Figure 2.4.1 Westinghouse Candle Filter System } & 17\end{array}$

Figure 2.4.2 Example of a Test Facility used in Germany 18

Figure 2.4.3 Example of the IGCC Candle Filter System in 19

Figure 2.4.4 Siemens-Westinghouse Inverted Candle Filter System 20

Figure 2.4.5 Example of Tube Filter System used in the Wakamatsu 21 PFBC in Japan

Figure 3.2.1 Cap Design for Second System 25

$\begin{array}{lll}\text { Figure 3.2.2 Flow Controls for System } 2 & 26\end{array}$

Figure 3.2.3 New Cap and Exhaust with Injector and Labels 29 
$\begin{array}{lll}\text { Figure 3.2.4 Drawing of Cap } & 30\end{array}$

$\begin{array}{lll}\text { Figure 3.2.5 Chamber Body } & 30\end{array}$

Figure 3.2.6 Chamber Cone 31

Figure 3.3.1 Choppiness from Old Data Acquisition System 33

Figure 3.3.2 Time Delay for 5B-30 Signal Conditioners 35

Figure 3.4.1 XTM-190M-25A Pressure Transducer 36

Figure 3.4.2 Schematic of XCQ-093-50A Pressure Transducer 37

Figure 3.4.3 BM-1100-250A Pressure Transducer 38

$\begin{array}{lll}\text { Figure 3.4.4 5B-40 Signal Conditioner } & 39\end{array}$

$\begin{array}{lll}\text { Figure 3.4.5 5B-08 Backplane } & 39\end{array}$

Figure 3.4.6 Backplane Pin Assignment 40

Figure 3.4.7 Microstar Laboratories MSTB 009-09 Analog Termination Board 40

Figure 3.4.8 Wired Analog Termination Board 41

Figure 3.4.9 Microstar Laboratories DAP 5200a/526 Data Acquisition Board 42

Figure 3.4.10 Microstar Laboratories MSTB 008-01 Digital Termination Board 43

Figure 3.4.11 Trigger Box and Connections 44

Figure 4.3.1 Reference Curve for Lanxide Filter 51

Figure 4.4.1 Generic Sketch of Chamber and Filter Pressure 53

Figure 4.4.2 Graph of Pressure vs. Time for Thick Ash with a Face Velocity of $5.75 \mathrm{~cm} / \mathrm{s}$ and a Reservoir Pressure of $1000 \mathrm{kPa}$ 
Figure 4.4.3 Graph of Pressure vs. Time for Thin Ash with a Face Velocity of $5.75 \mathrm{~cm} / \mathrm{s}$ and a Reservoir Pressure of $1000 \mathrm{kPa}$

Figure 4.4.4 Graph of Pressure Drop Across Filter vs. Time for Thick Ash with a Face Velocity of $5.75 \mathrm{~cm} / \mathrm{s}$ and a Reservoir Pressure of $1000 \mathrm{kPa}$

Figure 4.4.5 Graph of Pressure Drop Across Filter vs. Time for Thin Ash with a Face Velocity of $5.75 \mathrm{~cm} / \mathrm{s}$ and a Reservoir Pressure of $1000 \mathrm{kPa}$

Figure 4.4.6 Graph of Efficiency vs. Face Velocity for $1000 \mathrm{kPa}$ Reservoir Pressure and Thin and Thick Ash Thicknesses

Figure 4.4.7 Graph of Efficiency vs. Reservoir Pressure for Face Velocity of $5.75 \mathrm{~cm} / \mathrm{s}$ and Thin and Thick Ash Thicknesses

Figure 4.4.8 Efficiencies for Thick and Thin Ash

Figure 4.4.9 $\phi$ for Comparing Thick and Thin Ash 66

Figure 4.4.10 Graph of $\phi$ vs. Face Velocity for Reservoir Pressure of 68 $1000 \mathrm{kPa}$

Figure 4.4.11 Graph of $\phi$ vs. Reservoir Pressure for Face Velocity of $5.75 \mathrm{~cm} / \mathrm{s}$

Figure 4.5.1 Regeneration for a Thick Ash at $5.75 \mathrm{~cm} / \mathrm{s}$ Face Velocity and $1000 \mathrm{kPa}$ Reservoir Pressure

Figure 4.5.2 Regeneration for a Thin Ash at $5.75 \mathrm{~cm} / \mathrm{s}$ Face Velocity and $1000 \mathrm{kPa}$ Reservoir Pressure

Figure B.1 Schematic of Filter and Radii

Figure C.1 Graph of Pressure vs. Time for Thick Ash with a Face Velocity of $3.65 \mathrm{~cm} / \mathrm{s}$ and a Reservoir Pressure of 145 psia

Figure C.2 Graph of Pressure vs. Time for Thick Ash with a Face Velocity of $5.75 \mathrm{~cm} / \mathrm{s}$ and a Reservoir Pressure of 115 psia 
Figure C.3 Graph of Pressure vs. Time for Thick Ash with a Face

Velocity of $5.75 \mathrm{~cm} / \mathrm{s}$ and a Reservoir Pressure of 145 psia

Figure C.4 Graph of Pressure vs. Time for Thick Ash with a Face

Velocity of $5.75 \mathrm{~cm} / \mathrm{s}$ and a Reservoir Pressure of $160 \mathrm{psia}$

Figure C.5 Graph of Pressure vs. Time for Thick Ash with a Face

Velocity of $9.5 \mathrm{~cm} / \mathrm{s}$ and a Reservoir Pressure of $145 \mathrm{psia}$

Figure C.6 Graph of Pressure vs. Time for Thin Ash with a Face

Velocity of $3.65 \mathrm{~cm} / \mathrm{s}$ and a Reservoir Pressure of 145 psia

92

Figure C.7 Graph of Pressure vs. Time for Thin Ash with a Face

Velocity of $5.75 \mathrm{~cm} / \mathrm{s}$ and a Reservoir Pressure of $115 \mathrm{psia}$

93

Figure C.8 Graph of Pressure vs. Time for Thin Ash with a Face

Velocity of $5.75 \mathrm{~cm} / \mathrm{s}$ and a Reservoir Pressure of $145 \mathrm{psia}$

93

Figure C.9 Graph of Pressure vs. Time for Thin Ash with a Face

Velocity of $5.75 \mathrm{~cm} / \mathrm{s}$ and a Reservoir Pressure of $160 \mathrm{psia}$

94

Figure C.10 Graph of Pressure vs. Time for Thin Ash with a Face

Velocity of $9.5 \mathrm{~cm} / \mathrm{s}$ and a Reservoir Pressure of $145 \mathrm{psia}$

Figure C.11 Graph of Pressure Drop Across Filter vs. Time for Thick Ash with a Face Velocity of $3.65 \mathrm{~cm} / \mathrm{s}$ and a Reservoir Pressure of 145 psia

Figure C.12 Graph of Pressure Drop Across Filter vs. Time for Thick Ash with a Face Velocity of $5.75 \mathrm{~cm} / \mathrm{s}$ and a Reservoir Pressure of 115 psia

Figure C.13 Graph of Pressure Drop Across Filter vs. Time for Thick Ash with a Face Velocity of $5.75 \mathrm{~cm} / \mathrm{s}$ and a Reservoir Pressure of 145 psia

Figure C.14 Graph of Pressure Drop Across Filter vs. Time for Thick Ash with a Face Velocity of $5.75 \mathrm{~cm} / \mathrm{s}$ and a Reservoir Pressure of 160 psia

Figure C.15 Graph of Pressure Drop Across Filter vs. Time for Thick Ash with a Face Velocity of $9.5 \mathrm{~cm} / \mathrm{s}$ and a Reservoir Pressure of 145 psia 
Figure C.16 Graph of Pressure Drop Across Filter vs. Time for Thick Ash with a Face Velocity of $3.65 \mathrm{~cm} / \mathrm{s}$ and a Reservoir Pressure of 145 psia

Figure C.17 Graph of Pressure Drop Across Filter vs. Time for Thick Ash with a Face Velocity of $5.75 \mathrm{~cm} / \mathrm{s}$ and a Reservoir Pressure of 115 psia

Figure C.18 Graph of Pressure Drop Across Filter vs. Time for Thick Ash with a Face Velocity of $5.75 \mathrm{~cm} / \mathrm{s}$ and a Reservoir Pressure of 145 psia

Figure C.19 Graph of Pressure Drop Across Filter vs. Time for Thick Ash with a Face Velocity of $5.75 \mathrm{~cm} / \mathrm{s}$ and a Reservoir Pressure of 160 psia

Figure C.20 Graph of Pressure Drop Across Filter vs. Time for Thick Ash with a Face Velocity of $9.5 \mathrm{~cm} / \mathrm{s}$ and a Reservoir Pressure of 145 psia 
Table

\section{List of Tables}

Number Title

$\underline{\text { Page }}$

$\begin{array}{lll}\text { Table 4.2.1 } & \text { Test Matrix } & 50\end{array}$

Table 4.4.1 Thick Ash Results $\quad 56$

Table 4.4.2 Thin Ash Results $\quad 58$

$\begin{array}{lll}\text { Table 4.4.3 Cleaning Efficiencies } & 62\end{array}$

Table 4.4.4 $\Phi$ Used to Compare Thick and Thin Ash Regenerations 65

Table D.1 Data and Possible Errors Used in Reference Curve 100

Table E.1 Data for Time Interval for Crack Initiation 101 


\section{Chapter 1}

\section{Introduction}

\subsection{Introduction}

One possible contributor to the destruction of a healthy environment is the creation of electric power from thermal power plants. Each method of creating power, whether it is coal, nuclear, oil, natural gas, or even hydroelectric, has its own environmental problems. Any improvements in the efficiency of power plants can lessen the environmental harm done and thus is important. Ninety percent of the nation's electricity is created with the use of fossil fuels with coal alone providing $56 \%$ of the nation's energy [Cicero]. New high performance power systems could reduce $\mathrm{CO}_{2}$ emissions by 25 to $30 \%$ [Natesan]. With coal being such a large source of our power, it is vital that either improvements be made to the current methods of coal power generation, or new methods of power generation be introduced. Two possible methods of improving efficiency are integrated gasification combined-cycle (IGCC) and pressurized fluidized-bed combustion (PFBC). Both of these options require hot gas cleanup for optimum efficiency. Unfortunately hot gas cleanup is not a well-established process and many problems have occurred. Right now the most promising methods for hot gas cleanup are barrier filters. A large collection of candle filters in a pressurized vessel appears to have received the greatest amount of attention in dealing with this topic, but problems are still persisting and there does not seem to be a clear-cut answer to the problems. This research is an investigation of the candle filter cleaning process, a process known as surface regeneration. This research will lead to a more basic knowledge of the candle filter cleaning process so that the fundamentals of these systems 
is better understood. This overall effort consists of several projects. Two of these projects have been (1) development of method(s) to determine ash layer strength and (2) development of the optics to measure the ash removal processes during surface regeneration.

Specifically, the objective of this part of the research program has been to build a room temperature test facility (RTTF) in order to develop the instrumentation necessary to investigate the surface regeneration process. This effort then led to the development of a technique for measuring the ash strength and for the optic system used in this study. This work also provides other researchers with experience in running the RTTF and prepares them for a more advanced system. The eventual goal in this research is to build a high temperature test facility (HTTF) to evaluate candle filters in an environment that would be close, with the exception of high pressure, to their normal operating conditions. Before such a facility was to be built it was decided to build a room temperature test facility so that many of the possible unforeseen problems would be exposed and corrected.

Originally the first room temperature facility was built with the exclusive purpose of developing the optics system. During the initial testing it was realized that the room temperature facility could yield important results and valuable insight into the surface regeneration process. The decision was made to build a second room temperature system with instrumentation with the expectation of: (1) gaining knowledge of the regeneration process, (2) obtaining operational information that could be used for the high temperature system, and (3) adapting to changing industry design concepts. Devices to control many of the parameters that were not considered in the design of the first facility were also 
installed. The controls for the new system were to allow the operator to control important parameters in the regeneration process, such as flow rates and back pulse times. This system is also to be used to develop the optical system, which is not part of this thesis.

The instrumentation used should also give a better description of the regeneration process. The goal for the instrumentation was to have pressure transducers throughout the system so that the pressure histories for the entire facility could be known. The ability to time the pressure readings with the pictures taken by the optics system was also a priority.

\subsection{Background}

As mentioned earlier hot gas cleaning is essential to a pressurized fluidized bed combustion (PFBC) cycle. A fluidized bed is a bed of particles, in this case coal and sorbents, that are suspended in a pressurized vessel in the gas. A particle moves about the bed attempting to find a balance between the drag force pushing up on the particle and the weight of the particle pulling it down. When this bed is formed the surface contact between the particles and the gas is much greater than it would be if the particles were in contact with other particles. This added surface contact allows for a more efficient combustion and thus more efficient power generation.

Figure 1.2.1 [Stringer] shows a simple diagram of a PFBC combined cycle. First, the fluidized bed contains a heat exchanger where steam is generated for a steam turbine that drives a generator which produces electricity. The pressurized exhaust gases from the bed drives a gas turbine which drives an air compressor and an electric generator. The compressed air from the air compressor is then fed back into the fluidized bed [Stringer]. Before the exhaust from the bed can be sent to the gas turbine, it must be 


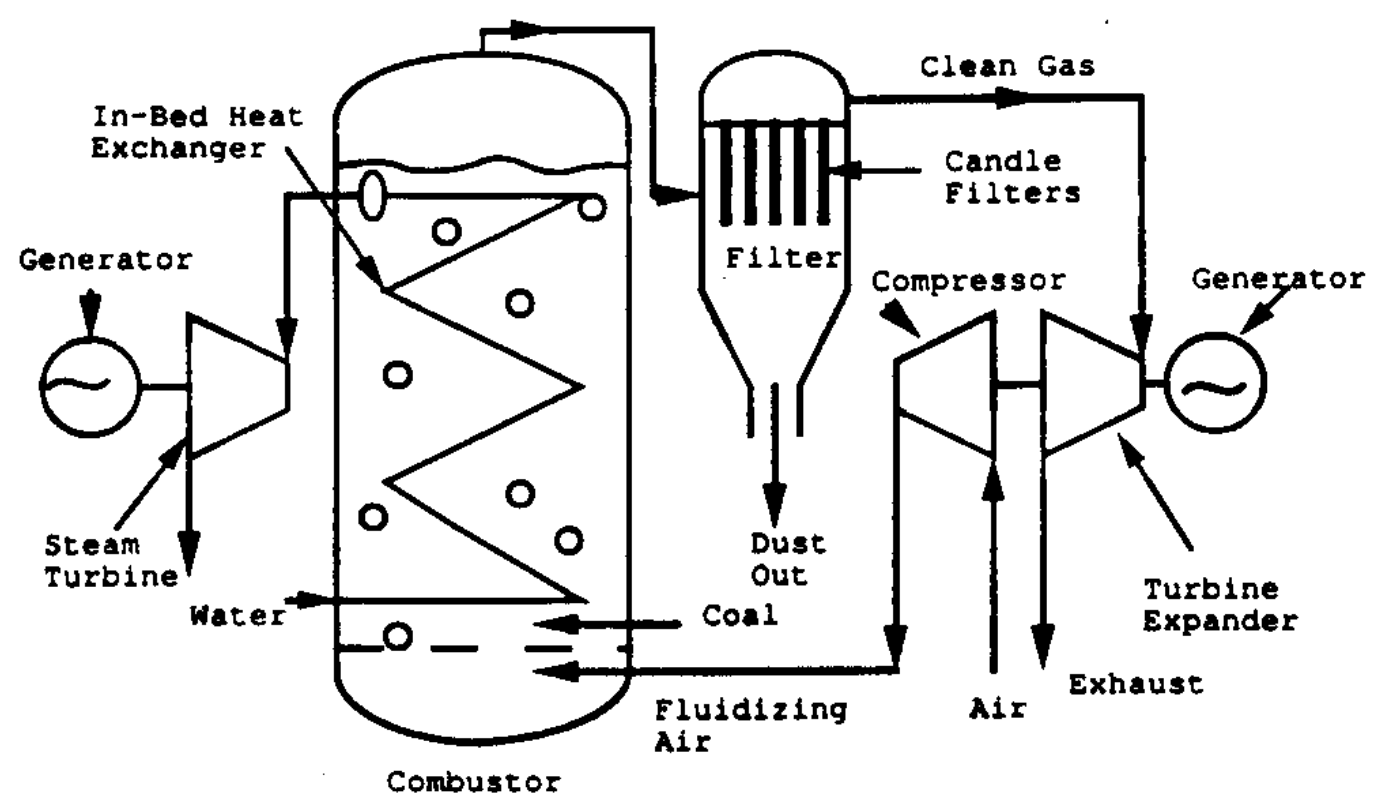

Figure 1.2.1

Simple PFBC Process [Stringer]

cleaned. If the gas is not cleaned then the turbine performance will deteriorate rapidly and the gained efficiency from using the cycle will be diminished by the economics of the plants. An estimate made for various Westinghouse turbines states that no particles above $20 \mu \mathrm{m}$ diameter are permitted. For two other characteristic size ranges, $0-2 \mu \mathrm{m}$ and $1-20 \mu \mathrm{m}$, the estimates are no more than 2.2 to $3.0 \mathrm{ppmw}$ and 4.4 to $5.8 \mathrm{ppmw}$, respectively [Newby].

The integrated gasification combined cycle (IGCC) is another power production system requiring hot gas cleaning. In the IGCC cycle, the coal is gasified instead of combusted. A simple version of IGCC is shown in Figure 1.2.2 [Cicero]. As can be seen in the figure, coal, air, steam, and limestone are sent to the gasifier. The hot fuel gas then passes through a hot gas cleanup system. Clean hot fuel gas is then sent to a combustor and from there the products are sent to a high efficiency turbine. The rest of the cycle 
can be seen in the figure. IGCC plant efficiencies will achieve 52 percent or greater as advanced turbines systems are incorporated [Cicero].

There are other designs for power plants that require hot gas cleaning. There are

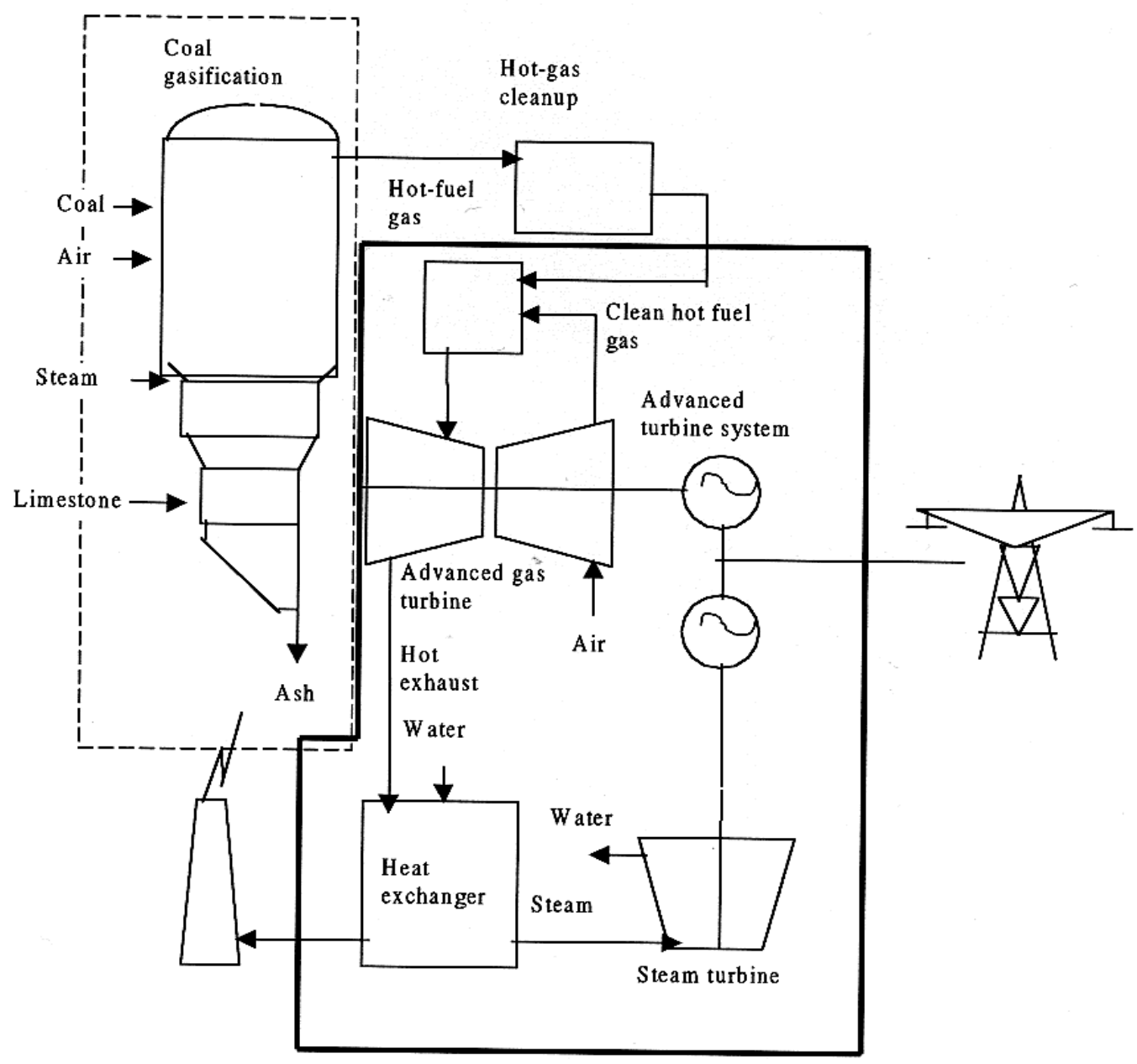

Figure 1.2.2

Schematic of IGCC Power Plant [Cicero]

advanced cycles that combine the IGCC and PFBC processes. Figure 1.2.3 [Cicero] shows that hot gas cleaning is used twice, once after the gasifier to separate the char from 
the coal gas and once after the fluidized bed to separate the ash from the hot gas. The figure shows the rest of the process using turbines, heat exchangers, etc.

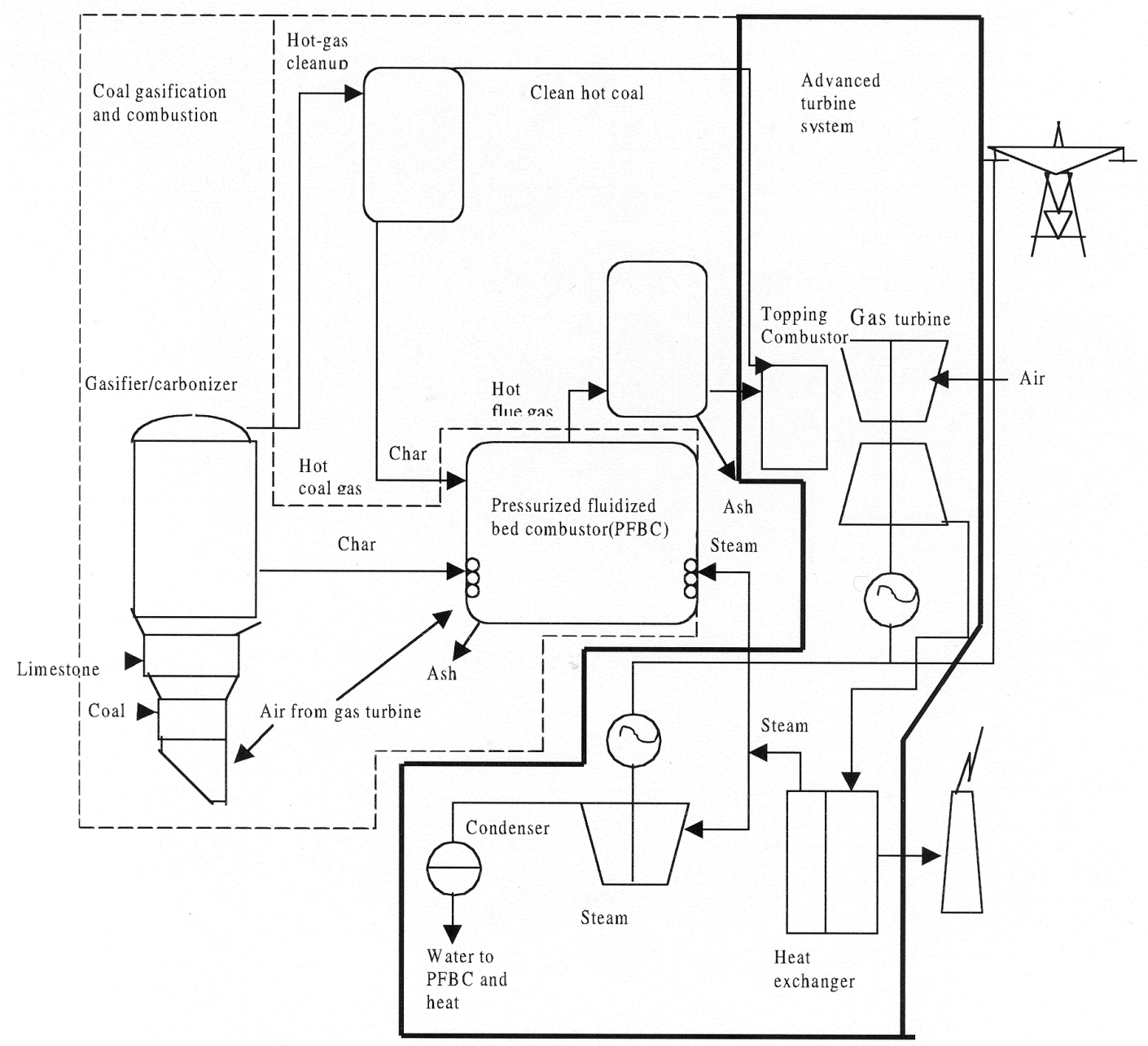

Figure 1.2.3

Schematic of Possible PFBC-Gasification Combined

Cycle Layout [Cicero] 


\section{Chapter 2}

\section{Description of Problem}

\subsection{Introduction}

High-temperature gas cleanup is vital for PFBC and IGCC systems. In this section different methods of filtration will be discussed with a focus on barrier filters.

Pressure drops across candle filters during pressure pulses will be investigated. Candle filter regeneration efficiencies will also be discussed.

\subsection{Filtration Devices}

Many different types of particulate collection devices are being developed for applications in advanced power generation systems. Some of the more prominent ones are [Quimby]:

1. High performance mechanical collectors.

2. High efficiency barrier filtration filters.
A. Bag Filters.
B. Ceramic cross flow filters.
C. Candle filters.

3. Electrostatic precipitators.

4. Sonic agglomerators upstream of mechanical filters.

5. Electrostatic agglomerators ahead of mechanical filters.

Of the listed filtration devices, only barrier filters will be reviewed in the thesis. 


\subsection{Barrier Filters}

Barrier filters use a porous medium as a barrier to remove the dirt from the gas. The porous medium is porous enough to allow the air through, along with possibly some small particles, but dense enough to collect the larger particles.

\subsubsection{Bag Filters}

When a bag filter starts collecting dust from dirty air it uses that ash on its surface as a filter. The pores in the ash are smaller than pores in the bag itself, so once ash builds up, fewer particles bypass the bag. The bag is essentially using the ash on the filter to collect the ash in the air. When the ash builds up in the bag the pressure drop across the bag increases. Once the pressure drop reaches a certain pressure the bag then needs to be cleaned. On-line pulse cleaning is the only practical technique available for highpressure and high-temperature situations.

There are many reported bag filter failures when used at high-temperature and high-pressure. Mechanical degradation of ceramic threads that were used to stitch the bag seams resulted in failure. Fabric degradation when exposed to high-temperatures has also been reported. The fabric had exhibited mechanical degradation that was thought to be time and temperature dependent [Quimby].

\subsubsection{Ceramic Cross Flow Filters}

A schematic of a ceramic cross flow filter is shown in Figure 2.3.1 [Quimby]. The arrangement of the porous parallel plates forces the gas upwards through the plates and out in channels which are perpendicular to the entering dirty gas. A pulse jet cleaning is used to clean the filter. Although ceramic cross flow filters have excellent collection efficiencies when working properly, the repeatability of the process becomes 


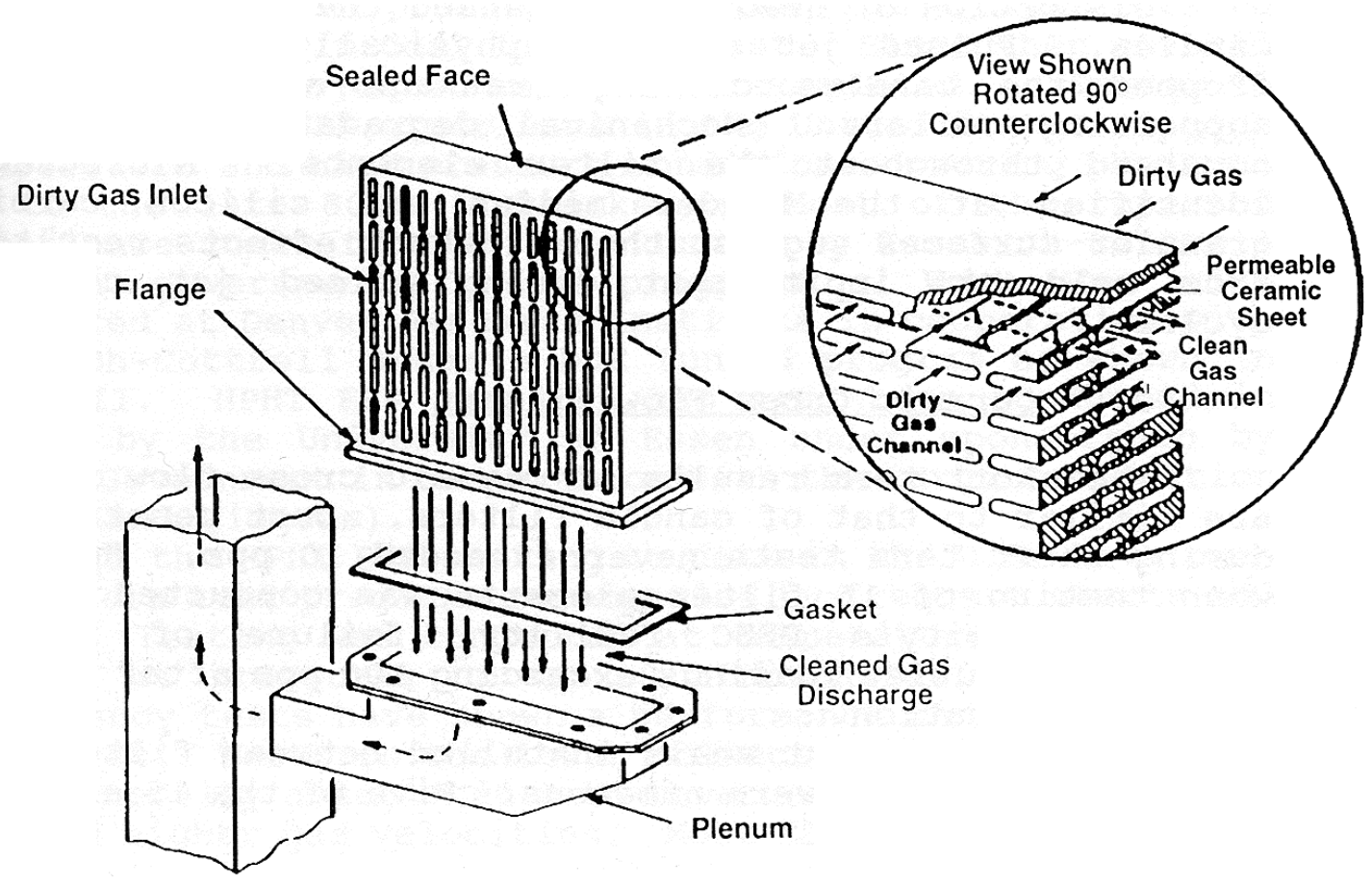

Figure 2.3.1

Schematic of Ceramic Cross Flow Filter [Quimby]

difficult in a high-pressure and high-temperature system and failures may occur

[Quimby].

\subsubsection{Candle Filters}

Candle filters are long porous cylinders, usually with one open end and one closed end. Candle filters are built rigid with pore sizes of 5 to 100 microns [Quimby]. The filter tested in this investigation is $0.5 \mathrm{~m}$ long, but most of the filters being used in industry are $1.5 \mathrm{~m}$ long. There are currently many different types of filters being produced. One major difference in these filters is the material composition of the filter. Materials such as alumina/mullite, cordierite, aluminosilicate foam, clay bonded silicon carbide, bonded or sintered silicon nitride, and cordierite-silicon nitride are used in these 
porous candle filters [Lippert, 1]. Metals are also being considered for two reasons: 1) advancements have been made in processing methods for corrosion resistant alloys, allowing them to be fabricated into metal filter media, and 2) lower hot gas filter temperatures associated with second generation PFBC are being considered that will provide lower-risk entry opportunities into the commercial market [Dennis]. The material composition of the filters is not considered in this study.

One difference in candle filters is in the design of the open end of the filter. This shaping can become a factor when attaching the filter to a plenum or filter tubesheet. If the shape of the open end of the candle filter does not allow for a good seal then ash will bypass the filter.

A candle filter is used as a barrier that gas can pass through, but most of the ash cannot. A simple schematic is shown in Figure 2.3.2. Dirty gas passes through the filter

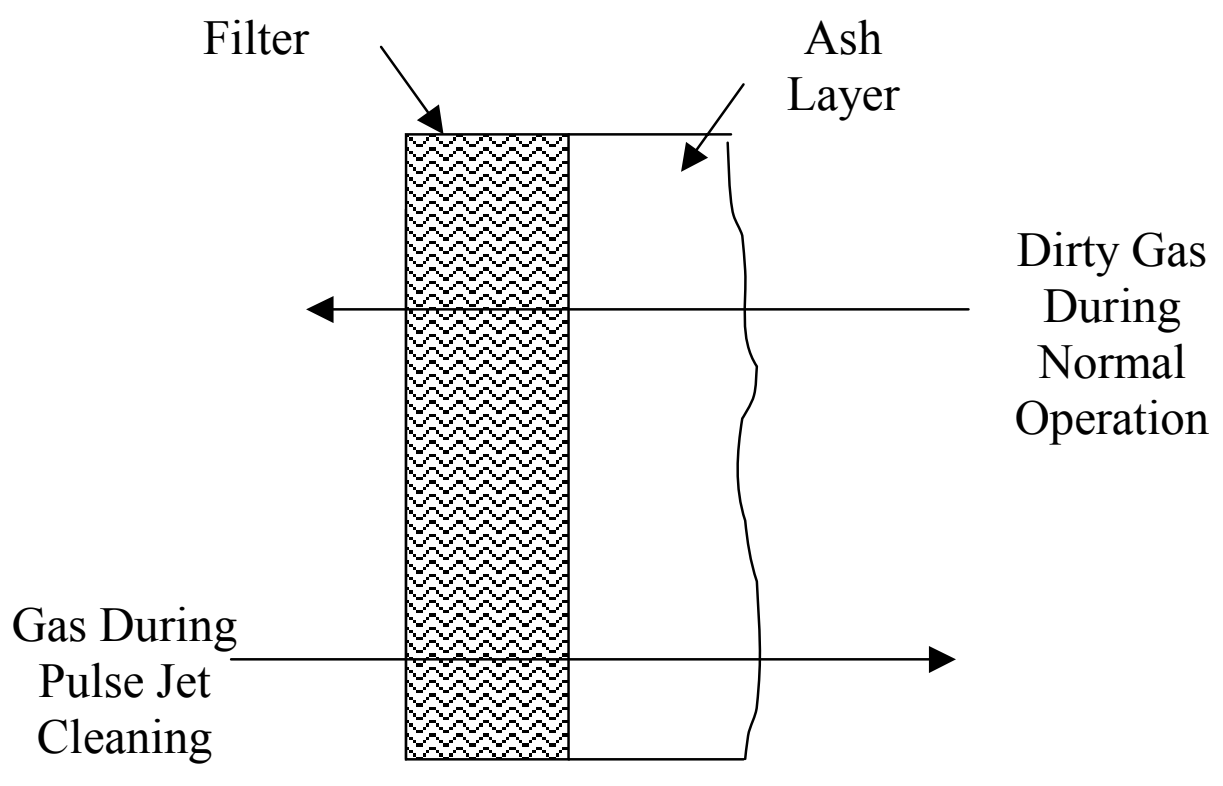

Figure 2.3.2

Simple Schematic of Candle Filter Operation 
and in the process the ash in the gas collects on the filter. When the ash builds up on the filter, the pressure drop across the filter increases. Once the pressure drop reaches a certain pressure, or a certain time limit is reached, the filter then needs to be cleaned. Online pulse jet cleaning is the only practical technique available for high-pressure and high-temperature situations. Pulse jet cleaning is a process of cleaning the filter where a high pressure pulse of gas is sent through the filter in the opposite direction of normal use. This pulse of gas blows the ash off of the filter when the cleaning is successful. This cleaning process is called surface regeneration. An on-line pulse jet cleaning is where surface regeneration occurs while the dirty gas continues to flow into the vessel.

Candle filter failures can be caused by several different occurrences. The filters can fail from being lifted from the filter tubesheet and dropped during pulse jet cleaning [Stringer]. The bridging of ash in between filters can also cause failure. Thermal shock effects have also been suspected of causing failure [Quimby].

\subsubsection{Pressures Histories Found in Literature}

The pressure drop across a candle filter is an important parameter during cleaning. If the pressure of the back pulse is not large enough to overcome the pressure in the chamber, then successful regeneration is unlikely. Figure 2.3.3 [Laux] shows the pressure drop across the filter for different back pulse pressures. These pressures were obtained from the experimental system shown in Figure 2.4.2 [Laux]. Another example of pressure drop across a candle filter is shown in Figure 2.3.4 [Laux].

Pressure histories can also be observed over multiple surface regenerations. An example of a long term pressure history is shown in Figure 2.3.5 [Mudd]. Notice that over time an average residual ash builds and the pressure drop across the filter increases. 


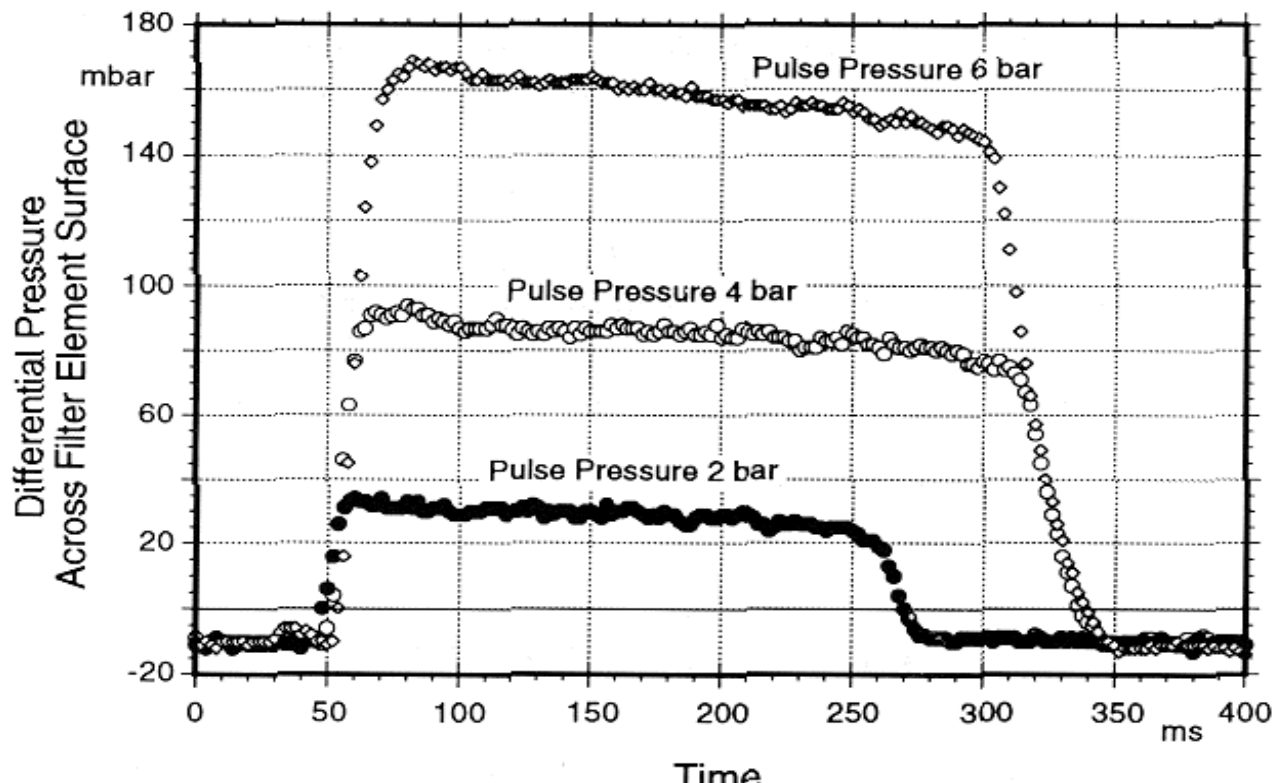

Figure 2.3.3

Pressure Drop Across Candle Filter for Different Back Pulse Pressures [Laux]

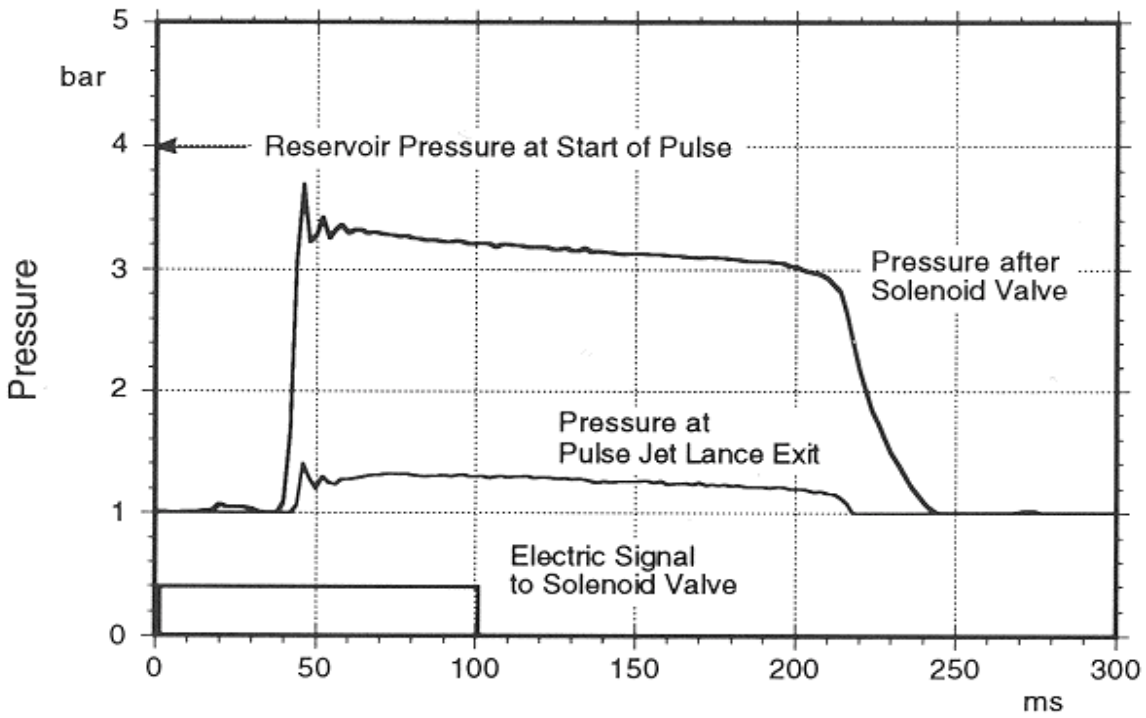

Time

Figure 2.3.4

Pressure Drop Across Filter [Laux] 


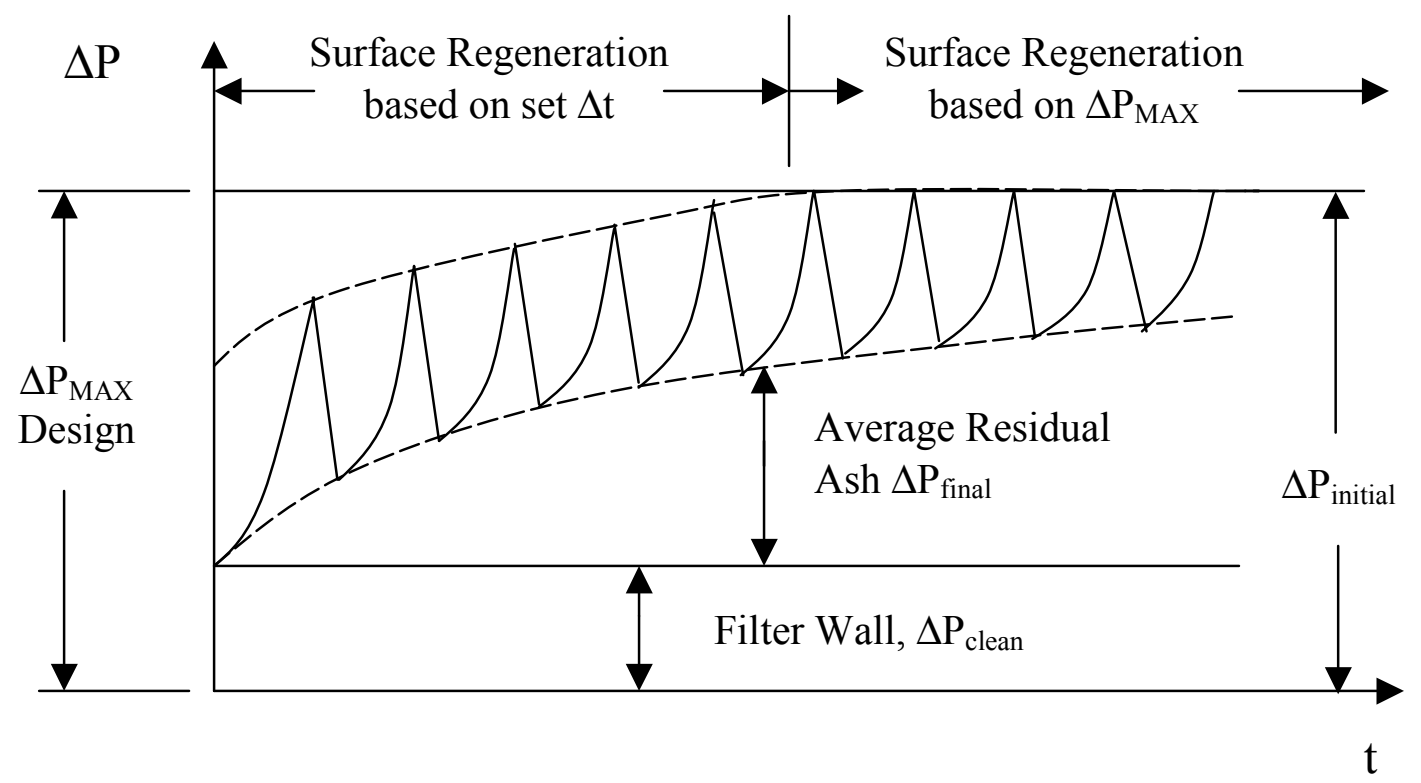

Figure 2.3.5

The Effect of the Growth of the Residual Ash on the Performance of the Filter

\subsubsection{Efficiencies}

\subsubsection{Mass Removal Efficiency}

There are different efficiencies when dealing with candle filters. There is the efficiency for how well the filter is cleaned during regeneration and there is the efficiency for how well the candle filter cleans the gas, i.e. how many particles bypass the filter, also known as gas cleaning efficiency. This thesis will deal only with surface regeneration efficiency and surface regeneration efficiency will be implied when only efficiency is mentioned. There are many different ways to calculate efficiencies. One method of calculating efficiency is to calculate an incremental efficiency, $R$, using the equation: 


$$
\mathrm{R}=1-\frac{\mathrm{W}_{\mathrm{E}, \mathrm{i}}}{\mathrm{W}_{\mathrm{R}, \mathrm{i}}}
$$

where: $\mathrm{W}_{\mathrm{E}, \mathrm{i}}=$ Incremental areal dust density just before cleaning process

$$
\begin{aligned}
& \mathrm{W}_{\mathrm{R}, \mathrm{i}}=\text { Incremental areal dust density just after cleaning process } \\
& \mathrm{i}=\text { sample location on the candle filter [Berbner]. }
\end{aligned}
$$

This method divides the candle filter into different sections so that different surface regeneration efficiencies can be different from one portion of the filter to the next. Figure 2.3.6 shows a graph of this efficiency. An x-ray source inside of the filter and radiation

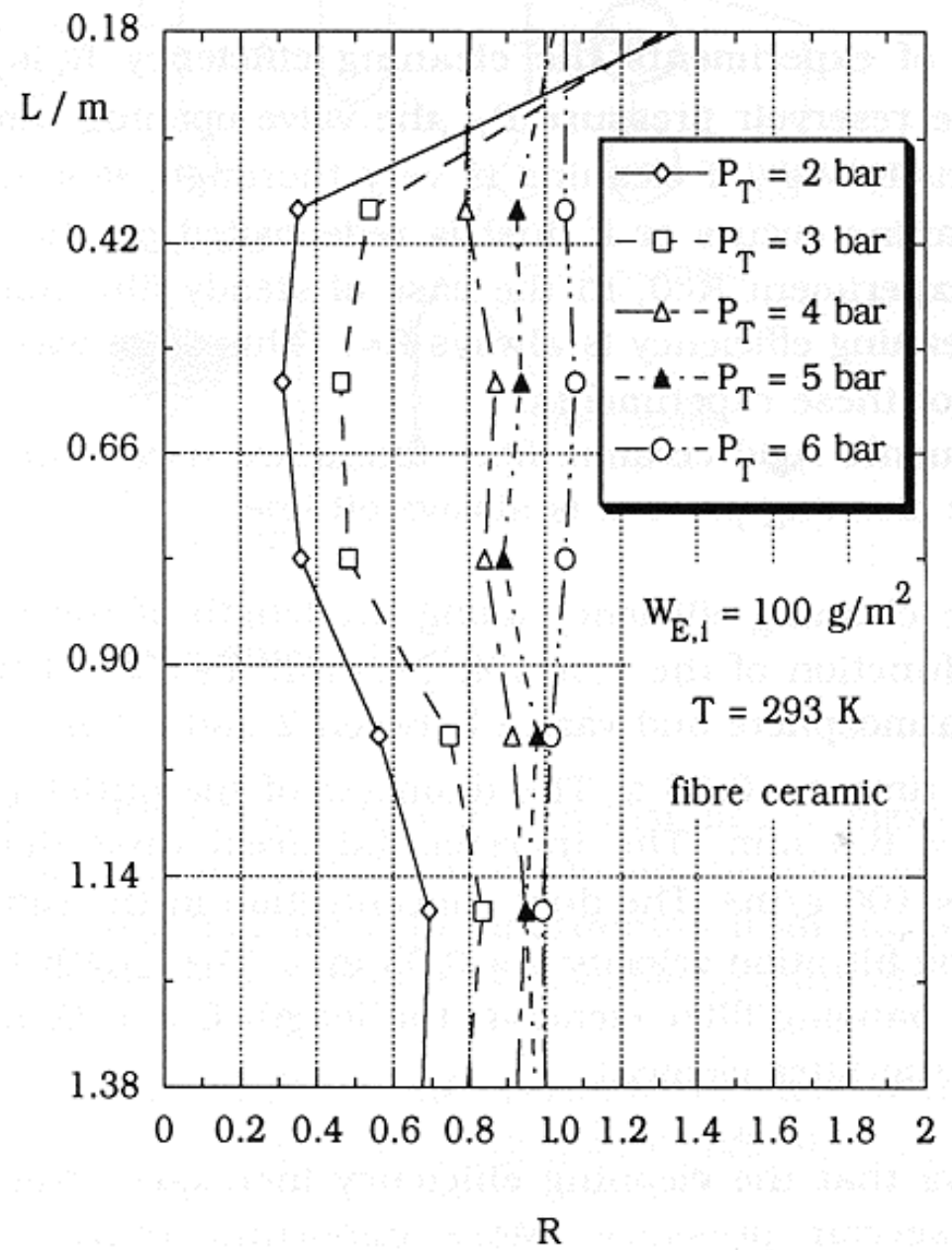

Figure 2.3.6

Graph of Efficiency Across Filter 
detectors outside of the filter were used to determine the amount of ash on different points on the filter. This method would be difficult to employ at high temperatures unless the researcher would be willing to allow the system to cool after a test to make the measurements.

\subsubsection{Pressure Drop Efficiency}

For this work the pressure drop efficiency, $\eta$, will be defined as $\eta=1-\gamma$, and:

$$
\gamma=\frac{\Delta \mathrm{P}_{\text {final }}-\Delta \mathrm{P}_{\text {clean }}}{\Delta \mathrm{P}_{\text {initial }}-\Delta \mathrm{P}_{\text {clean }}}
$$

where $\Delta \mathrm{P}_{\text {final }}=$ Pressure drop across the candle filter just after cleaning process

$\Delta \mathrm{P}_{\text {initial }}=$ Pressure drop across the candle filter just before cleaning process

$\Delta \mathrm{P}_{\text {clean }}=$ Pressure drop across the candle filter with no ash [Chiang].

These pressures can be seen in Figure 2.3.5. When subtracting the $\Delta \mathrm{P}_{\text {clean }}$ from the other $\Delta \mathrm{P}$ 's in this equation, the pressure drop across the filter caused by the ash is calculated. When comparing tests with the same face velocity, the pressure drop caused by the ash can be used as an indication of how much ash is on the filter. Simple algebraic manipulation leads to:

$$
\eta=\frac{\Delta \mathrm{P}_{\text {initial }}-\Delta \mathrm{P}_{\text {final }}}{\Delta \mathrm{P}_{\text {initial }}-\Delta \mathrm{P}_{\text {clean }}}
$$

This efficiency is the change in pressure drop caused by the removal of ash divided by the pressure drop caused by the ash before surface regeneration. 


\subsection{Candle Filter Systems}

The Siemens-Westinghouse candle filter system is a pressure vessel that consists of several candle filter clusters. A schematic drawing of the system is shown in Figure 2.4.1 [Lippert, 1]. Each cluster consists of several plenums stacked vertically. A plenum is a support sheet that supports a collection of candle filters. In this design each plenum is cleaned as a group, i.e. one pulse jet per plenum.

There are systems in Germany that are very similar to the Siemens-Westinghouse system with the exception of the fact that each candle filter has its own pulse jet tube. Figure 2.4.2 [Laux] shows a diagram of a test facility trying to recreate one of these systems.

At the IGCC power plant in Puertollano, Spain, a different candle filter system is being used. The candle filters are similar in dimensions, but they are up side down. Figure 2.4.3 [Krein] shows the candle filter system at this IGCC plant. One thing not shown in this diagram is the fact that each candle filter is held in position with a counter weight. In addition to holding the candle filter in position, this counter weight is also used to put the candle filters under compression, which is a favorable stress for ceramic materials [Krein].

Siemens-Westinghouse also has an inverted candle filter system, but ash is filtered on the inside of the filter instead of the outside of the filter. In this system, shown in Figure 2.4.4 [Lippert, 2], the filters can be separated individually, as shown in Figure 2.4.4a, or as an array, as shown in Figure 2.4.4b. The candle filters are protected from ash bridging and are accessible without removal of equipment or other filters. This 
allows the filters to be closely packed without bridging. It also protects broken filters from damaging other filters when they break [Lippert, 2].

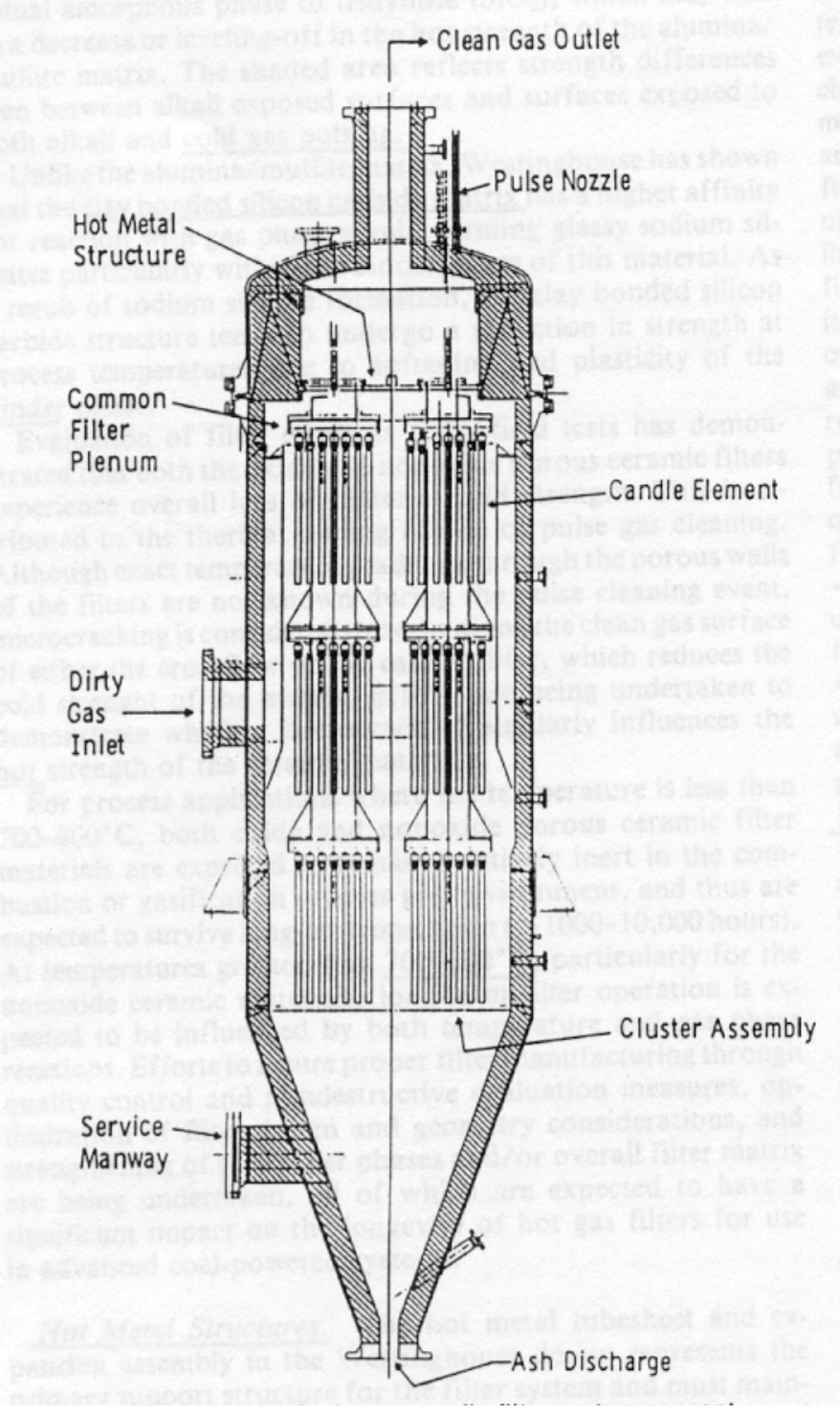

Figure 2.4.1

Siemens-Westinghouse Candle Filter System

[Lippert, 1] 


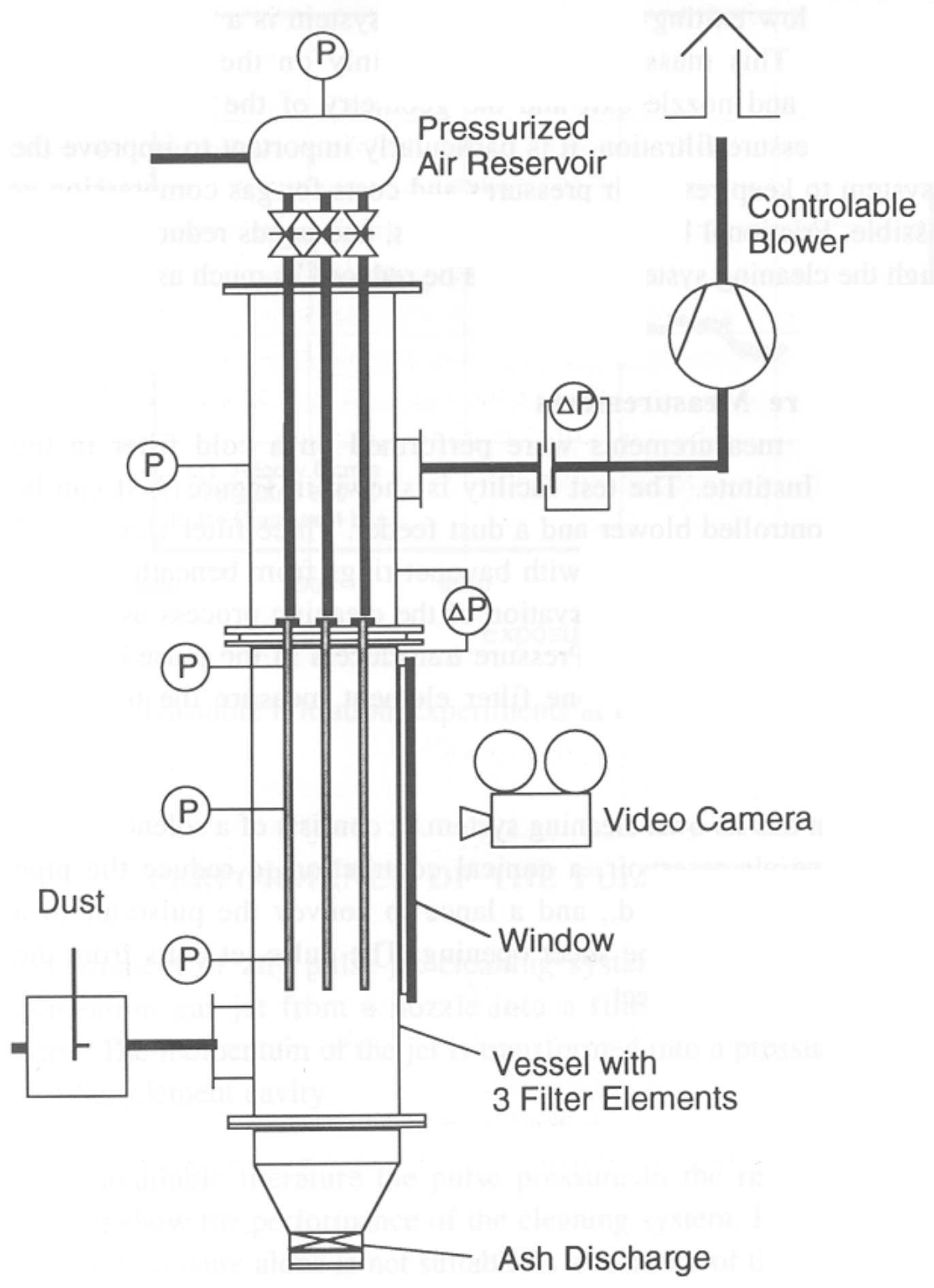

Figure 2.4.2

Example of a Test Facility used in Germany [Laux] 

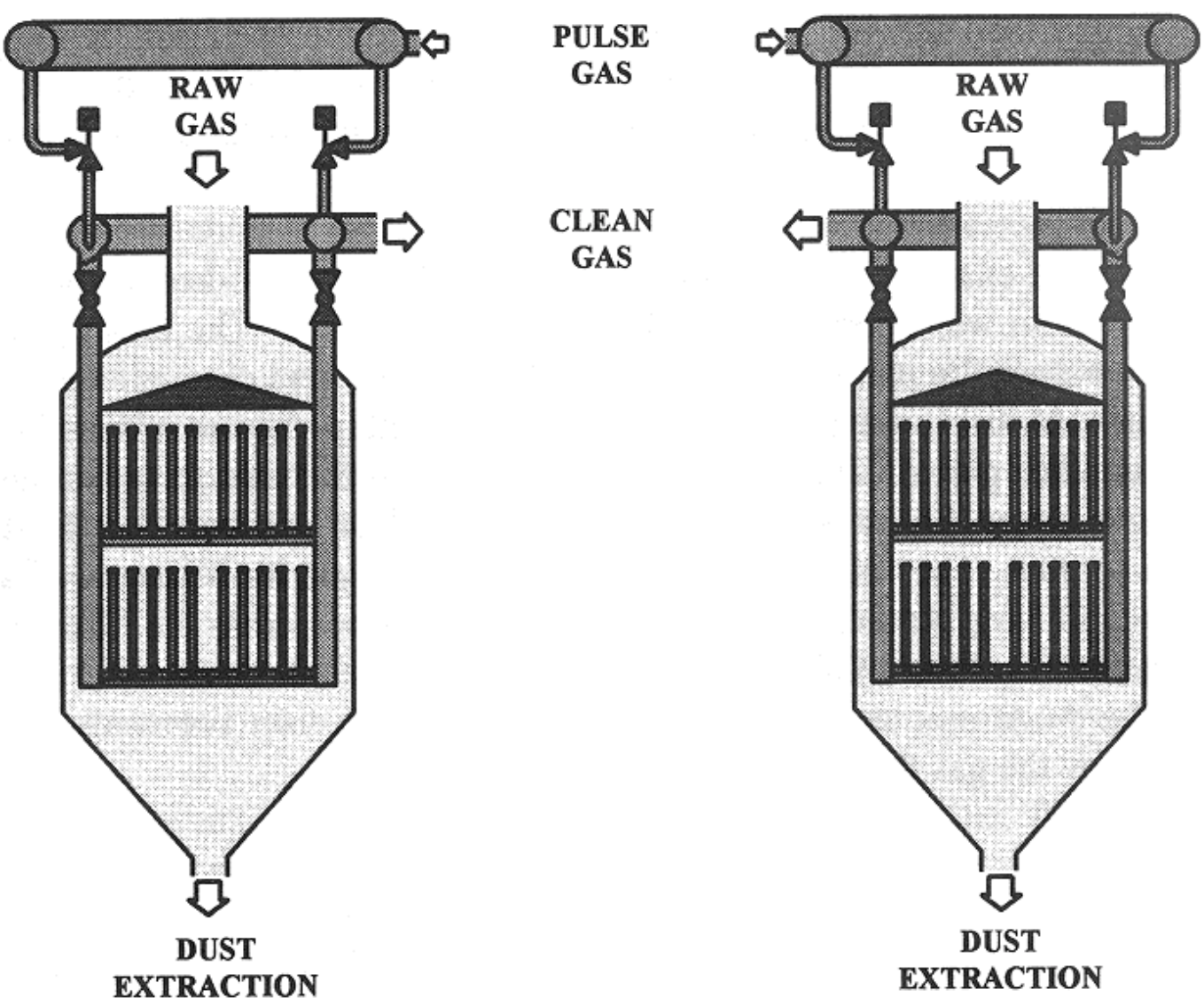

Figure 2.4.3

Example of the IGCC Candle Filter System in

Puertollano, Spain [Krein]

There are other systems that use tube filters. A tube filter is a candle filter with two open ends instead of just one. For this system the ash was collected on the inside of the filter instead of the outside of the filter. A demonstration PFBC plant in Wakamatsu, Japan uses tube filters for its hot gas clean up. An outline diagram of their system is shown in Figure 2.4.5 [Sasatsa]. 

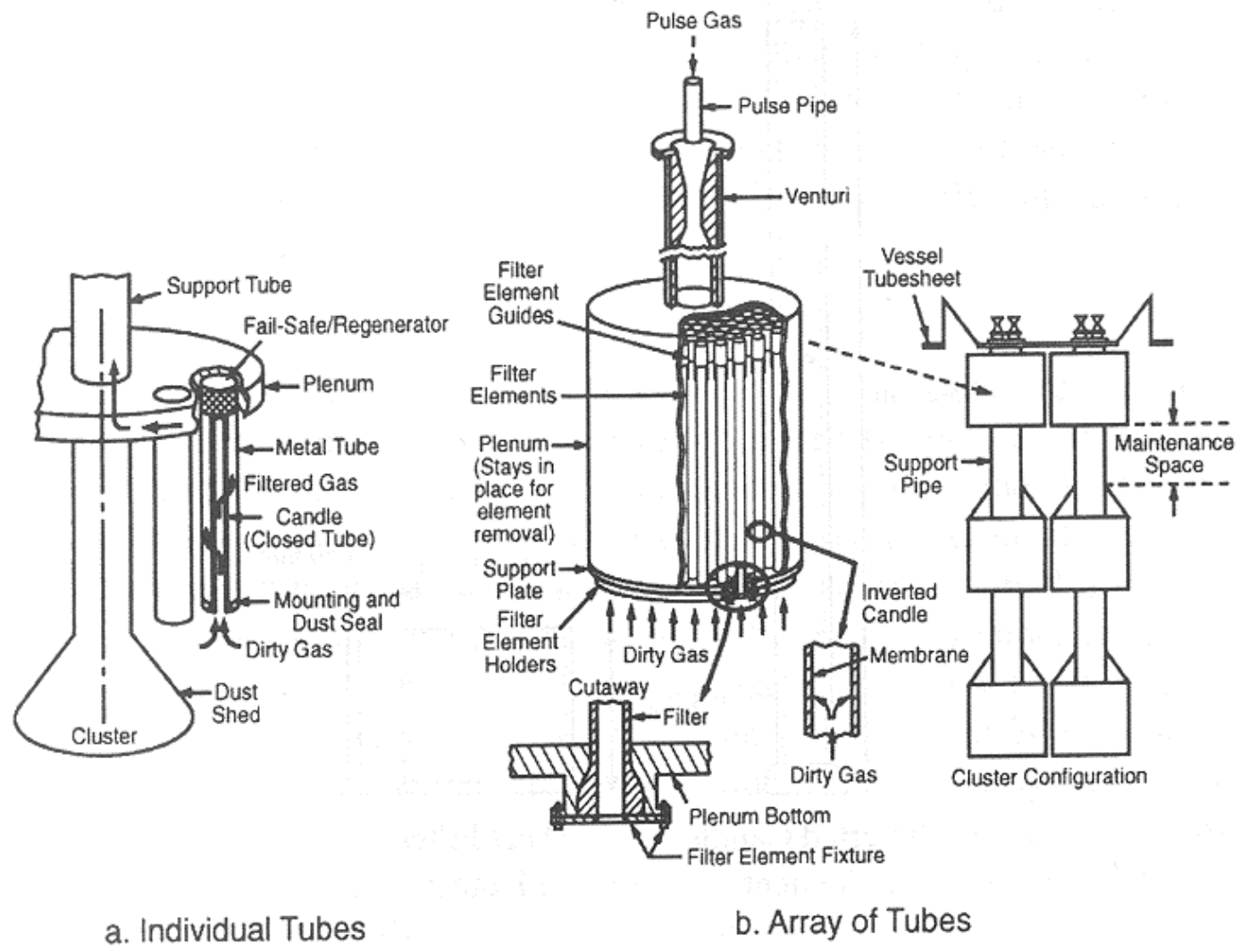

Figure 2.4.4

Siemens-Westinghouse Inverted Candle Filter

System [Lippert, 2] 


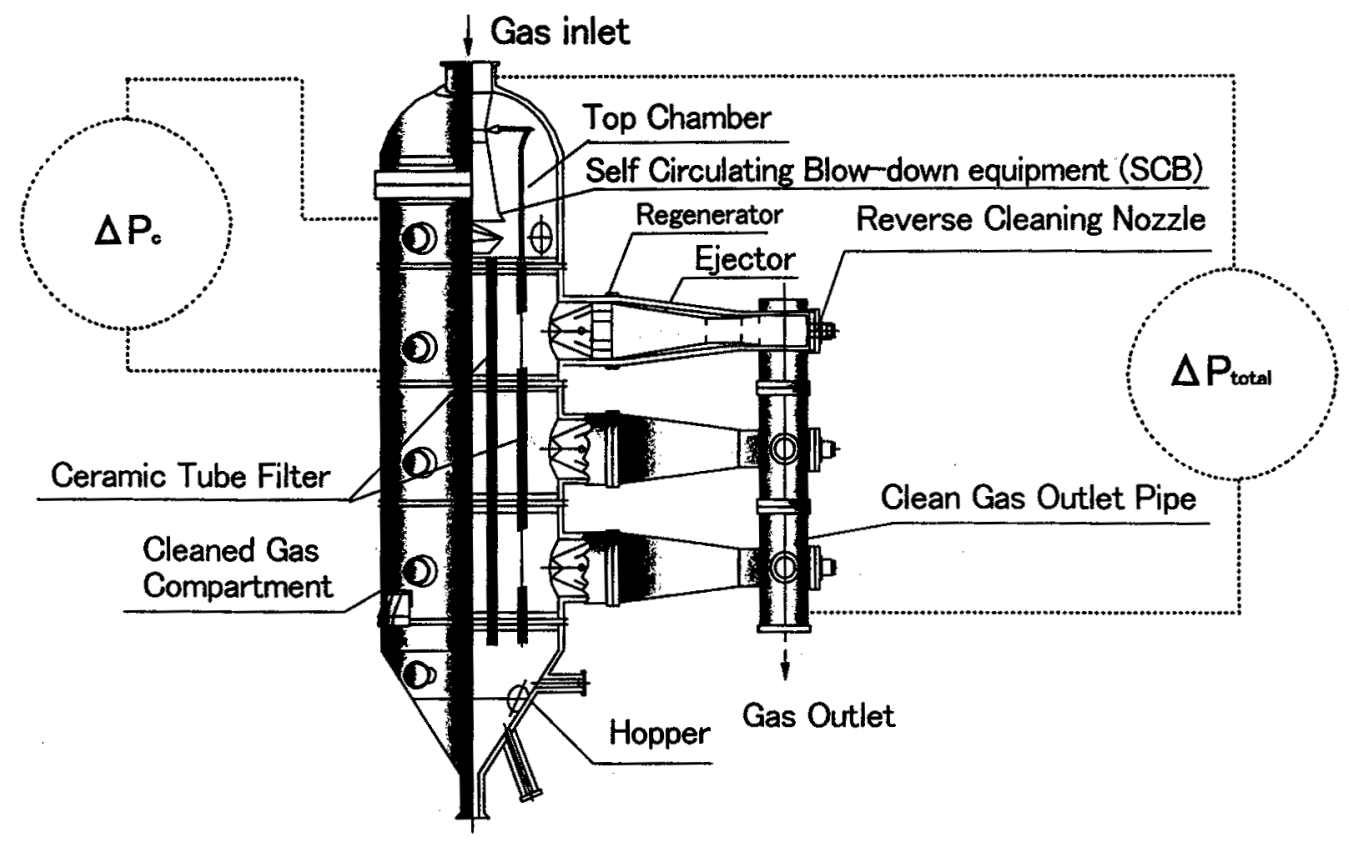

Figure 2.4.5

Example of Tube Filter System used in the Wakamatsu

PFBC in Japan [Sasatsa] 


\section{Chapter 3}

\section{Experimental System}

\subsection{Introduction}

There were many problems that were faced while constructing the room temperature test facility [RTTF], the experimental system that is used today. The evolution of the room temperature facility has revealed much information and eliminated many of the problems that could have been faced by building a high temperature facility in the beginning. There were three major room temperature facilities that will be discussed. The first was the original system that was in place from previous research. The second was the "remodeling" of the original with the main changes being the addition of smaller windows, a cap, and flow control devices. The third is the current system that is in place now. This third facility was built with the knowledge gained from the first two systems. This chapter will only deal with the development of the RTTF used in this thesis research effort.

\subsection{Chamber History}

\subsubsection{System 1}

Initially, a room temperature chamber was available from previous research. This system had been designed to develop the optical system to be used with the high temperature test facility. Consequently, the design of this system was simple. The chamber had been built with one-eighth inch thick aluminum. This original system had large windows which were not only difficult to keep clean, but nearly impossible to keep sealed. Eliminating leaks in the chamber is important because leaks will allow the chamber to act as though it has a much larger volume than what it actually has. In other 
words, if the chamber leaks during regeneration the chamber pressure will not raise as high as it would if it were sealed and thus makes regeneration easier. Also the fine particles escaping represent a health hazard. Another problem with large windows is trying to keep them clean. Keeping a smaller window clean should be much easier than keeping a large window clean.

The original system required major improvements to the "top" of the facility. The first was the lack of flanges to hold it down. This led to leaks in the chamber. Also, when the original system was being built the pulse jet was directed into the filter. This design is still used in much of the world.

Another major limitation with the original facility was the source for the regeneration gas. The gas that was used for regeneration was the high pressure air from the building (Engineering Research Building). This was also the source of the flow into the chamber for ash build-up. This meant that it was impossible to perform an on-line test. An on-line test is where a regeneration occurs while the normal ash build-up air into the chamber is still on. This limitation was critical because it eliminated the superficial velocity as a parameter and made regeneration much easier. It will later be shown that superficial velocity is an important parameter in the regeneration process.

Although this system had many flaws its original purpose was only to aid in the setup of the optics system and it succeeded in that. It also made it obvious from the observations that a room temperature facility may yield interesting results if redesigned and properly instrumented. Consequently, the decision was made to improve the system. 


\subsubsection{System 2}

With the modifications desired in the first facility incorporated into the second facility came some major changes. First, the large windows were eliminated in exchange for three small four-inch by four-inch windows. Second, a cap was added to the system. Third, devices to control and measure the build-up airflow into the system were added. Fourth, a high pressure nitrogen tank was added for the regeneration gas supply.

In redesigning the windows the main objective was to find a way to keep them clean so that the light source and the camera's vision were not blocked. An air curtain was unsuccessfully attempted to keep the windows clean. The reason the air curtain did not work was the restriction of flow to the air curtain. The total flow through the filter is fixed. The total flow consisted of the fluidizing air and the window curtain. Even if the air curtain flow were to be increased it would take away from the air that is needed to build the ash on the filter and thus would lead to longer build-up time or the incapability to build an ash at all. The results from the air curtain were so poor that it was decided not to pursue that as an option for keeping the windows clean. Our solution to the window problem was to build windows that opened on a hinge. This way the windows could be cleaned before each regeneration.

Another modification to the facility was the addition of a cap. This version of a cap, seen in Figure 3.2.1, had an inlet for the regeneration gas, and an outlet for the exhaust. Note that the regeneration entrance does not have an injector.

The first limitation was the absence of fringes on the cap. The top of the chamber was more like a lid that was glued to the chamber. The cap was bolted to this lid and although the seal between the cap and lid was adequate, the seal between the lid and 
chamber was insufficient. This lid did not have the strength to remain sealed when a large superficial flow was used. With large flows the lid would literally start to rise off of the chamber. One would have to assume that this also would have been a problem during regeneration.

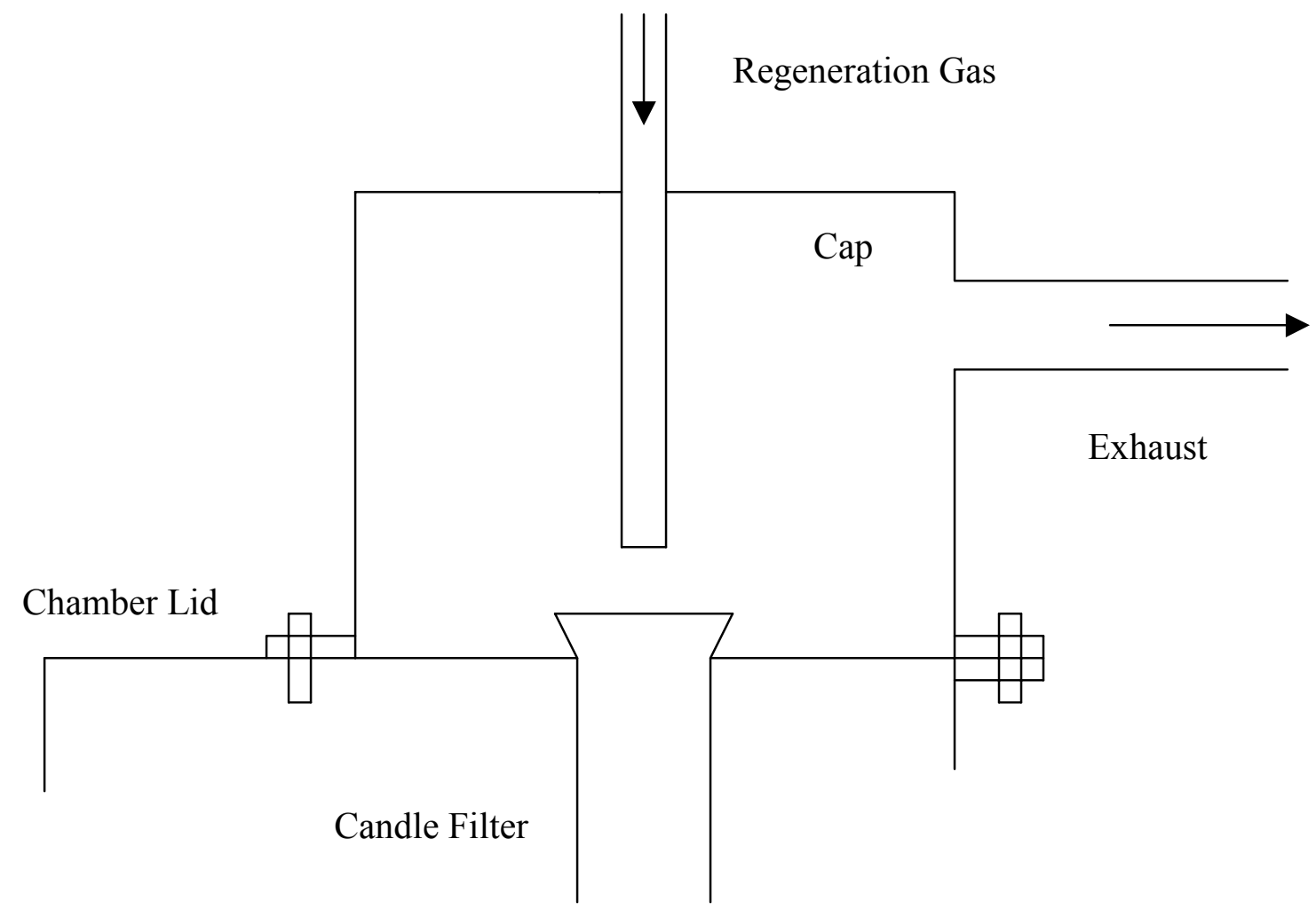

Figure 3.2.1

Cap Design for Second System

Many additions were made outside of the chamber to allow the flow into the facility to be controlled (Figure 3.2.2). First, the airflow into the chamber for the ash build-up was needed. The source for this gas was the "house air" from the building. For this arrangement the gas was first run through a pressure regulator that would eliminate any fluctuations in the gas. The gas then flowed through a valve and then a flow meter. 


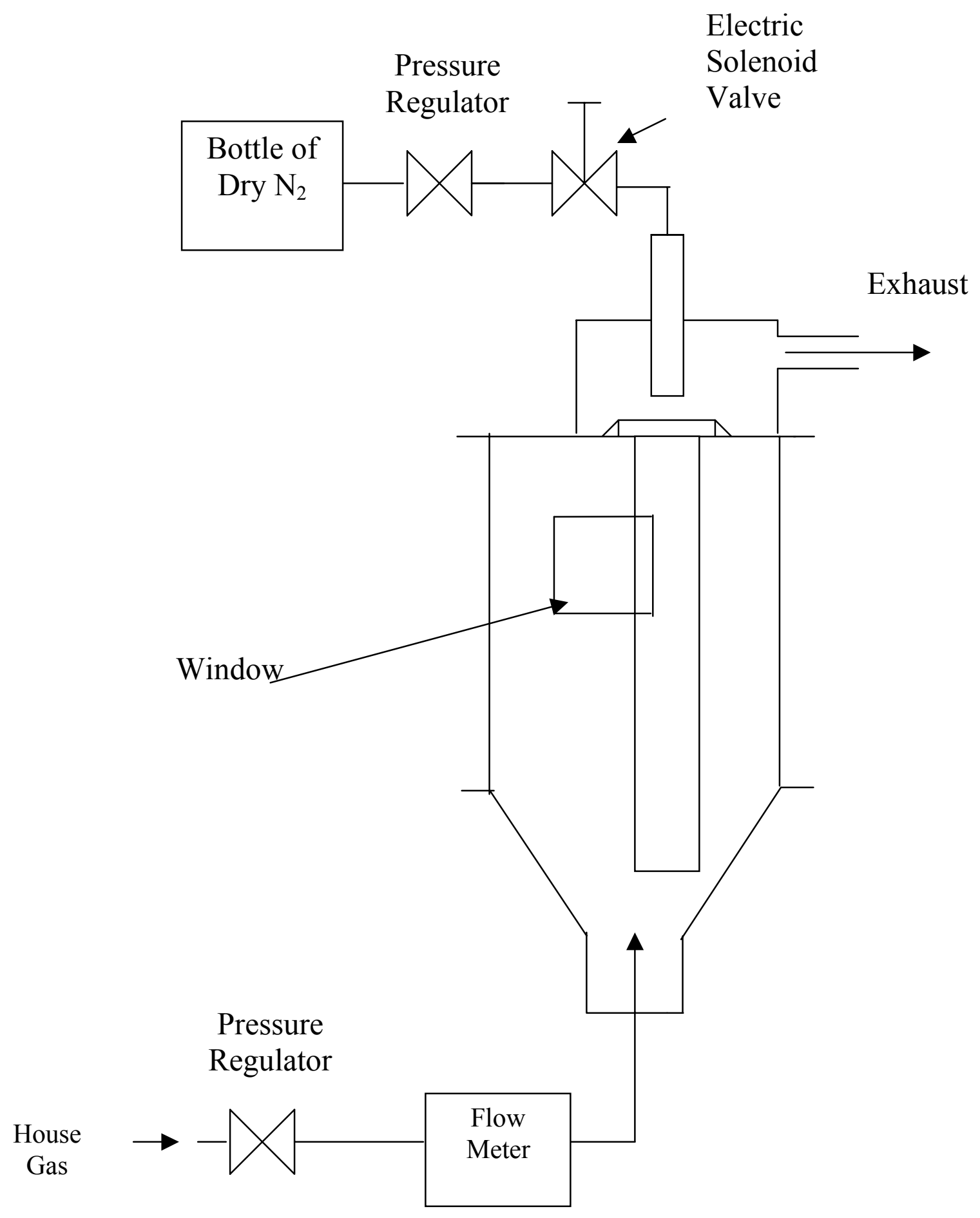

Figure 3.2.2

Flow Controls for System 2 
Directly after the flow meter was a pressure gauge. From there the gas flowed into the bottom of the chamber. This setup was repeated with the outlet traveling to the cap for the permeability test that will be discussed later.

The next addition was a source for the regeneration gas. A high-pressure tank full of nitrogen was used for the source. A pressure regulator was used to control the regeneration pressure. An electric solenoid valve was used to open the channel to allow the high-pressure gas to pass through for a specified amount of time. This solenoid valve was triggered by the computer's data acquisition system. The solenoid valve can be controlled to open for a specified amount of time during regeneration. The time that the solenoid valve is open to allow the regeneration gas to flow through is an important parameter. This gas leads to the cap so that regeneration can take place.

\subsubsection{System 3}

The third, and final, room temperature facility was completed with the intention of conforming to new Department of Energy design recommendations, correcting the leakage problems, and attempting a new solution to the dirty window problem. This facility was made with quarter inch thick aluminum for sturdiness.

In trying to maintain clean windows, gates were built for each window.

Unfortunately in the design for the gates, large threaded rods were used to open and close the gates. This threading would have worked for a clean system but unfortunately the ash jammed the threading such that the gates were eventually impossible to open and close. Once again the solution for clean windows involved removing the windows and cleaning them before each regeneration. 
The rest of the changes all involve the cap. Flanges were added to the top of the chamber and to the cap and a filter tubesheet was added. The tubesheet has a hole in it which is larger than the diameter of the filter, but smaller than the diameter of the lip on the filter so that the filter can be placed in the tubesheet. The lip of the filter will set on the tubesheet. Using the tubesheet to support the filter will allow a change in the positioning of the candle filter, or allow the addition of more candle filters to the chamber to see how they react with each other. This can be done by simply changing the existing tubesheet or building a new tubesheet.

An important change made to the new facility was the addition of an injector nozzle for the regeneration gas. As can be seen in Figure 3.2.3, the exhaust outlet is "behind" the injector so that the regeneration air cannot go directly out the exhaust instead of helping regenerate the candle filter. A full set of drawings of the current room temperature test facility can be seen in Figures 3.2.4 -3.2.6. 


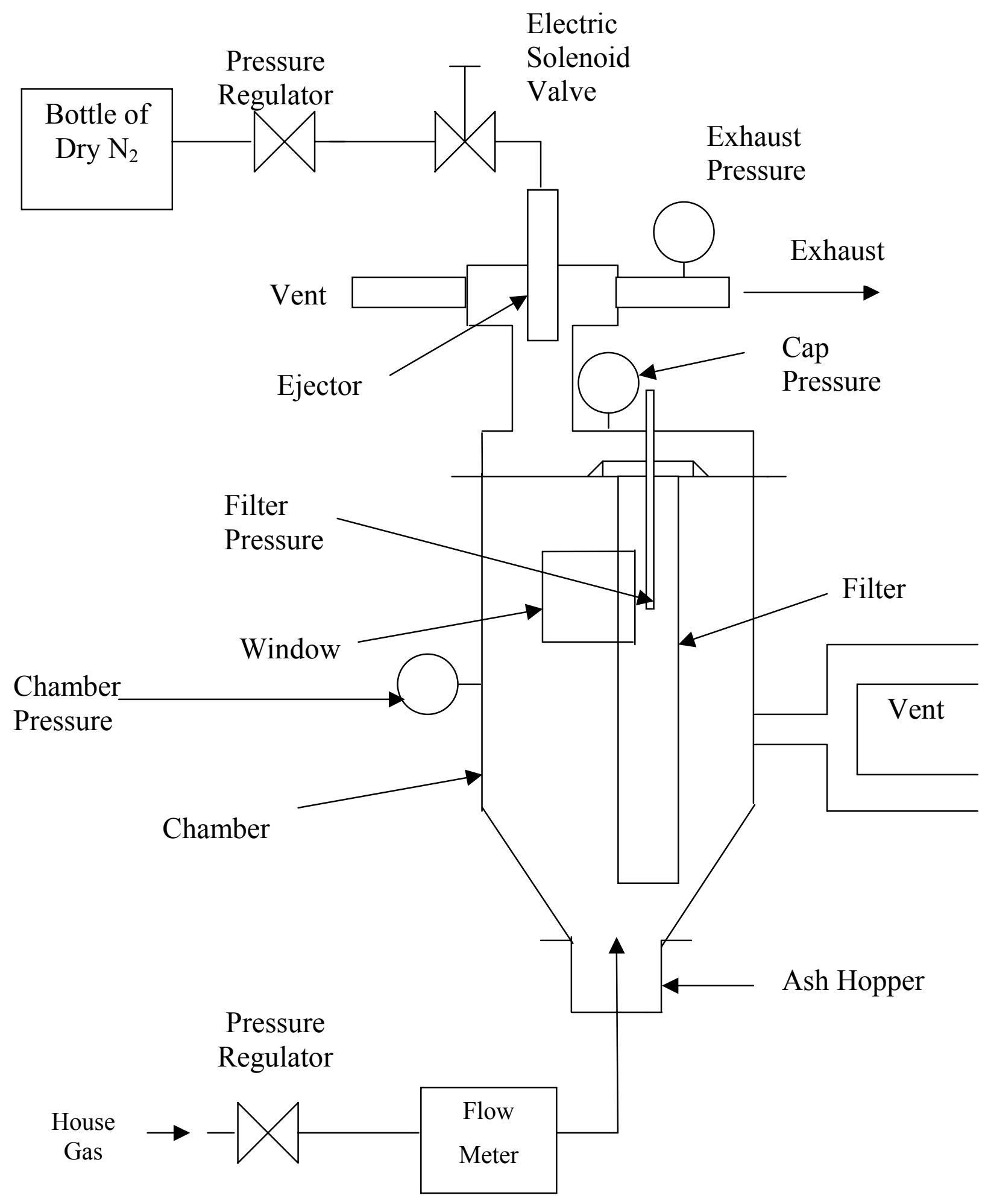

Figure 3.2.3

New Cap and Exhaust with Injector and

Instrumentation 


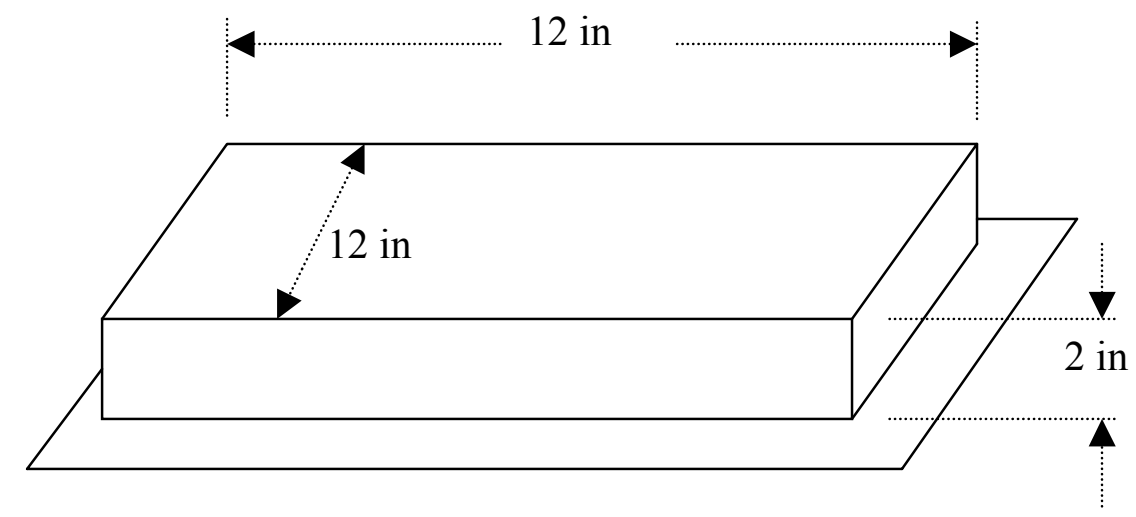

Figure 3.2.4

Drawing of the Basic Cap

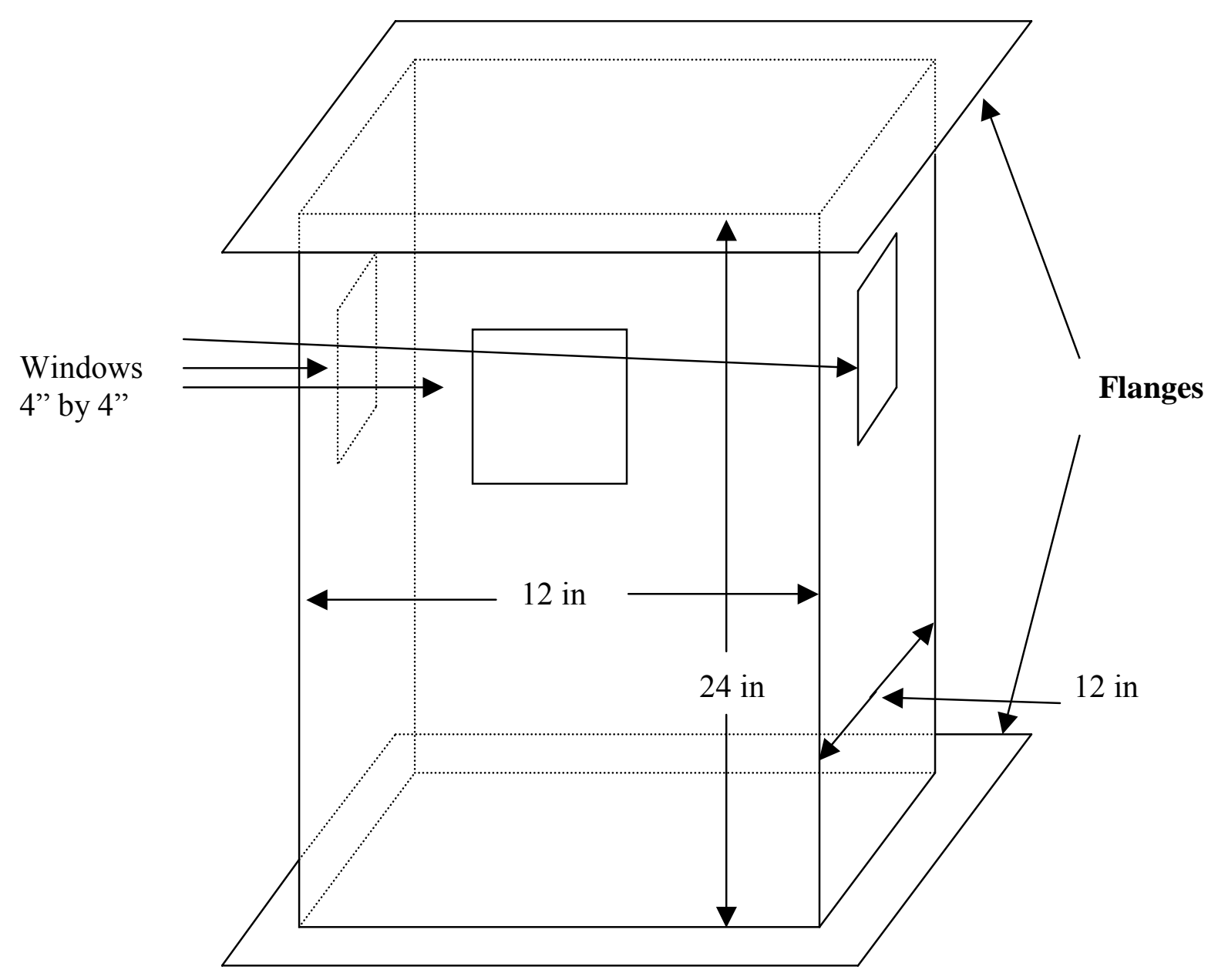

Figure 3.2.5

Chamber body 


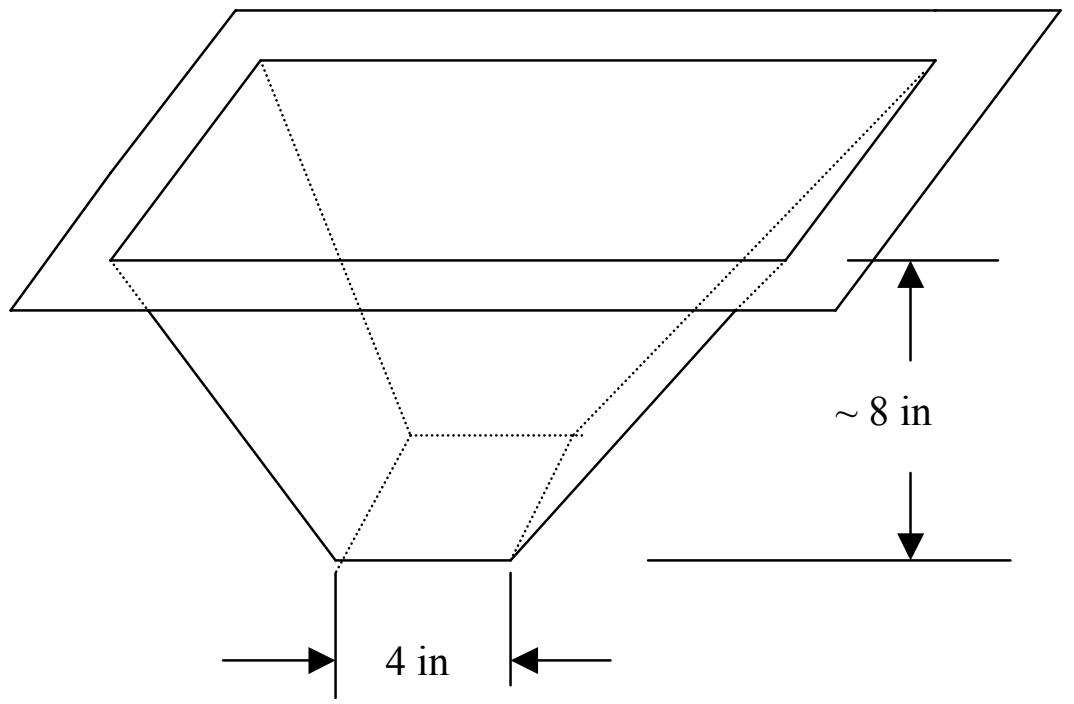

Figure 3.2.6

Chamber Cone 


\subsection{Instrumentation and Noise}

The goal of the system was to be able to accurately read voltages from pressure transducers and to be able to time the readings with the CCD pictures taken with and stored in a second computer. Two different data acquisition systems were installed in the facility. The first effort was unfunded and many of the items used were only borrowed. There were many problems in the first system as well as in the preconditioning of the signals while that system was implemented. The problems have been either solved or dealt with.

\subsubsection{History}

The first data acquisition board used was an RTI-815 Board (National Instruments). This board was borrowed and thus was only a temporary installation. DOS was used as the operating system for this board and Quick Basic was used to control the board. The RTI- 815 board that was used was a 12-bit board and was capable of sending 5-volt digital signals as triggers. It was capable of triggering both the camera and the electric solenoid valve accurately. The fact that the board was a 12-bit board yields 4096 divisions for the specified voltage range.

The original signal conditioners were the 5B30 signal conditioners (Analog Devices). All signal conditioners that have any kind of noise filtering have a time delay due to filtering. The time delay is partially dependent on the amount of filtering that the conditioner is built for. It is also dependent on the speed and magnitude of the voltage change. One characteristic of the 5B30 series was the long "rise time". The rise time is the time it takes for the output voltage of the signal conditioner to adjust to increase from $10 \%$ to $90 \%$ of the total input. For example, if the input for the signal conditioner is 0 


\section{Graph of Pressure vs. Time for 5.75 scfm, 145 psia, Thin Ash with \\ Old Data Acquisition System}

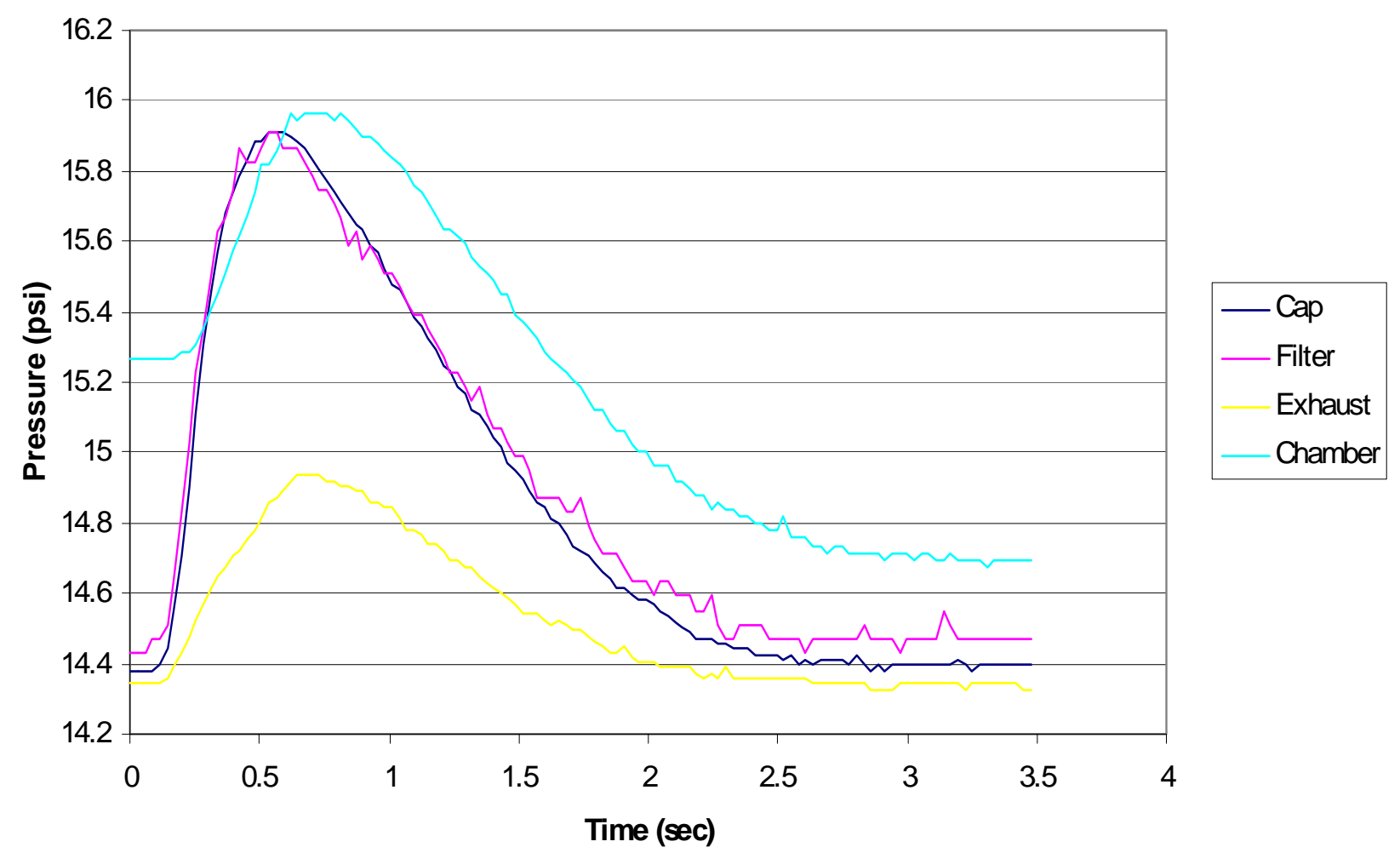

Figure 3.3.1

Choppiness from Old Data Acquisition System

$\mathrm{mV}$ to $100 \mathrm{mV}$ and the voltage instantaneously increases from $10 \mathrm{mV}$ to $90 \mathrm{mV}$, the output will take the rise time to reach the calibrated output. The rise time for the $5 \mathrm{~B} 30$ series conditioners was 0.2 seconds.

\subsubsection{Discussion of Problems}

When the board was set to read from 0 to 5 volts, which was the case here, and using the signal conditioners that were available at the time, the psi per division for the pressure signals ranged from .019 to .0386 . This is not enough resolution for a smooth graph and it led to graphs that look "choppy" as seen in Figure 3.3.1. 
One major problem with the original data acquisition was the signal conditioners that were used to amplify the voltage signal from the pressure transducers. This delay was noticed when the camera was triggered by the data acquisition board. The pictures showed that the candle filters were regenerating before the pressures started to change. This obviously cannot happen so we searched for a delay and eventually realized it was the signal conditioners. The 5B30 signal conditioners were then exchanged for the 5B40 signal conditioners that have a rise time of $35 \mu$ s. Figure 3.3.2 shows filter pressures from both the $5 \mathrm{~B} 30$ and no signal conditioners to show the delay caused by the $5 \mathrm{~B} 30$ conditioner.

One problem that was in the old system, but was hidden by the filtering in the signal conditioners, was noise. When the pressure signals were connected directly to an oscilloscope, bypassing the signal conditioners, the noise was evident. Figure 3.3.2 shows this noise as well as the delay mentioned earlier. A signal that is only 0 to $100 \mathrm{mV}$ is so small that it is difficult, if not impossible, to get rid of the noise. The old system had screw terminals and ribbon cable as a connection to the data acquisition board, both of which can cause noise. One attempt at eliminating some of the noise involved shielding the ribbon cable with grounded aluminum foil. This did not seem to help the noise situation. With the new system, terminal boards have Wago connection points that may or may not eliminate some of the noise. Another item which may have eliminated some of the noise is the round and shielded cable that connects the analog terminal board to the data acquisition board. This cable replaces the ribbon cable from the old system.

Eventually, it was decided that a new data acquisition system should be purchased and everything but the pressure transducers changed. The second data acquisition board 


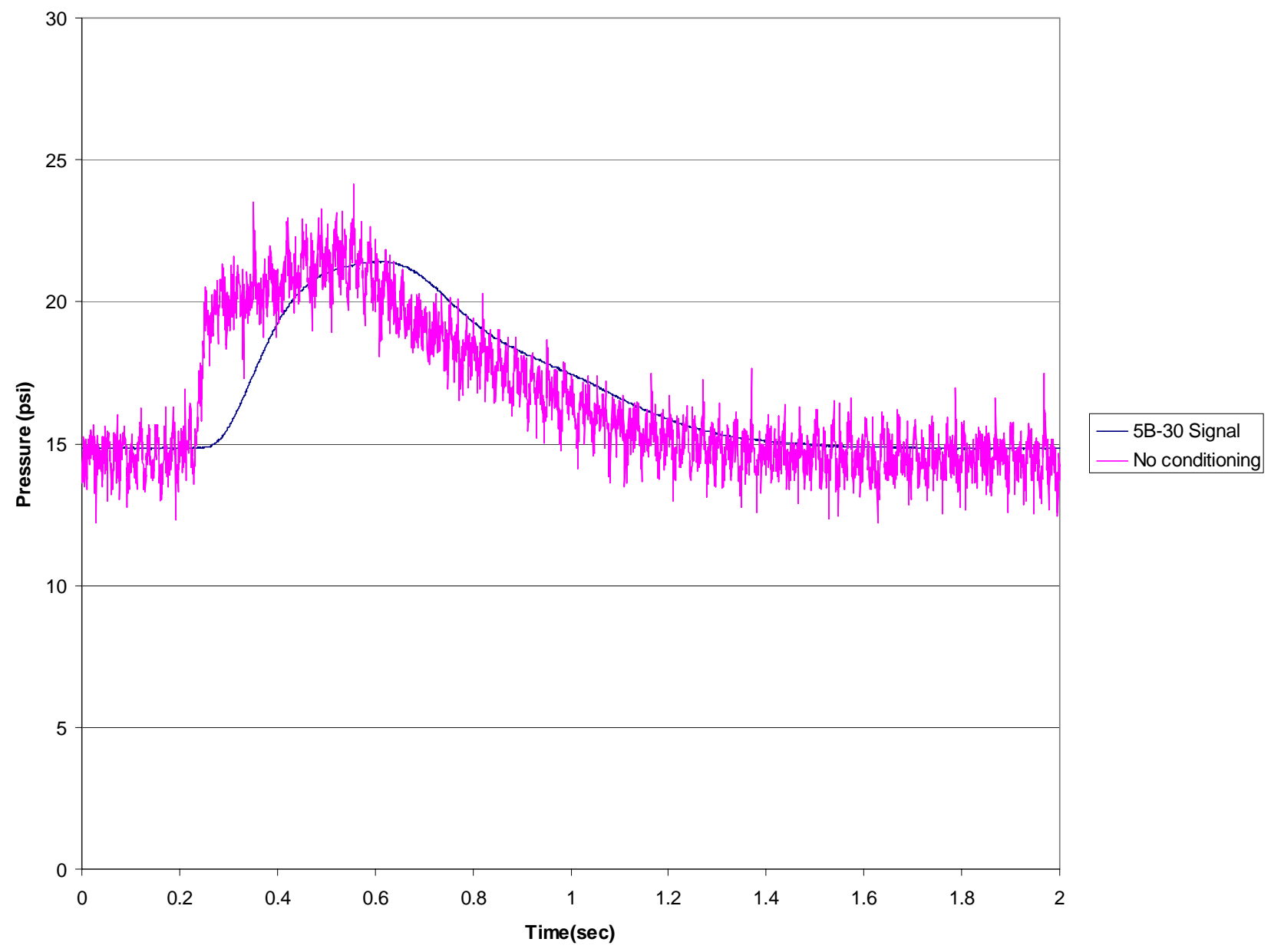

Figure 3.3.2

Time Delay for 5B-30 Signal Conditioners

was a DAP 5200a/526 (Microstar Laboratories). This board has a $300 \mathrm{MHz}$ and $32 \mathrm{Mb}$ RAM that allow it to be used under MS Windows NT without a time delay in the data. This allowed us to get away from DOS as the operating system and still get good results. This board is a 16-bit board which is set to read from $-5 \mathrm{~V}$ to $5 \mathrm{~V}$. This gives 32,768 points between $0 \mathrm{~V}$ and $5 \mathrm{~V}$. This added resolution makes the bumps in the graphs much smaller and yielded psi per divisions as low as 0.00344 


\subsection{Employed Instrumentation}

The data acquisition system described here was almost entirely a Microstar Laboratories system. The main component of this system was of course the data acquisition board, which was a DAP 5200a/576 board. As mentioned earlier this board has a $300 \mathrm{MHz}$ processor and $32 \mathrm{Mb}$ RAM to allow for accurate real time results while working under a Microsoft Windows operating system.

\subsubsection{Transducers}

Each of the pressure transducers used in this project was purchased from Kulite Semiconductor Products Inc. Three of the transducers are the XTM-190M 25A (Figure 3.4.1). Each of these transducers is rated for 25 psia. These transducers have a full scale output of $75 \mathrm{mV}$. These transducers are placed in the cap, chamber, and exhaust. There are a couple of options in choosing the surface on the transducer face. The two main options are the "B" screen and the "M" screen. The "M" screen has small holes in it which is adequate for clean air but not suited for dirty air which is the case in our chamber. The " $\mathrm{B}$ " screen is a flat surface which obviously will not be clogged up with

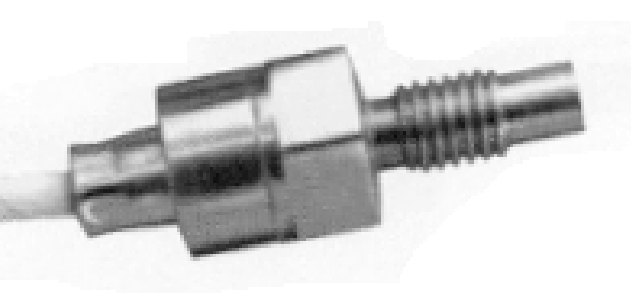

Figure 3.4.1

XTM-190M-25A Pressure Transducer 
ash. The "B" screen was used because of the particulate that needs to be dealt with within the chamber. Ash passing by the filter is also a concern so the "B" screen is used on all three of the XTM-190M 25A transducers.

The small transducer placed in the filter was an XCQ-093-50A (Kulite). This transducer is rated for $50 \mathrm{psia}$ and has a full scale output of $100 \mathrm{mV}$. Figure 3.4.2 shows the size of this transducer. One obstacle that had to be overcome was how to get the transducer in the filter without hampering the flow. The solution was to epoxy the transducer into the end of a metal tube. This solution gave the researcher the ability to move the transducer up and down to measure the pressures at different heights within the filter.

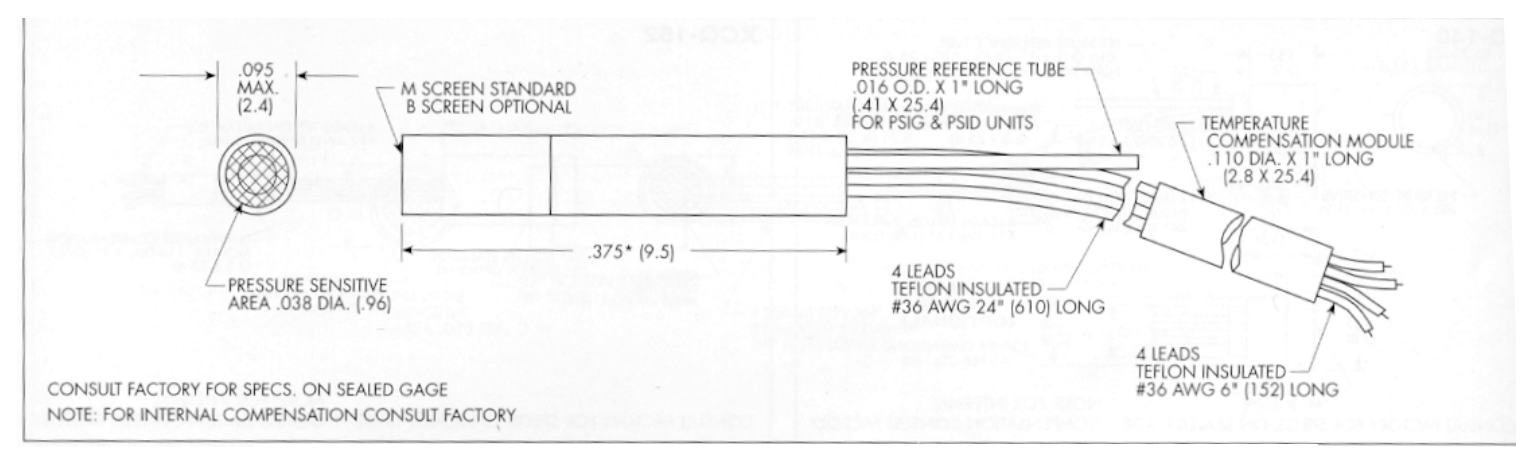

Figure 3.4.2

Schematic of XCQ-093-50A Pressure Transducer

The fifth and final transducer in the system was a BM-1100-250A (Kulite) in the velocity tube. This transducer was rated for 250 psia and has a full scale output of 100 $\mathrm{mV}$. Figure 3.4.3 shows the BM-1100-250A transducer. All five of the mentioned transducers were powered by the same $12 \mathrm{~V}$ power supply. 


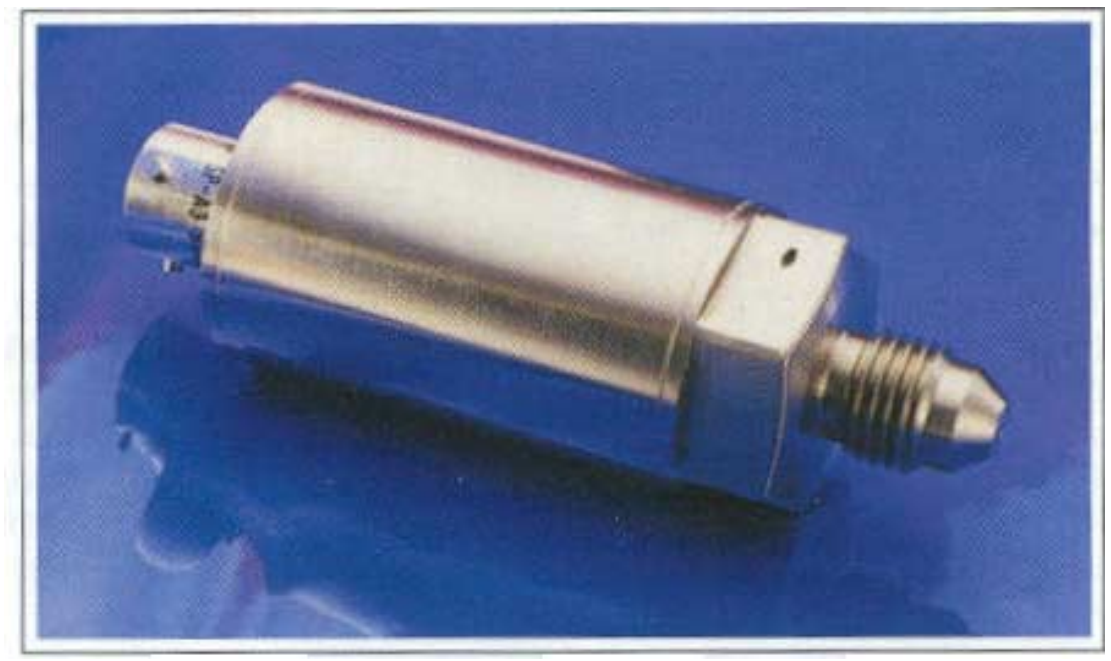

Figure 3.4.3

BM-1100-250A Pressure Transducer

\subsubsection{Signal Conditioning}

The transducer signals were then run through signal conditioners to clean up and amplify the signal. The signal conditioners used were 5B40-03 (Analog Devices), seen in Figure 3.4.4, which have an input of $-100 \mathrm{mV}$ to $100 \mathrm{mV}$ and an output of $-5 \mathrm{~V}$ to 5 V. These signal conditioners cleaned up the signal with a minimal time delay. As was mentioned earlier, the rise time of these signal conditioners is only $35 \mu \mathrm{s}$. This delay is small enough to be ignored for this purpose. These signal conditioners were housed in a 5B08 backplane shown in Figure 3.4.5 which was also purchased form Analog Devices. This backplane is powered by a $5 \mathrm{~V}$ power supply and is capable of supporting up to eight 5B signal conditioners.

From the 5B08 backplane the signals were sent via a short ribbon cable to an analog termination board. The pin assignment from the ribbon cable coming from the backplane is shown in Figure 3.4.6. The analog termination board used was the MSTB 009-09 (Microstar Laboratories), seen in Figure 3.4.7, with Wago connection points. 


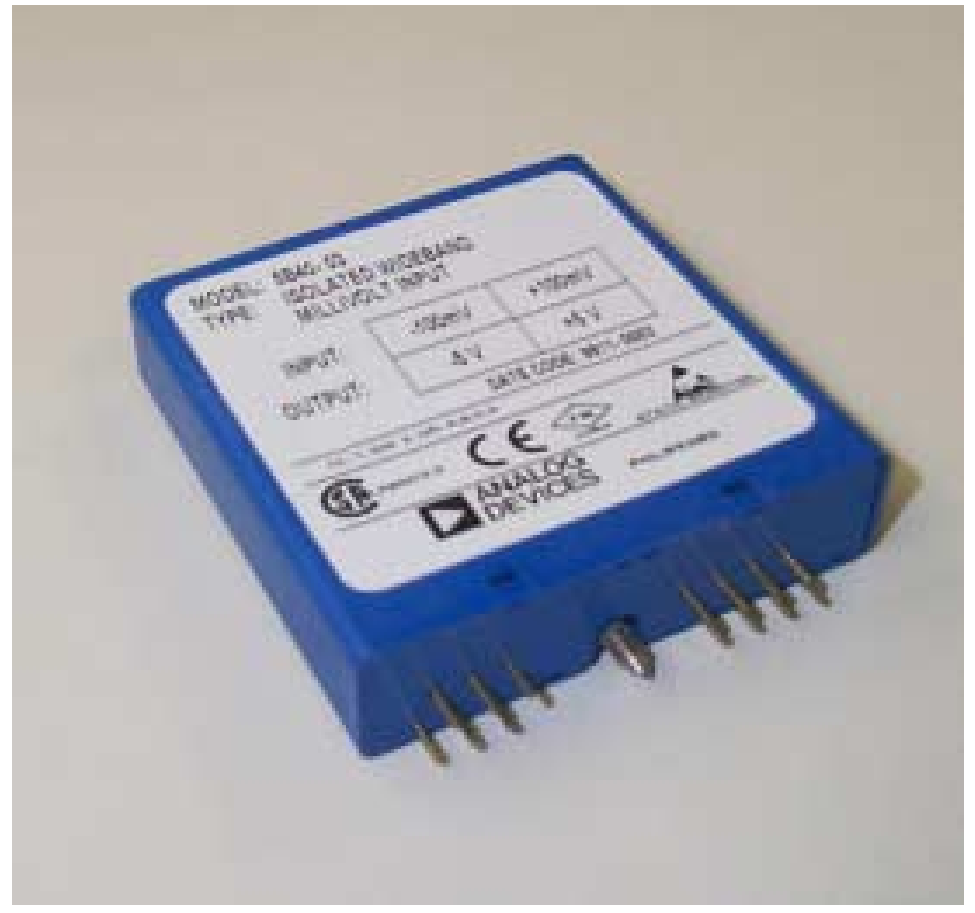

Figure 3.4.4

5B-40 Signal Conditioner

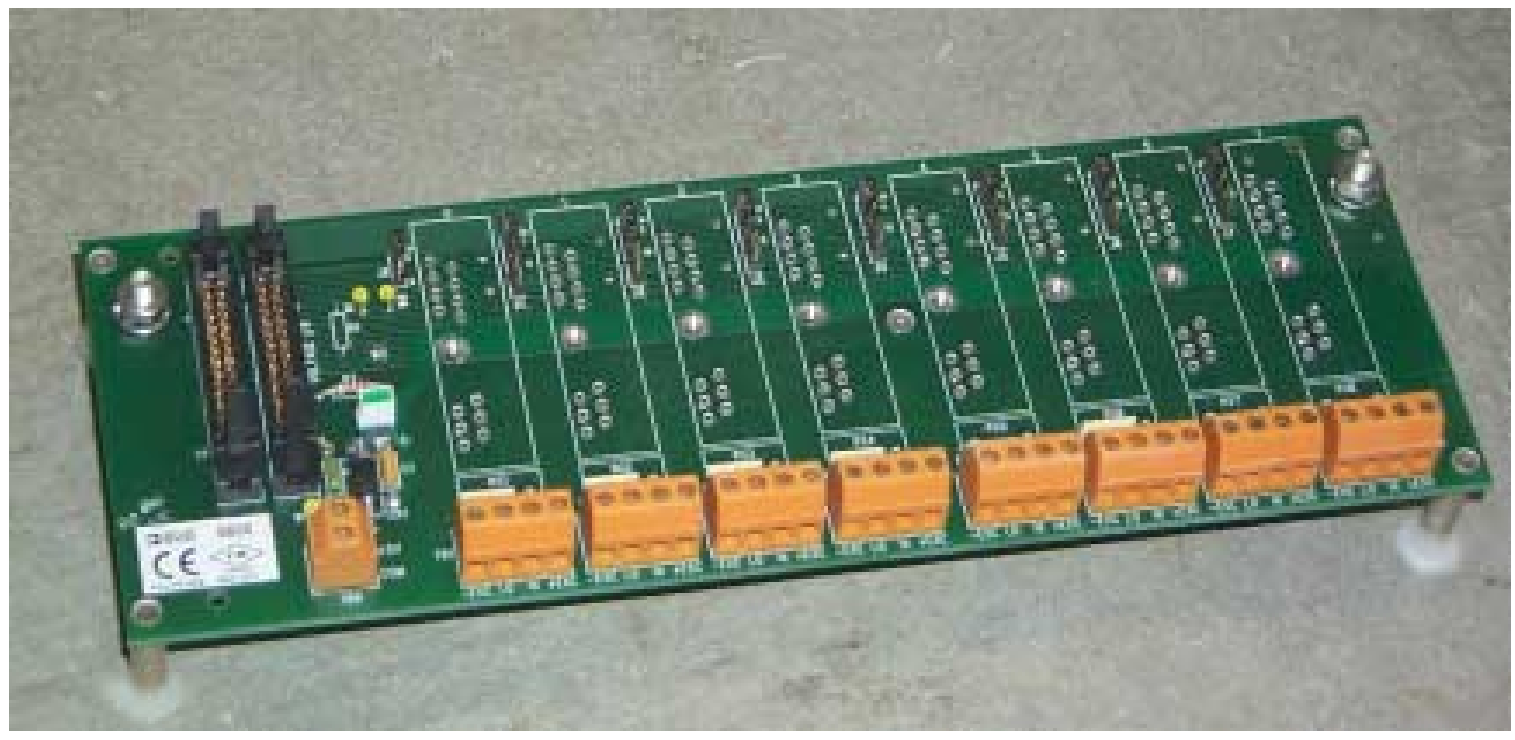

Figure 3.4.5

5B-08 Backplane 


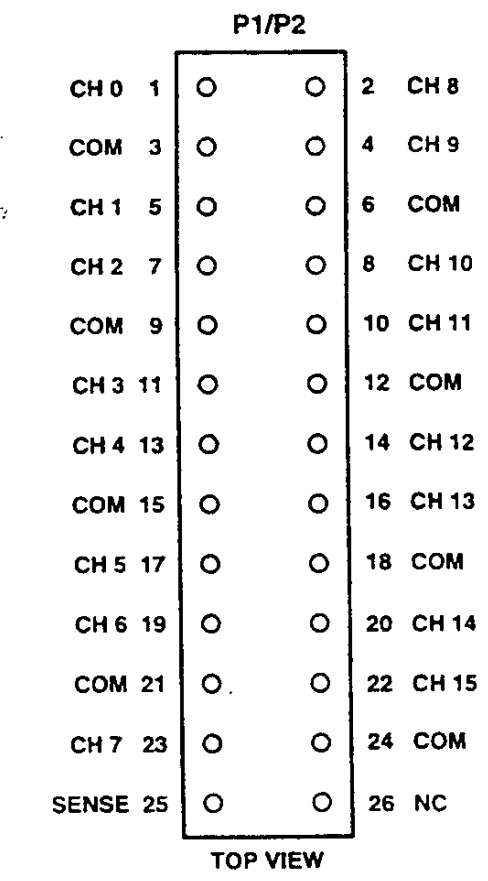

Figure 3.4.6

Backplane Pin Assignment

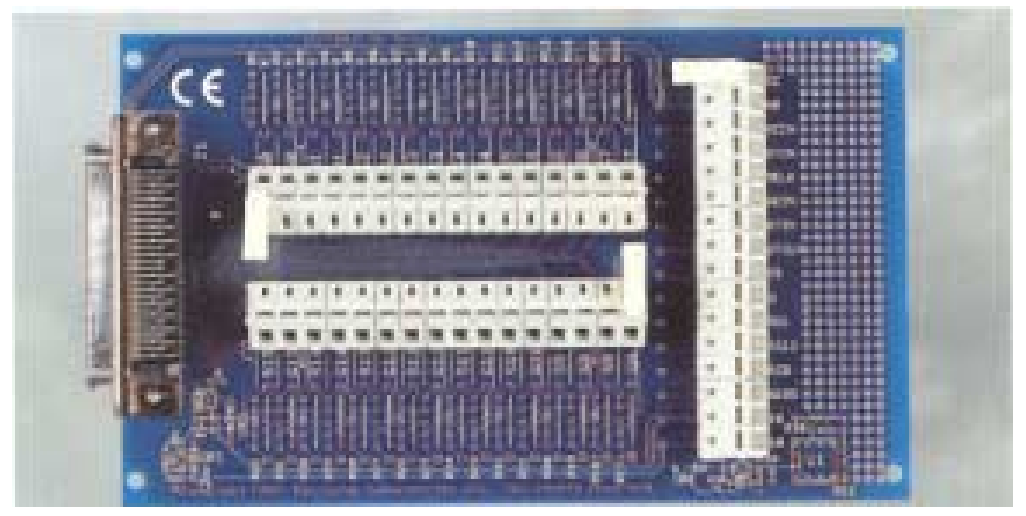

Figure 3.4.7

Microstar Laboratories MSTB 009-09 Analog Termination Board 
On the termination board the S0 and G0 connection points are for the high and low for Channel 0,S1 and G1 are for the high and low for Channel 1, etc. Figure 3.4.8 shows the wired analog termination board. Note that not all of the connections that were wired were used. There was also a digital termination board that is completely separate from this one and will be discussed later on in this section.

The signal was then sent to through a MSTB 040-01 cable (Microstar Laboratories). This cable is a 68-line round and shielded cable reduces the noise when compared to a long ribbon cable.

This cable is directly connected to the DAP 5200a/526 data acquisition board

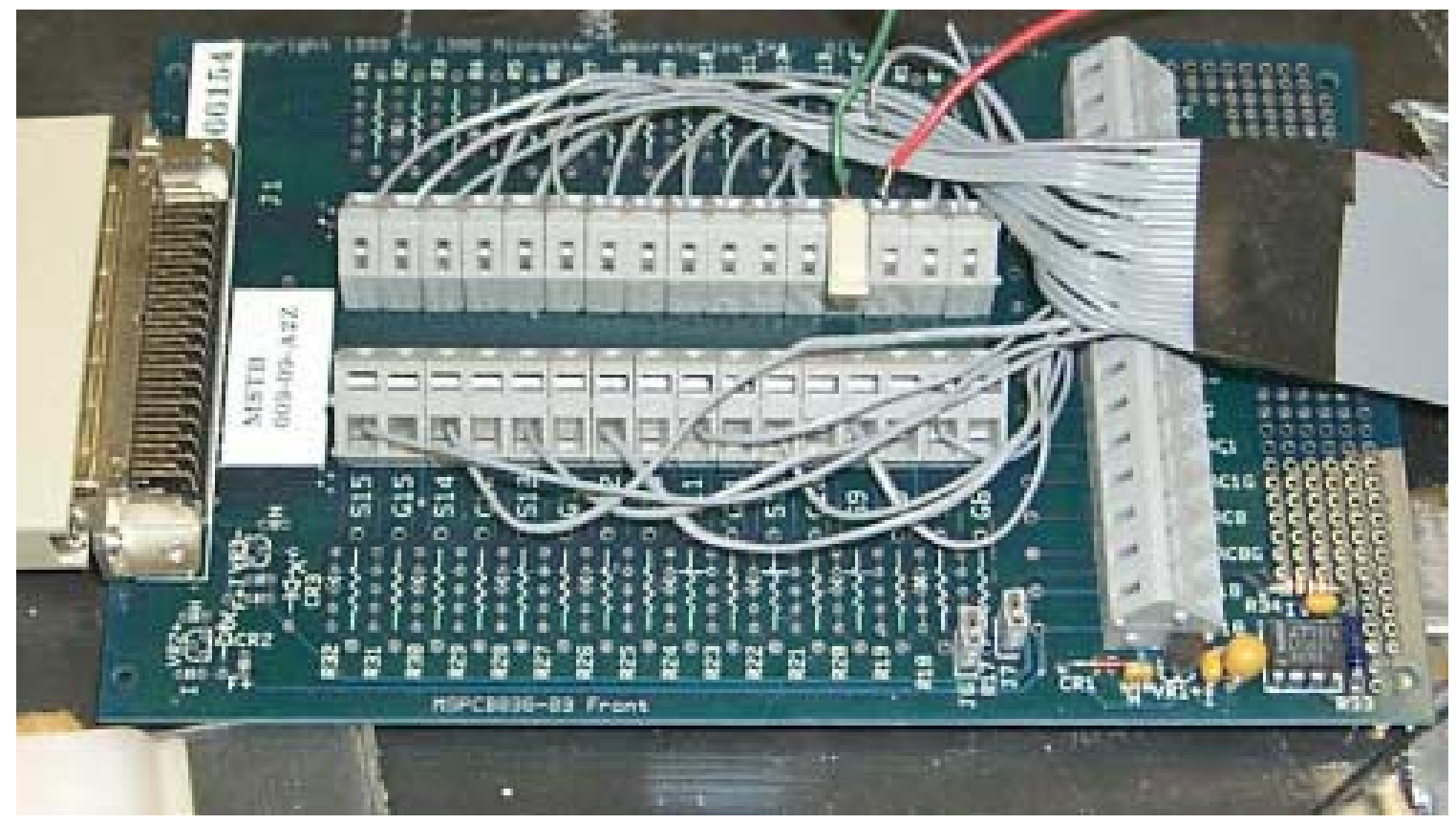

Figure 3.4.8

Wired Analog Termination Board 
(Microstar Laboratories), the heart of the system. This board, shown in Figure 3.4.9, was chosen because it is capable of running under an MS Windows operating system and still produces good real time results. Windows causes delays in most data acquisition boards, but this board uses its own CPU and memory and eliminates the delays that Windows causes. The DAP 5200a/526 has a $300 \mathrm{MHz}$ AMD K6-2 processor and $32 \mathrm{Mb}$ RAM and it uses a PCI interface to communicate with the computer. This board was set to read a5 to $5 \mathrm{~V}$ signal with 16-bit resolution. The board also had digital outputs that were used to control an electric solenoid valve and also trigger the camera to take pictures of the surface regeneration process. Digital inputs to trigger the board are also traits of this board but not necessary for this application.

As mentioned the digital outputs were used to trigger the solenoid valve and the camera. The board was actually set up to use three of the outputs. The data acquisition

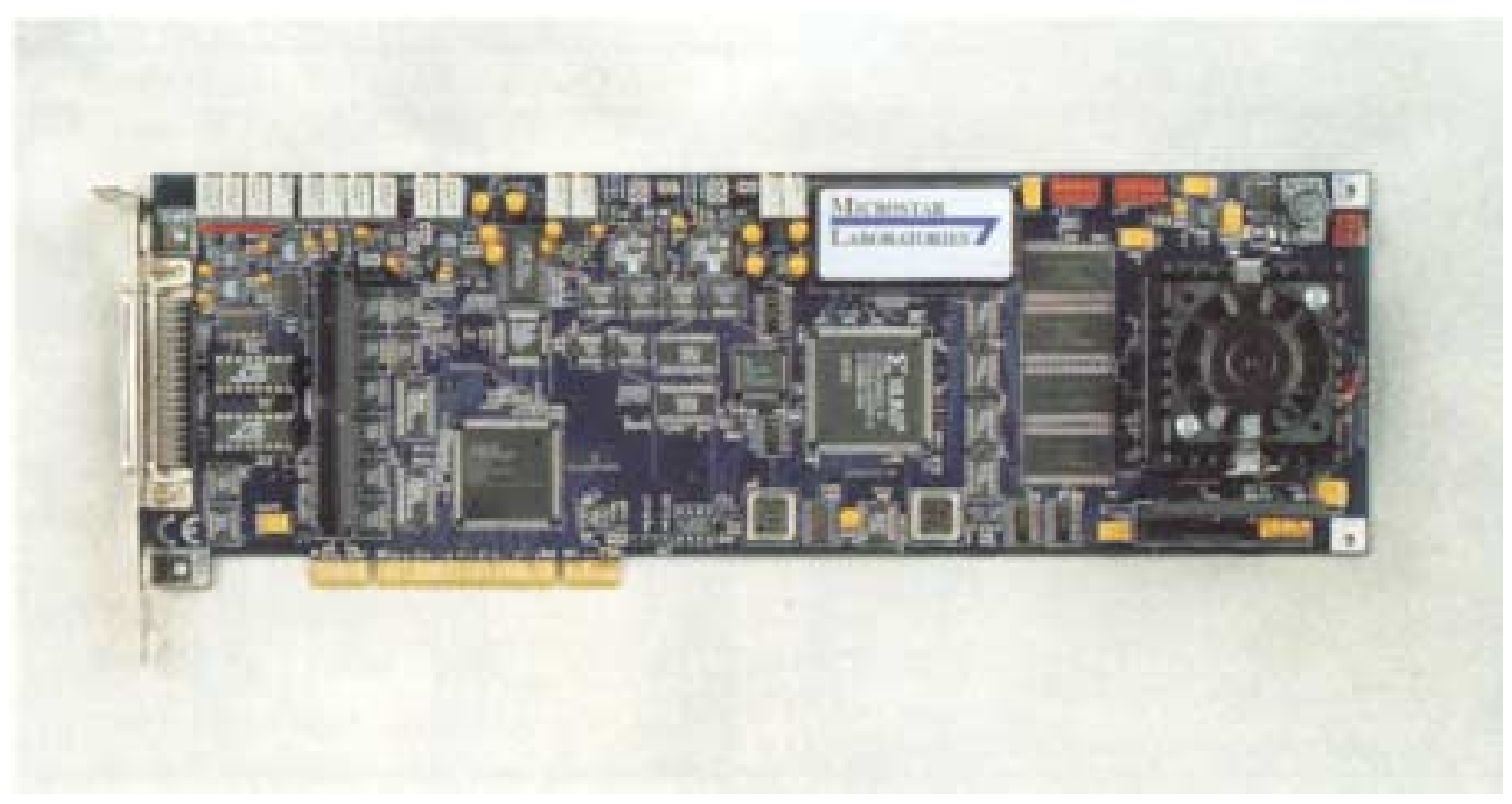

Figure 3.4.9

Microstar Laboratories DAP 5200a/526 Data Acquisition Board 
board was connected to the MSTB-008-01 (Microstar Laboratories) via ribbon cable, shown in Figure 3.4.10. The third output was a duplicate signal of the signal sent to the solenoid valve and was sent to one of the analog input channels to be read by the board. This is done so that the person studying the data knows the time that the solenoid valve is open. The third signal was used to trigger the camera so that the pictures were started at the same time that the solenoid valve opens. This was necessary to find a good estimate

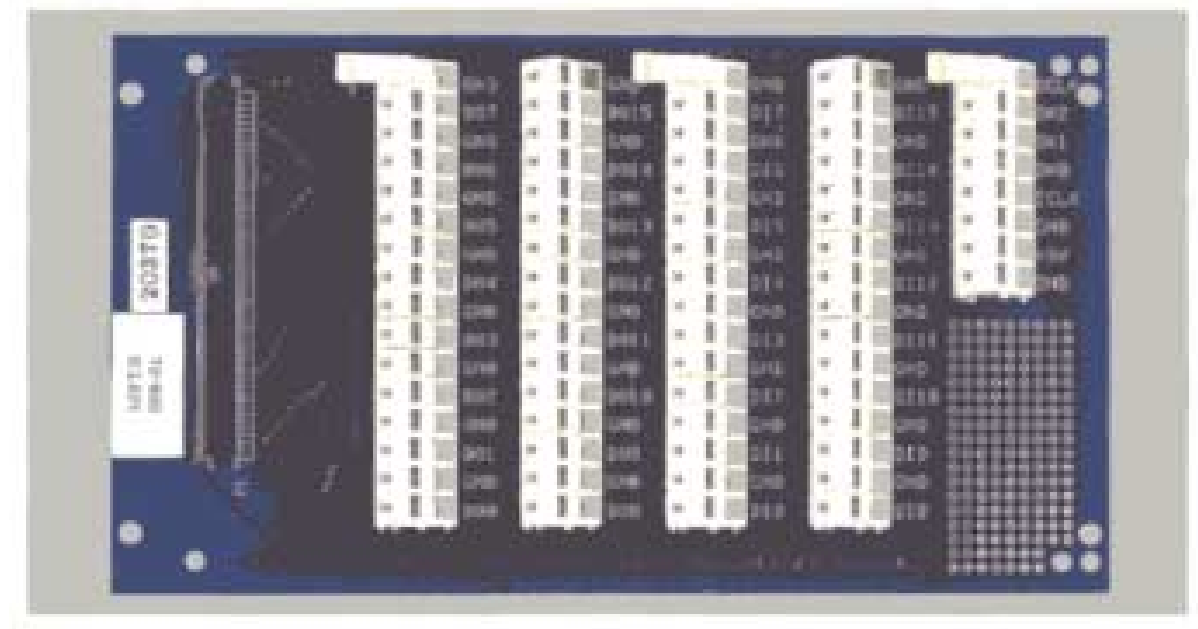

Figure 3.4.10

Microstar Laboratories MSTB 008-01 Digital Termination Board

of the time of the crack initiation of the ash during regeneration. With this time $\Delta \mathrm{P}_{\tau}$ can be found which can help us find the ash strength for the tests.

The signal used to trigger the solenoid valve was not sent directly to the solenoid valve. The solenoid valve only opened when alternating current from a standard wall outlet is allowed to pass through it. Fortunately, a "trigger box" that solved this problem had already been designed by Richard Atkinson for another research project. This box had six connections, a high and low for the $5 \mathrm{~V}$ trigger from the data acquisition board, a high and low for a $12 \mathrm{~V}$ power supply, and two connections for the $\mathrm{AC}$ current and the 


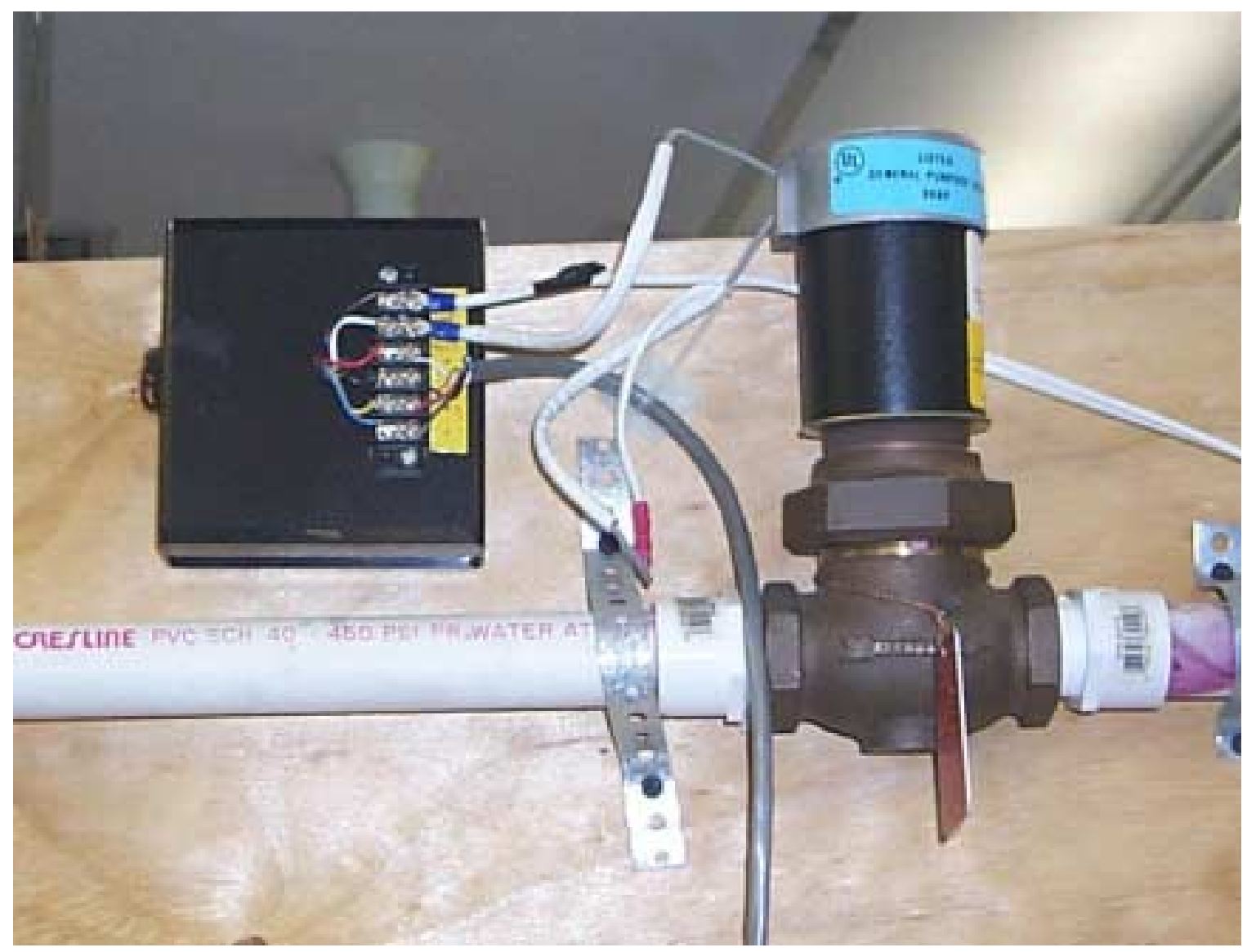

Figure 3.4.11

Trigger Box and Connections

solenoid valve. The AC connections are illustrated in Figure 3.4.11. The solenoid valve had two wires. One of those wires was connected directly to the box and the other was connected to the one of the lines coming from the wall outlet. The other line from the wall was connected to the box. With the wires connected in this manner, whenever a $5 \mathrm{~V}$ signal was sent from the computer to the "box" the AC current was able to pass through the solenoid valve and open it. The valve remained open for the duration of the $5 \mathrm{~V}$ signal. 
The programs used to take data for the system will now be presented. The programs were written in a language called DAPL. DAPL was the language that the computer uses to communicate directly with the data acquisition board. The first of these two programs was named "calib.dap" and was used to collect the data during ash buildup. The second was titled "fastack.dap" and was used to take data, trigger the camera, and open the solenoid valve. These programs are shown and explained in Appendix A. The program used to run DAPL, DAPView for Windows, is also explained in Appendix A. 


\subsection{Test Procedure}

For each test there are two main steps. The first is to build up ash on the filter. The second is to clean the filter with a back-pulse cleaning. The goal for the instrumentation was to have pressure transducers throughout the system so that the pressure histories for the entire facility could be known throughout the process. The ability to time the pressure readings with the pictures taken by the optics system was also a priority. This section explains the test procedure used to accomplish this.

With the filter installed and hoses properly connected, ash is added to the chamber until the hopper is full. Note that it is difficult to keep the amount of fluidized ash constant because the ash tends to stick to the walls. The flow is then set to provide a predetermined face velocity. The gas will fluidize the ash in the hopper and deposit it on the candle filter. Once a sufficient ash thickness is obtained the gas flow used for the ash build-up is shut off. When this gas is shut off, the face velocity of the gas entering the filter is zero. On the candle filter which was used for these tests, there were bald spots toward the top of the filter. This allowed for a qualitative estimate of the ash thickness just by looking at the filter. The next step is to wait and allow the ash floating in the chamber to settle. The length of time to wait is dependent on the amount of ash suspended in the chamber. Once the ash has settled the windows need to be cleaned. The window for the camera is removed and cleaned. The window for the light source is also cleaned and then both windows are reattached to the chamber. When cleaning the windows the exhaust gas flow is maintained so that the pressure drop across the filter aids in keeping the ash on the filter. Care was also taken not to shake the chamber while the fluidizing gas flow is turned off or the ash can be knocked off the filter. Once the 
windows have been reattached to the chamber, the exhaust is closed and the vents shown in Figure 3.2.3 are opened and the data acquisition board is set to read the data points to see if the pressure transducers all read the same pressure, atmospheric pressure. The "calib.dap" program, seen and described in Appendix A, is used for this. Once this data is taken the vents are closed and the exhaust is opened back up.

Next the fluidizing gas is turned back on so that the test is run on-line. An on-line test is a test where the fluidizing gas is left on during the regeneration process. All of the tests run for this thesis were on-line tests. Once the gas is started up again, the ash will tend to be kicked up and will need time to settle if clean pictures are to be taken. The time needed to wait is dependent on the face velocity and the amount of ash in the chamber that is not caked on the filter. A test for a thick ash did not take long because there was not much ash left in the chamber, so very little, if any, additional ash was collected on the filter. Fluidized ash is seen on the pictures for the thin ash tests because there is often to much ash in the chamber for it to settle. In general, the pictures for the thin ash tests are not as clear as the thick ash tests. The next step is to set the camera's computer to capture the sequence in trigger mode. This means that the camera will not start to take the pictures until it sees the signal from the data acquisition board. Next the "calib.dap" program was stopped and closed on the data acquisition computer and the "fastack.dap" program, also described in appendix A, was opened. When this was done, the log file name was changed. If the log file is not changed, the calibration file will be overwritten. The log file name is the name of the file where the data was stored. Now the regulator valve to the nitrogen tank was opened and set to the desired regeneration pressure. All that needed to be done now was to hit "Start" in the DAPView program. 
The data and pictures were then taken in synchronization. At the completion of the test the cylinder valve for the regeneration gas was closed and the images were saved on the computer. 


\section{Chapter 4}

\section{Experimental Results}

\subsection{Introduction}

Several tests were run to see how well the parameters of the system may be measured and controlled, and to see if the results acquired from the system were logical. This section contains the test matrix; the pressure readings in the cap, filter, chamber, and exhaust; results from the evaluation of the measurement techniques to be employed on the HTTF system; and the pictures of the regeneration process.

\subsection{Test Matrix}

A basic test matrix was created to evaluate the performance of the facility. The independent variables employed were the face velocity of the gas penetrating the candle filter, the ash thickness, and the reservoir pressure of the surface regeneration gas. The test matrix consists of ten tests and is shown in Table 4.2.1. Note that a pulse pressure time of 0.3 seconds was used for all of the tests in this thesis. The dependent variables of the matrix are observed crack initiation, failure stress, cleaning efficiency, and pressure histories.

\subsection{Reference Curve}

The effect of the face velocity, ash thickness, and reservoir pressure on the regeneration process is the focus of this testing. From the pressure data and pictures taken the pressure drop across the filter will be the main focus of this analysis. The pressure drop across the filter is important before, during, and after regeneration. As a reference condition for the surface regeneration process, the filter was first tested without 
(Thick Ash: $6 \mathrm{~mm}$ thickness)

\begin{tabular}{|c|c|c|}
\hline $\begin{array}{c}\text { Face } \\
\text { Velocity }\end{array}$ & $3.65 \mathrm{~cm} / \mathrm{s}$ & $5.75 \mathrm{~cm} / \mathrm{s}$ \\
\hline $\begin{array}{c}\text { Reservoir } \\
\text { Pressure }\end{array}$ & & \\
\hline $\begin{array}{c}115 \mathrm{psia} \\
(790 \mathrm{kPa})\end{array}$ \\
\hline $\begin{array}{c}145 \mathrm{psia} \\
(1000 \mathrm{kPa})\end{array}$ \\
\hline $\begin{array}{c}160 \mathrm{psia} \\
(1100 \mathrm{kPa})\end{array}$
\end{tabular}

(Thin Ash: $2 \mathrm{~mm}$ thickness)

\begin{tabular}{|c|c|c|c|}
\hline $\begin{array}{l}\text { Face } \\
\text { Velocity }\end{array}$ & $3.65 \mathrm{~cm} / \mathrm{s}$ & $5.75 \mathrm{~cm} / \mathrm{s}$ & $9.5 \mathrm{~cm} / \mathrm{s}$ \\
\hline $\begin{array}{c}115 \mathrm{psia} \\
(790 \mathrm{kPa})\end{array}$ & & & \\
\hline $\begin{array}{c}145 \text { psia } \\
(1000 \mathrm{kPa})\end{array}$ & & & \\
\hline $\begin{array}{c}160 \mathrm{psia} \\
(1100 \mathrm{kPa})\end{array}$ & & & \\
\hline
\end{tabular}

Table 4.2.1

Test Matrix 


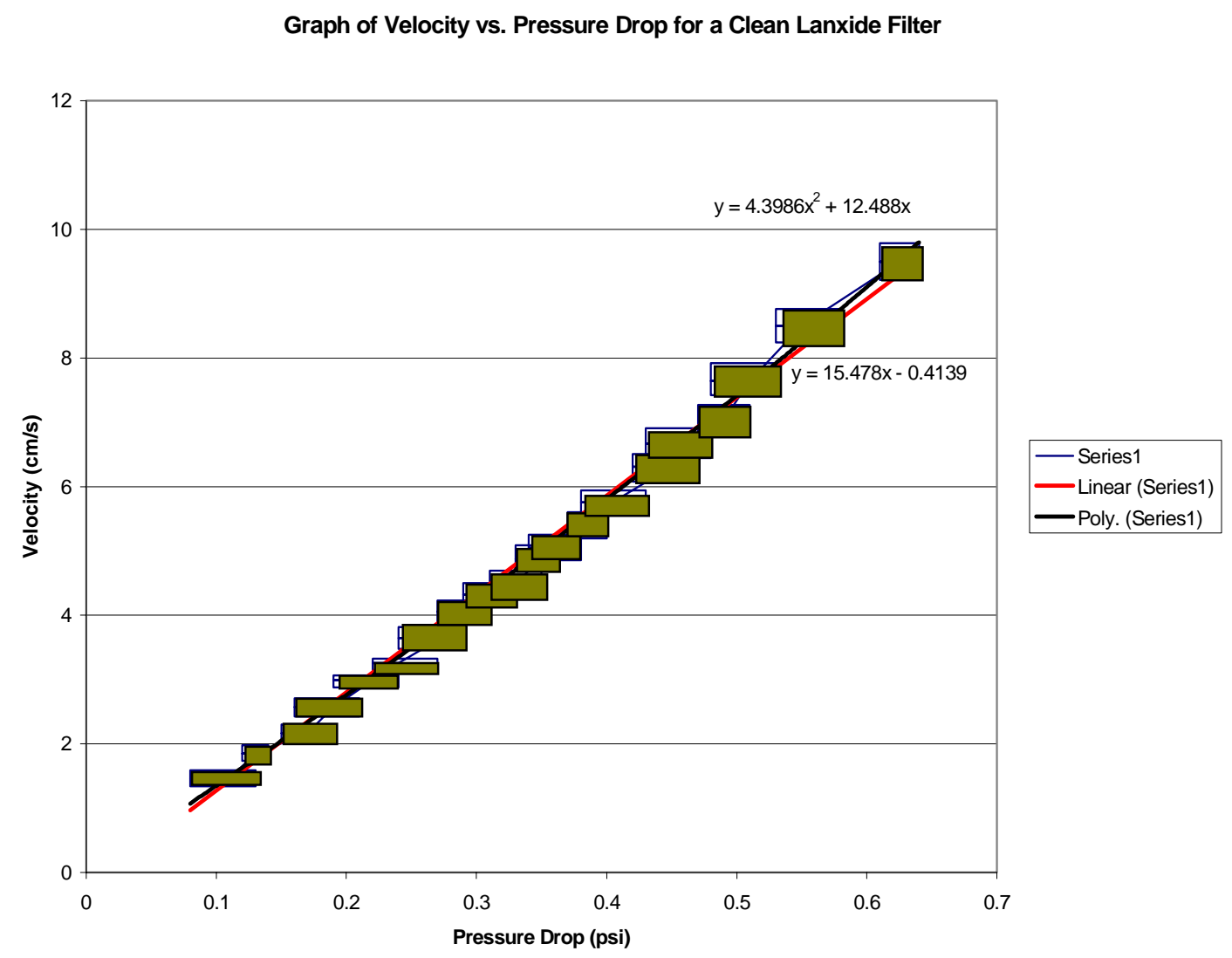

Figure 4.3.1

Reference Curve for Lanxide Filter

any ash to measure the pressure drop as a function of velocity. Note that in these tests a regeneration pulse was not employed, just normal build-up air without any ash. Figure 4.3.1 shows a graph of the clean filter data taken. For this curve the data that is used to find the line is an average pressure reading over approximately one minute. Data for this graph can be seen in Appendix D. This data also shows maximum and minimum pressure readings. There are also ranges for the velocities where the possible error in reading the data was taken into account. In Section 4.4, values of the pressure at the 
appropriate velocity will be taken from this graph and used in calculating the cleaning efficiency for the filter system. The graph of pressure vs. velocity should comply with Darcy's Law:

$$
\mathrm{v}=-\frac{\mathrm{k}}{\mu}(\nabla P)
$$

Where, $\mathrm{k}=$ permeability

$$
\begin{aligned}
& \mu=\text { viscosity } \\
& P=\text { pressure }
\end{aligned}
$$

This equation can be solved to find $\mathrm{v}$ in terms of pressure drop across the filter. This gives:

$$
\mathrm{v}=\frac{\mathrm{k}}{\mu} \frac{1}{2 \rho \mathrm{RT}}\left[\frac{-2 \Delta \mathrm{P}}{\ln \left(\frac{\mathrm{r}_{2}}{\mathrm{r}_{1}}\right)}\right]
$$

This derivation and the definition of these variables can be found in Appendix B.

For the range of velocities that were used the relationship between the velocity and pressure appear to be linear. The equation of an estimated line is shown on the graph.

\subsection{Pressure Histories}

The two main pressures that will be used in this research are the filter pressure and the chamber pressure. A generic sketch of these two pressures can be seen in Figure 4.4.1. More specifically, the difference in these pressures will be analyzed, i.e. the pressure drop across the filter. Labeled on this graph are the initial pressure drop across the filter, $\Delta \mathrm{P}_{\mathrm{i}}$; the time of crack initiation, $\tau$ and possible error (as seen by the camera); 
the pressure drop at the time of crack initiation, $\Delta \mathrm{P}_{\tau}$; the maximum pressure drop across the filter, $\Delta \mathrm{P}_{\mathrm{M}}$; and the final pressure drop across the filter, $\Delta \mathrm{P}_{\mathrm{f}}$. All of these values will be evaluated and compared in this section.

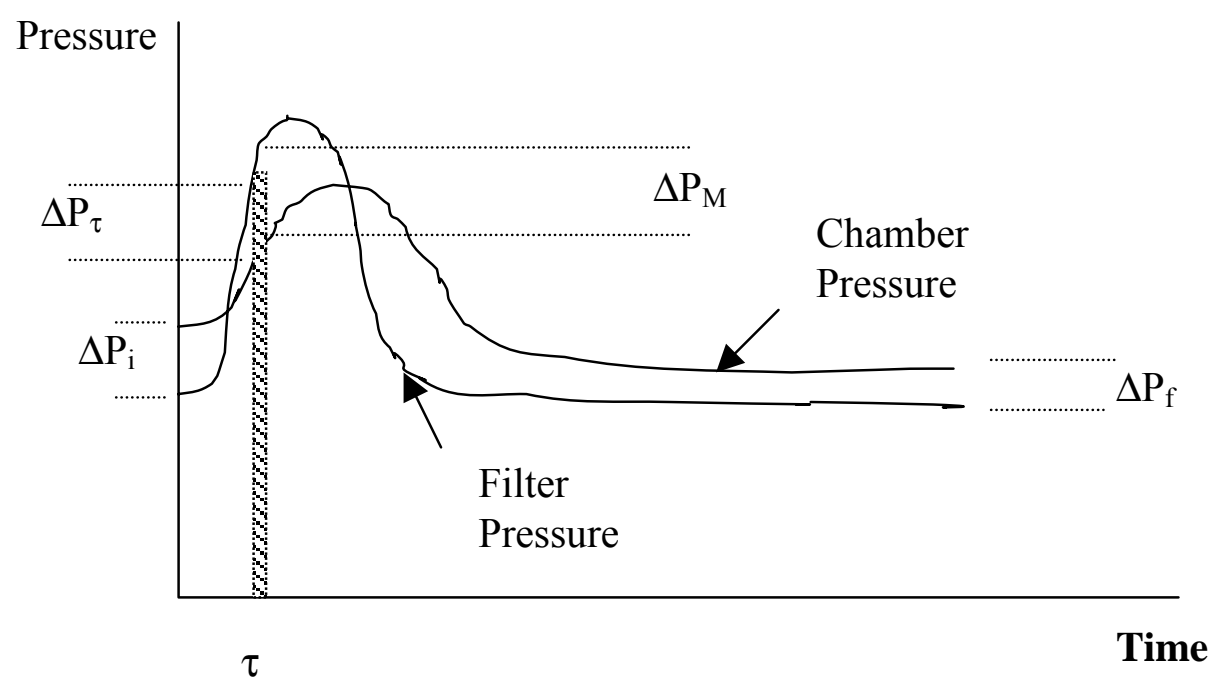

Figure 4.4.1

Generic Sketch of Chamber and Filter Pressure

Pressure histories for two tests can be seen in Figures 4.4.2 and 4.4.3. Figure

4.4.2 shows the graph of a thick ash regenerations with a face velocity of $5.75 \mathrm{~cm} / \mathrm{sec}$ and a reservoir pressure of $1000 \mathrm{kPa}(145 \mathrm{psia})$ and Figure 4.4.3 shows the graph of the same test with thin ash. Figures 4.4.4 and 4.4.5 show the graphs of the pressure drops across the filter for the same test in Figures 4.4.2 and 4.4.3. The graphs for all of the tests performed can be seen in Appendix C.

First the effect of face velocity on a thick ash will be examined. Before the regeneration process is started, a difference can be seen in the pressures. In Table 4.4.1 the initial pressure drop across the filter $\left(\Delta \mathrm{P}_{\mathrm{i}}\right)$ is shown for each thick ash test. The other 


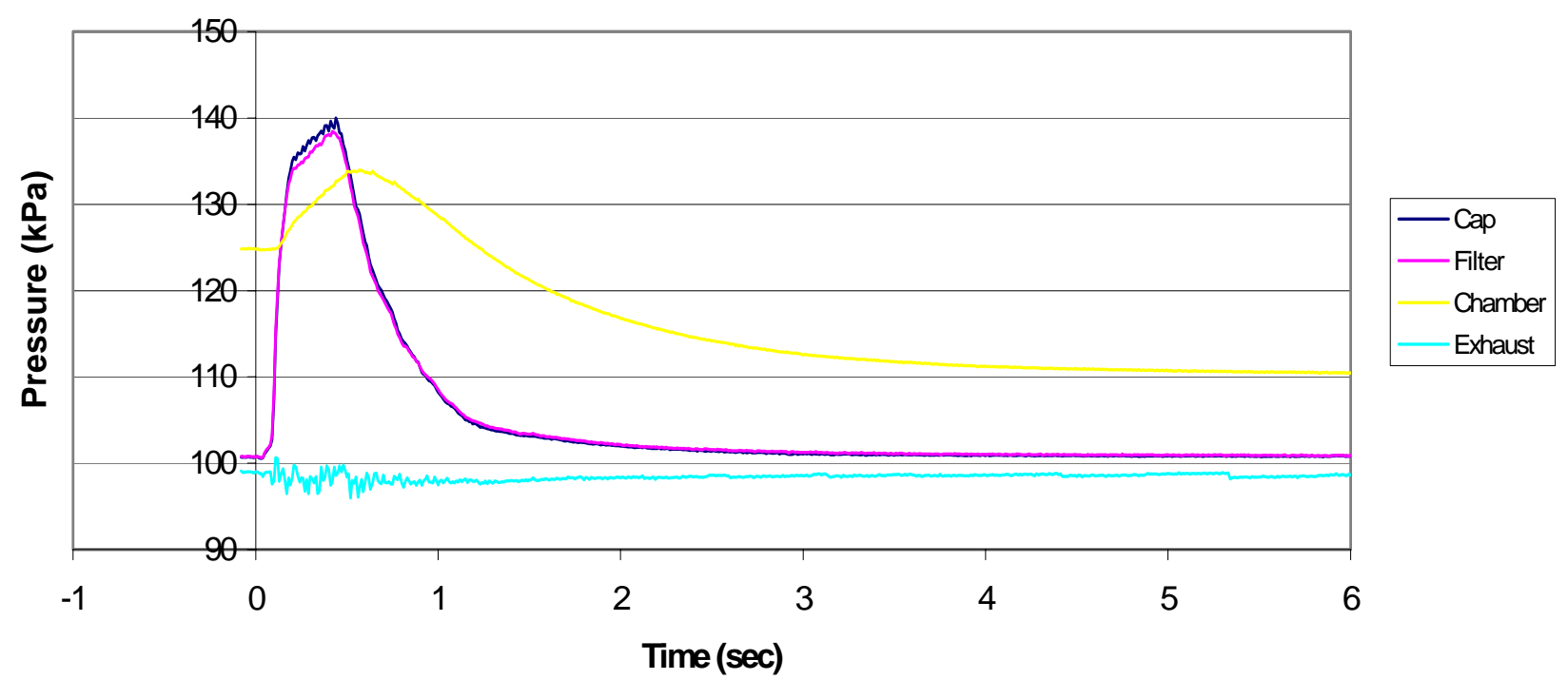

Figure 4.4.2

Graph of Pressure vs. Time for Thick Ash with a Face Velocity of $5.75 \mathrm{~cm} / \mathrm{s}$ and a

Reservoir Pressure of $1000 \mathrm{kPa}$

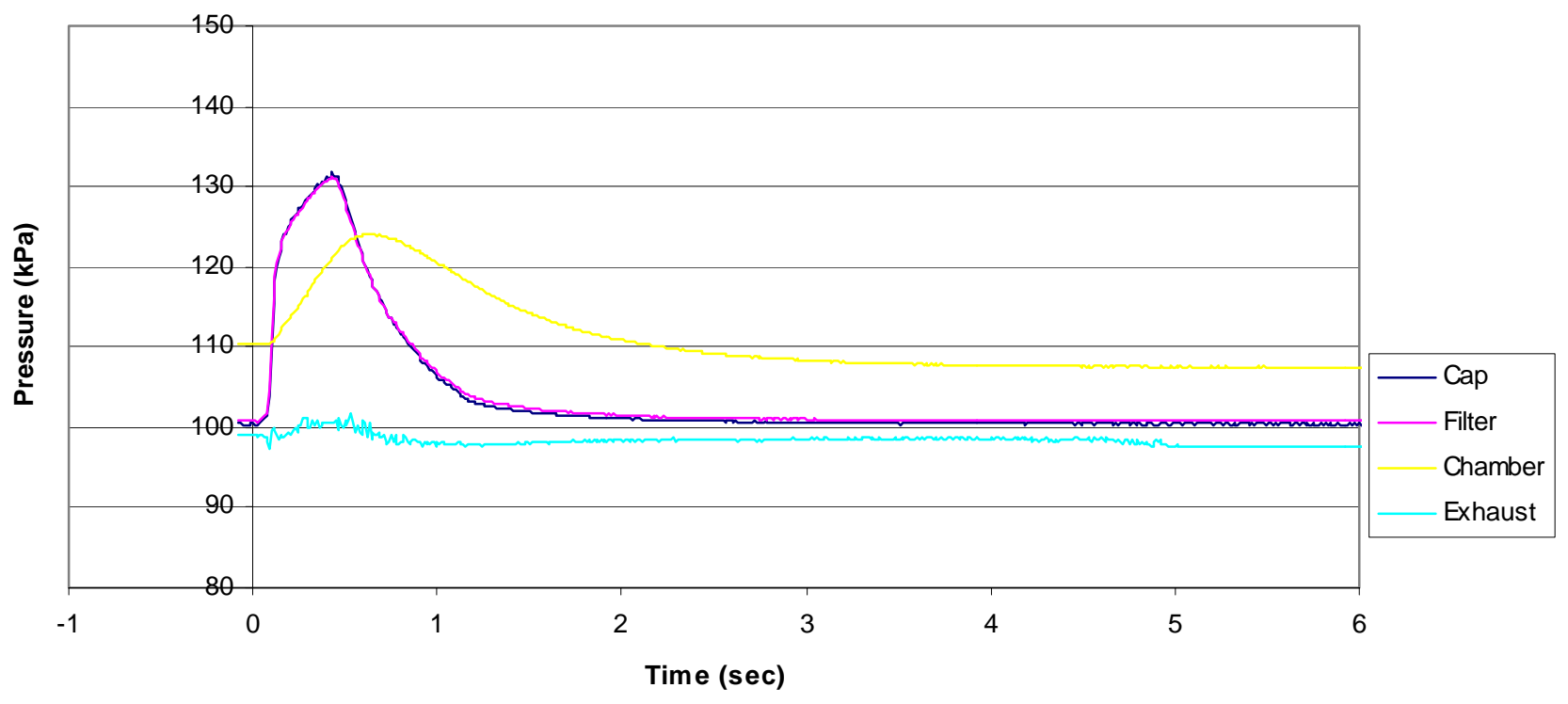

Figure 4.4.3

Graph of Pressure vs. Time for Thin Ash with a Face Velocity of $5.75 \mathrm{~cm} / \mathrm{s}$ and a Reservoir Pressure of $1000 \mathrm{kPa}$ 


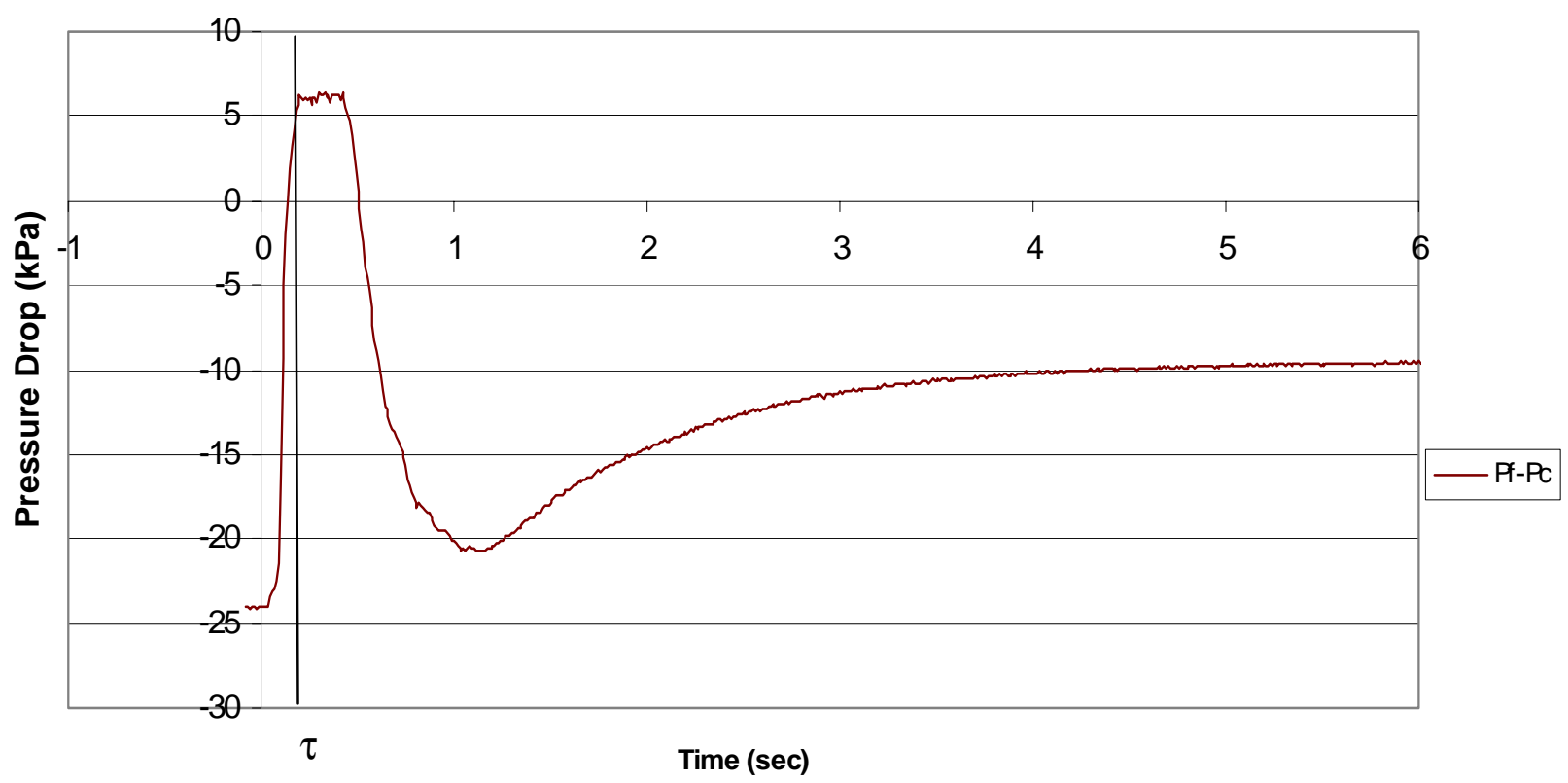

Figure 4.4.4

Graph of Pressure Drop for Thick Ash, $1000 \mathrm{kPa}$ Reservoir Pressure, and $5.75 \mathrm{~cm} / \mathrm{s}$ Face Velocity.

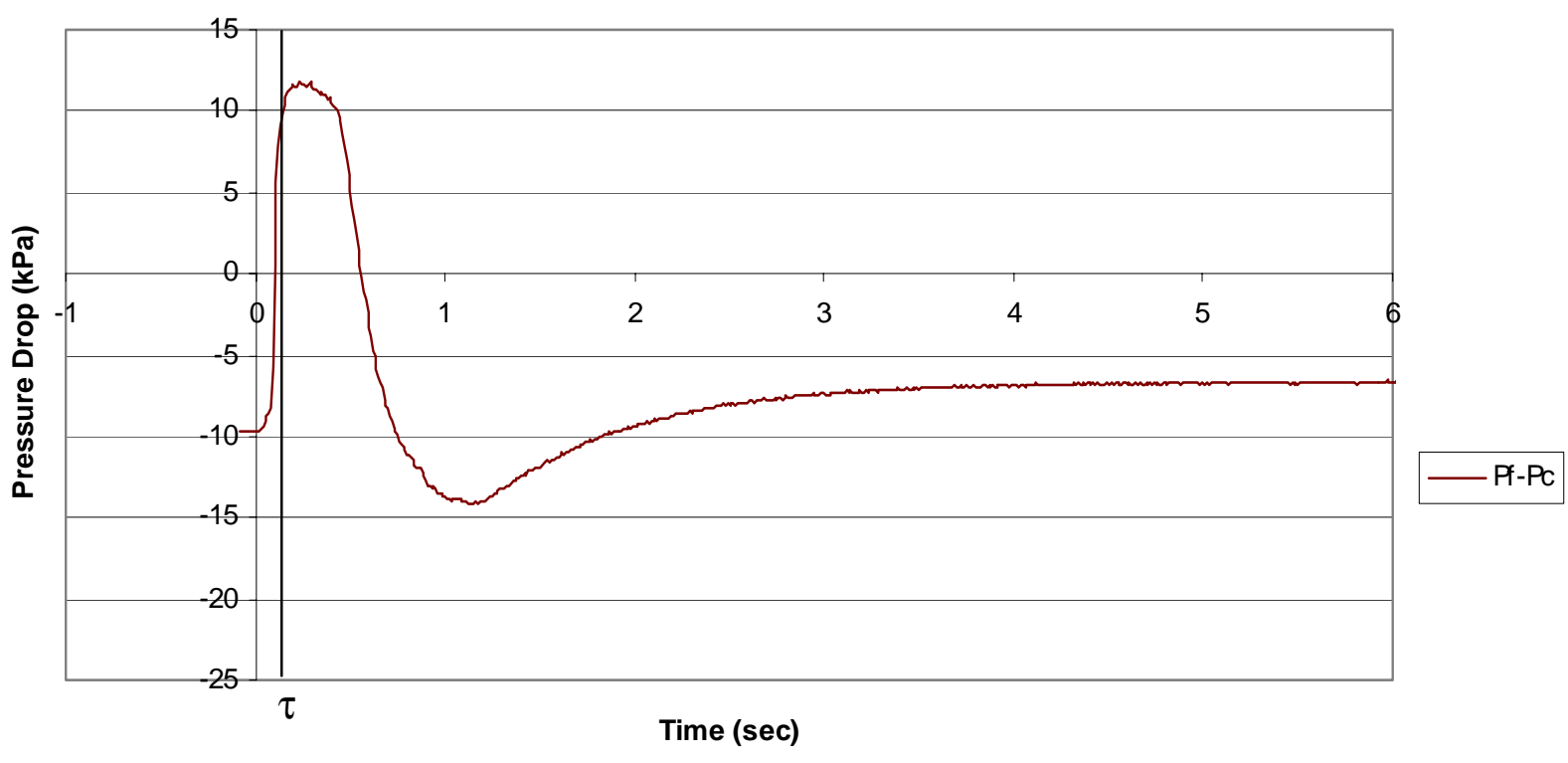

Figure 4.4.5

Graph of Pressure Drop Across Filter vs. Time for Thin Ash with a Face Velocity of $5.75 \mathrm{~cm} / \mathrm{s}$ and a Resenvoir Pressure of $1000 \mathrm{kPa}$ 
(Thick Ash: $6 \mathrm{~mm}$ thickness)

\begin{tabular}{c|c|c|}
\hline $\begin{array}{c}\text { Face } \\
\text { Velocity }\end{array}$ & $5.65 \mathrm{~cm} / \mathrm{s}$ & $5.75 \mathrm{~cm} / \mathrm{s}$ \\
Reservoir \\
Pressure
\end{tabular}

Table 4.4.1

Thick Ash Results 
data in Table 4.4.1 is discussed later on in this chapter. Looking at this table it can be seen that the initial pressure drop across the filter is about the same when the same face velocities are used for a thick ash. This is because the velocity and the ash thickness are the same. The starting pressure drops for the tests with a $5.75 \mathrm{~cm} / \mathrm{sec}$ face velocity and a 790,1000 , and $1100 \mathrm{kPa}(115,145$, and 160 psia) reservoir pressure are $3.36,3.48$, and 3.47 psi, respectively. The slight differences found here could be due to the fact that the ash thicknesses were not all the same or possibly small differences in the face velocity. It is easy to see that the pressure drop across the filter increases as the face velocity increases. The higher face velocity creates a higher pressure drop across the filter, which in turn causes a higher chamber pressure. This is consistent with the data from the clean filter. This high chamber pressure is caused by the fact that a higher flow rate of gas has to pass through the filter and the ash and requires a higher pressure drop. Note that this higher initial pressure drop is going to make it more difficult for surface regeneration because the pressure in the filter must now increase even more.

The initial pressure drops for the thin ash tests are shown in Table 4.4.2. Note that the pressure drops are all lower than those for the thick ash for the same conditions. This is because the thicker ash is creating more resistance to the flow and causing a higher pressure drop. The same trends apply with the thin ash as did with the thick ash. An increase in the face velocity causes an increase in the pressure drop across the filter. Knowledge of the pressure drop across the filter during surface regeneration can help determine the strength of the ash on the filter. The time interval of the crack initiation can be found from the pictures. With the pressure history, the pressure drop can 
(Thin Ash: $2 \mathrm{~mm}$ thickness)

\begin{tabular}{|c|c|c|}
\hline $\begin{array}{c}\text { Face } \\
\text { Velocity }\end{array}$ & $3.65 \mathrm{~cm} / \mathrm{s}$ & $5.75 \mathrm{~cm} / \mathrm{s}$ \\
Reservoir \\
Pressure
\end{tabular}

Table 4.4.2

Thin Ash Results 
be found at that particular time and thus the pressure drop at the crack initiation is known. One problem with this method of finding the ash strength is that it is assumed that the initiation shown in the pictures is characteristic of the first crack initiation on the filter. This is only an estimate. There should be a statistical study based on repeatability of the time of crack initiation and also based on placement of the viewed area. Having a test facility that allowed visual access for the entire length of the filter would be needed to test this.

The time for the crack initiations is also shown in Table 4.4.1 and Table 4.4.2. The time of crack initiation shown in these tables is only an estimate both because the camera is focussed on only a small section of the candle filter and there is a slight delay in the camera. The signal that is sent to trigger the camera is timed exactly with the signal to the solenoid valve, but the camera itself has a delay that could be anywhere from zero seconds to 0.0167 seconds, the time to finish one frame. Note that for the test with $5.75 \mathrm{~cm} / \mathrm{sec}$, thick ash, and 115 psia reservoir pressure no action was seen on the pictures taken. The top section of the candle filter, which is where the camera is focused, did not show signs of regeneration. The bottom section did regenerate somewhat though. The extent of the regeneration could not be determined visually because of the lack of visible area in the chamber, but it is obvious that the ash did not fully regenerate from the post regeneration pressure drop of 2.46 psi. Also, the efficiency, which will be discussed in more detail later in this section, was 0.3 . The corresponding pressure drops for the crack initiation are also shown in Table 4.4.1 and Table 4.4.2.

Looking at the thick ash results, all of the pressure drops at the time of crack initiation are about the same, around $0.77 \mathrm{psi}$. The exception is the test run at $9.5 \mathrm{~cm} / \mathrm{sec}$, 
which shows a pressure of $0.40 \mathrm{psi}$. Looking at the maximum pressure drop across the filter, as shown in Table 4.4.1 and Table 4.4.2 shows that for the test with $9.5 \mathrm{~cm} / \mathrm{sec}$ only reached a maximum pressure drop of $0.74 \mathrm{psi}$. This is due to the fact that the initial chamber pressure was high and the pressure rise due to the pulse jet only induced a relatively low positive filter pressure. Note that since the time of crack initiation is only an estimate, the pressure drop across the filter at the time of crack initiation is also an estimate. Taking into account the range of possible initiation times, the pressure drop for the test could range between 0.78 and 0.91 for the thick ash test with $5.75 \mathrm{~cm} / \mathrm{sec}$ and a $1000 \mathrm{kPa}$ reservoir pressure. A full set of this data is shown in Appendix E.

The time of the initiation is nearly the same for each of the thin regenerations. The pressure drop at the time of initiation however does vary. Note that as the face velocity increases so does the pressure drop. In the tests with a $5.75 \mathrm{~cm} / \mathrm{sec}$ face velocity the 115 psia test could not reach the 1.32 psi that the other tests obtained. This can be seen from the maximum pressure of 1.15 psi.

The pressure drop after regeneration can be a measure of how well the filter was cleaned. If a residual ash is left on the filter after regeneration, the gas will need a higher pressure drop to get through the filter. Table 4.4.1 and Table 4.4.2 show the final pressure after the regeneration.

Comparing the thick ash tests with a $5.75 \mathrm{~cm} / \mathrm{sec}$ face velocity it can easily be seen that the test with 115 psia had a residual ash, shown by the high pressure drop. Note that the trend for these tests is that the final pressure goes down as the reservoir pressure goes up. The filter is getting cleaner as the reservoir pressure increases. 
The final pressures for the thin ash show that the filters are relatively clean. Each of the $5.75 \mathrm{~cm} / \mathrm{sec}$ tests has nearly the same pressure at $0.96 \mathrm{psi}$. The tests with the different face velocity follow the trend of having a higher pressure as the face velocity increases. Note that all of the thin ash layers leave filters that are cleaner than those for the thick ash tests as is shown by the lower pressure drop for similar face velocities.

There is another way of looking at the final cleanliness of the filter. This is done by using the data obtained from a clean filter and using it to find the efficiency of the cleaning process. A graph of the clean filter data is shown in Figure 4.3.1. The values used to find the efficiencies are:

$\begin{array}{cc}\text { Velocity }(\mathrm{cm} / \mathrm{s}) & \text { Pressure Drop (psi) } \\ 3.65 & 0.273 \\ 5.75 & 0.404 \\ 9.5 & 0.625\end{array}$

The efficiencies, $\eta$, were calculated using the equation found in Section 2.3 .5 on page 15 . Table 4.4.3 shows the efficiency for each experiment. These efficiencies seem good for comparing results within a certain thickness, i.e. comparing thick ash results to thick ash results. However, when comparing thin ash results to thick ash results this efficiency can be misleading. The thick and thin ash results are plotted against face velocity in Figure 4.4.6 and against reservoir pressure in Figure 4.4.7. Consider the tests with a face velocity of $5.75 \mathrm{~cm} / \mathrm{s}$ and a reservoir pressure of $145 \mathrm{psia}$. When looking at the efficiencies in the table or at the graph it shows that the thick ash test has a higher efficiency that the thin ash. However, the final pressure drop across the filter is lower for 
(Thick Ash: $6 \mathrm{~mm}$ thickness)

\begin{tabular}{|c|c|c|c|}
\hline $\begin{array}{c}\text { Face } \\
\text { Velocity }\end{array}$ & $3.65 \mathrm{~cm} / \mathrm{s}$ & $5.75 \mathrm{~cm} / \mathrm{s}$ & $9.5 \mathrm{~cm} / \mathrm{s}$ \\
$\begin{array}{c}\text { Reservoir } \\
\text { Pressure }\end{array}$ & & 0.30 & \\
\hline $\begin{array}{c}115 \mathrm{psia} \\
(790 \mathrm{kPa})\end{array}$ & 0.69 & \\
\hline $\begin{array}{c}145 \mathrm{psia} \\
(1000 \mathrm{kPa})\end{array}$ & 0.71 & 0.75 \\
\hline $\begin{array}{c}160 \mathrm{psia} \\
(1100 \mathrm{kPa})\end{array}$ & & 0.66 \\
\hline
\end{tabular}

(Thin Ash: $2 \mathrm{~mm}$ thickness)

\begin{tabular}{|c|c|c|c|}
\hline $\begin{array}{c}\text { Face } \\
\text { Velocity }\end{array}$ & $3.65 \mathrm{~cm} / \mathrm{s}$ & $5.75 \mathrm{~cm} / \mathrm{s}$ & $9.5 \mathrm{~cm} / \mathrm{s}$ \\
\hline $\begin{array}{c}\text { Reservoir } \\
\text { Pressure }\end{array}$ & & 0.47 & \\
\hline $\begin{array}{c}115 \mathrm{psia} \\
(790 \mathrm{kPa})\end{array}$ & 0.44 & \\
\hline $\begin{array}{c}145 \mathrm{psia} \\
(1000 \mathrm{kPa})\end{array}$ & 0.40 & 0.47 & \\
\hline $\begin{array}{c}160 \mathrm{psia} \\
(1100 \mathrm{kPa})\end{array}$ & & 0.50 \\
\hline
\end{tabular}

Table 4.4.3

Cleaning Efficiencies 


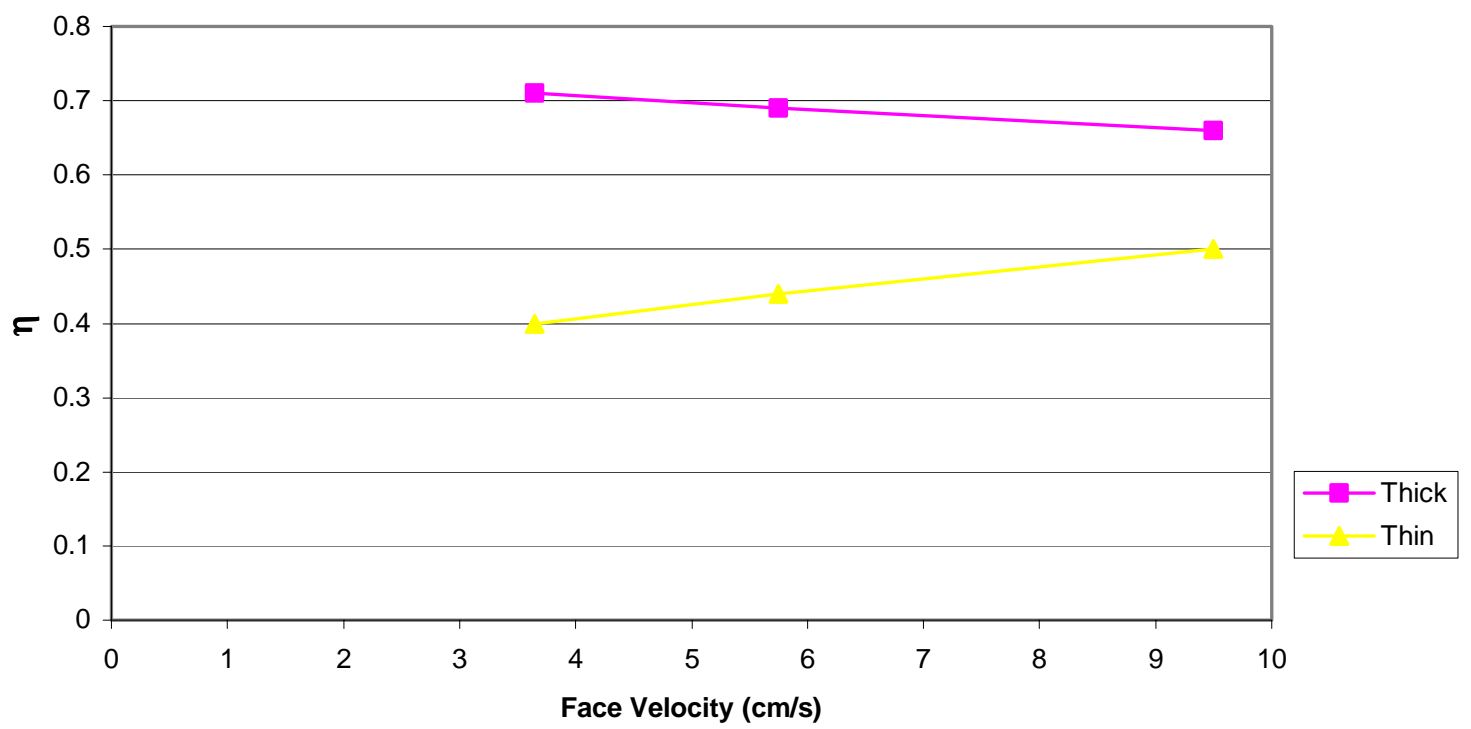

Figure 4.4.6

Graph of Efficiency vs. Face Velocity for 1000 kPa Reservoir Pressure and Thin and Thick Ash Thicknesses

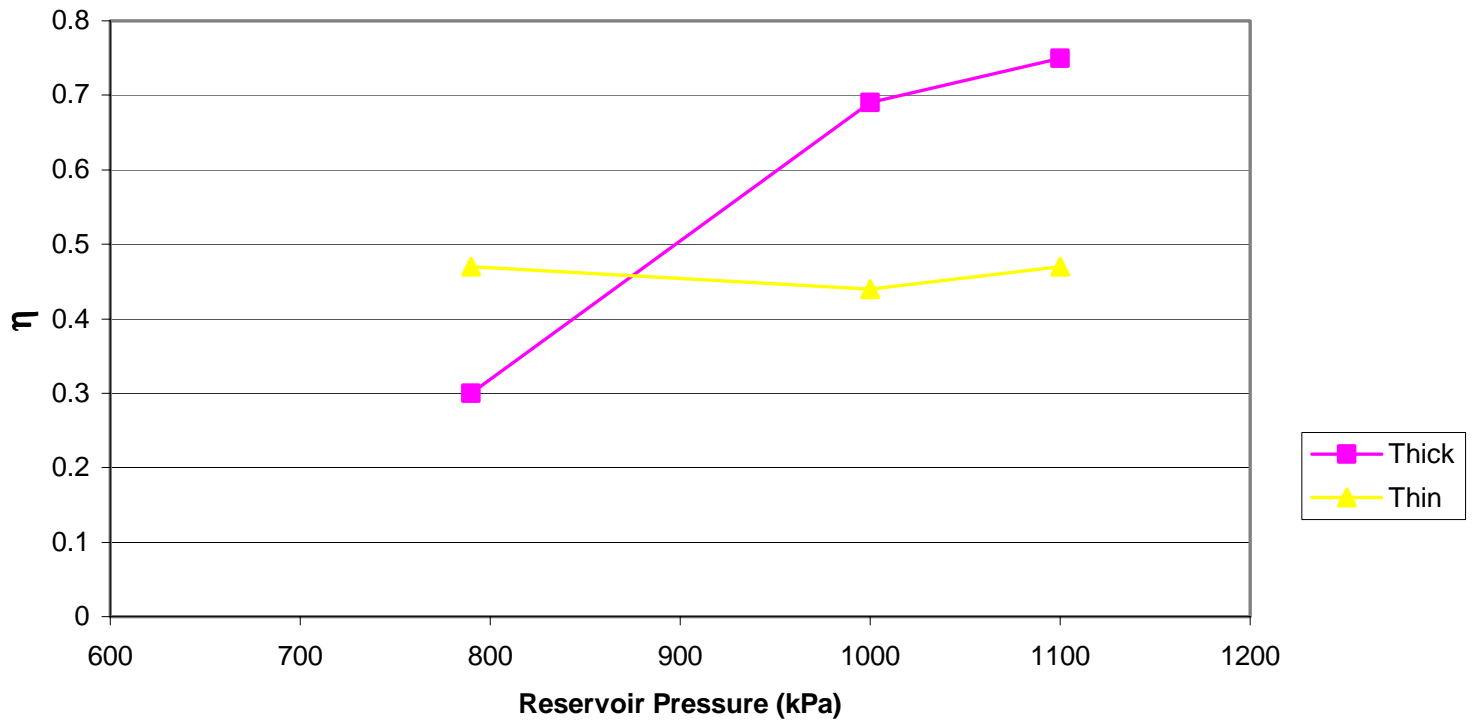

Figure 4.4.7

Graph of Efficiency vs. Reservoir Pressure for $5.75 \mathrm{~cm} / \mathrm{s}$ and Thin and Thick Ash Thicknesses 
the thin ash test than for the thick ash test, which implies a cleaner filter because the face velocities are the same. Figure 4.4.8 shows how the efficiency can be larger for the thick

\section{Thick ash}

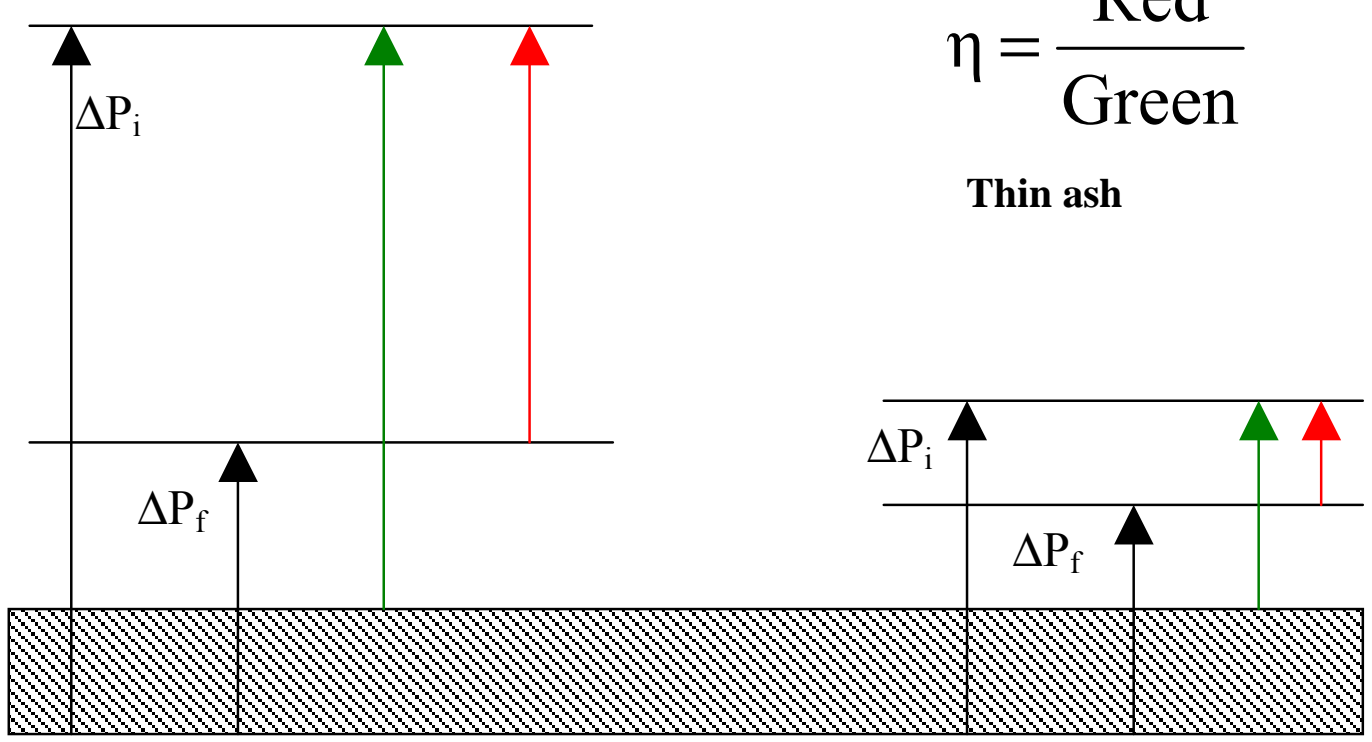

$$
\eta=\frac{\text { Red }}{\text { Green }}
$$

\section{Thin ash}

Figure 4.4.8

Efficiencies for Thick and Thin Ash

ash even though the filter is dirtier. Care must be taken when comparing these efficiencies from test to test.

There is another variable that can be used to compare the thin tests to the thick tests. Using the equation:

$$
\phi=\frac{\Delta \mathrm{P}_{\text {final }}\left(\delta_{1}\right)-\Delta \mathrm{P}_{\text {final }}\left(\delta_{2}\right)}{\Delta \mathrm{P}_{\text {initial }}\left(\delta_{1}\right)-\Delta \mathrm{P}_{\text {initial }}\left(\delta_{2}\right)}
$$

Where $\delta_{1}$ is the ash thickness for a thick ash and $\delta_{2}$ is the ash thickness for a thin ash.

Note that the only independent variable being changed in these tests is the ash thickness. 
The other variables are kept constant. $\phi$ is used to find the effect of operating with a thicker ash. This is analogous to waiting a longer time in between regenerations. In analyzing the extreme cases, if the $\Delta \mathrm{P}_{\mathrm{f}}$ for the different $\delta$ 's were the same than $\phi$ would be 0 and regeneration would encounter the same resistance. If the thick ash were to not regenerate, than $\phi$ would be large. Ideally, $\phi$ would be zero, but $\phi$ would be at a point where if the ash thickness is increased, than $\phi$ would increase. Figure 4.4 .9 shows a picture of the pressures used to calculate $\phi$. Table 4.4 .4 shows the comparison of the thick test to the thin test. Figures 4.4.10 and 4.4.11 show $\phi$ plotted against face velocity and reservoir pressure, respectively. Figure 4.4.10 shows that as the face velocity increases, $\phi$ increases for the range of face velocities used. Figure 4.4.11 shows that as the reservoir pressure increases, $\phi$ decreases for the range of face velocities used. This means as the face velocity increases the effect of the thick ash becomes harder to overcome during regeneration. The same is true as the reservoir pressure decreases.

\begin{tabular}{|c|c|c|c|}
\hline $\begin{array}{c}\text { Face } \\
\text { Velocity }\end{array}$ & $3.65 \mathrm{~cm} / \mathrm{s}$ & $5.75 \mathrm{~cm} / \mathrm{s}$ & $9.5 \mathrm{~cm} / \mathrm{s}$ \\
$\begin{array}{c}\text { Reservoir } \\
\text { Pressure }\end{array}$ & & 0.79 & \\
\hline $\begin{array}{c}115 \mathrm{psia} \\
(790 \mathrm{kPa})\end{array}$ & 0.13 & 0.20 & \\
\hline $\begin{array}{c}145 \mathrm{psia} \\
(1000 \mathrm{kPa})\end{array}$ & & 0.10 & \\
\hline $\begin{array}{c}160 \mathrm{psia} \\
(1100 \mathrm{kPa})\end{array}$ & & \\
\hline
\end{tabular}

Table 4.4.4

$\Phi$ Used to Compare Thick and Thin Ash Regenerations 
Thick Ash

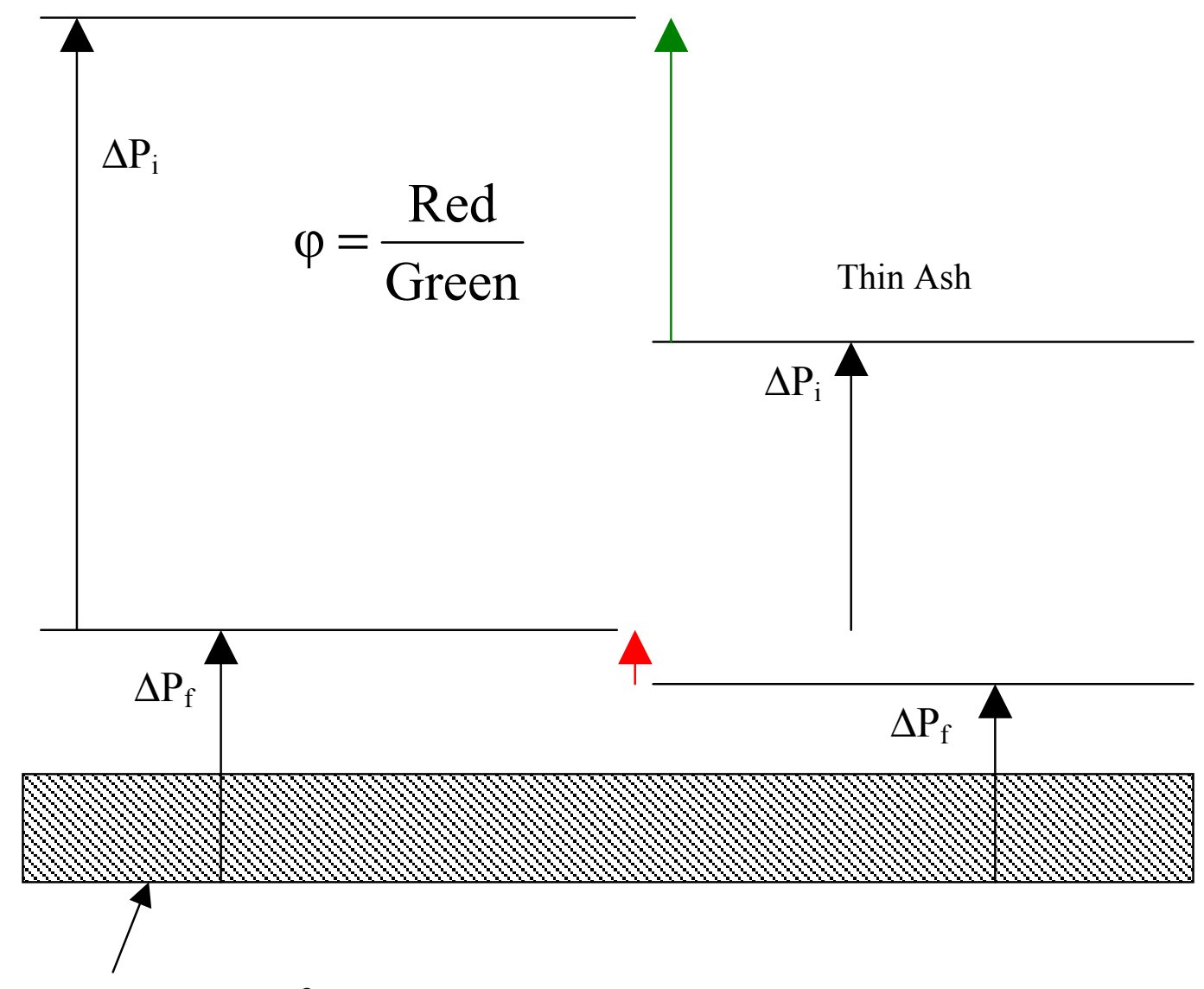

Pressure Drop for

Clean Filter

Figure 4.4.9

$\phi$ for Comparing Thick and Thin Ash

\subsection{Pictures}

There is a large difference in the sequence of pictures taken of the regenerations under various conditions. Pictures of two of these regenerations can be seen in Figures 4.5.1 and 4.5.2. Figures 4.5.1a- 4.5.1e show a set of pictures from a regeneration for a thick ash at a $5.75 \mathrm{~cm} / \mathrm{s}$ face velocity, and 145 psia reservoir pressure. Figures $4.5 .2 \mathrm{a}-$ 4.5.2d show pictures from a regeneration for a thin ash at a $5.75 \mathrm{~cm} / \mathrm{s}$ face velocity, and 
145 psia reservoir pressure. Note that not all of the pictures are shown in these abbreviated sequences. These pictures are representative of what happens in the regeneration process for the various ash thicknesses.

For a thick ash regeneration the ash tends to fall off in large chunks. This can easily be seen in Figure 4.5.1. The thin ash regeneration, in comparison to the thick ash regeneration, comes off in relatively small chunks. The time of the crack initiation is also different for a thick and thin ash. In each of the tests run, with the possible exception of the 115 psia reservoir test because the initiation was not recorded, the crack initiation for the thick ash took longer to start than the thin ash. This can be seen in Table 4.4.1. 


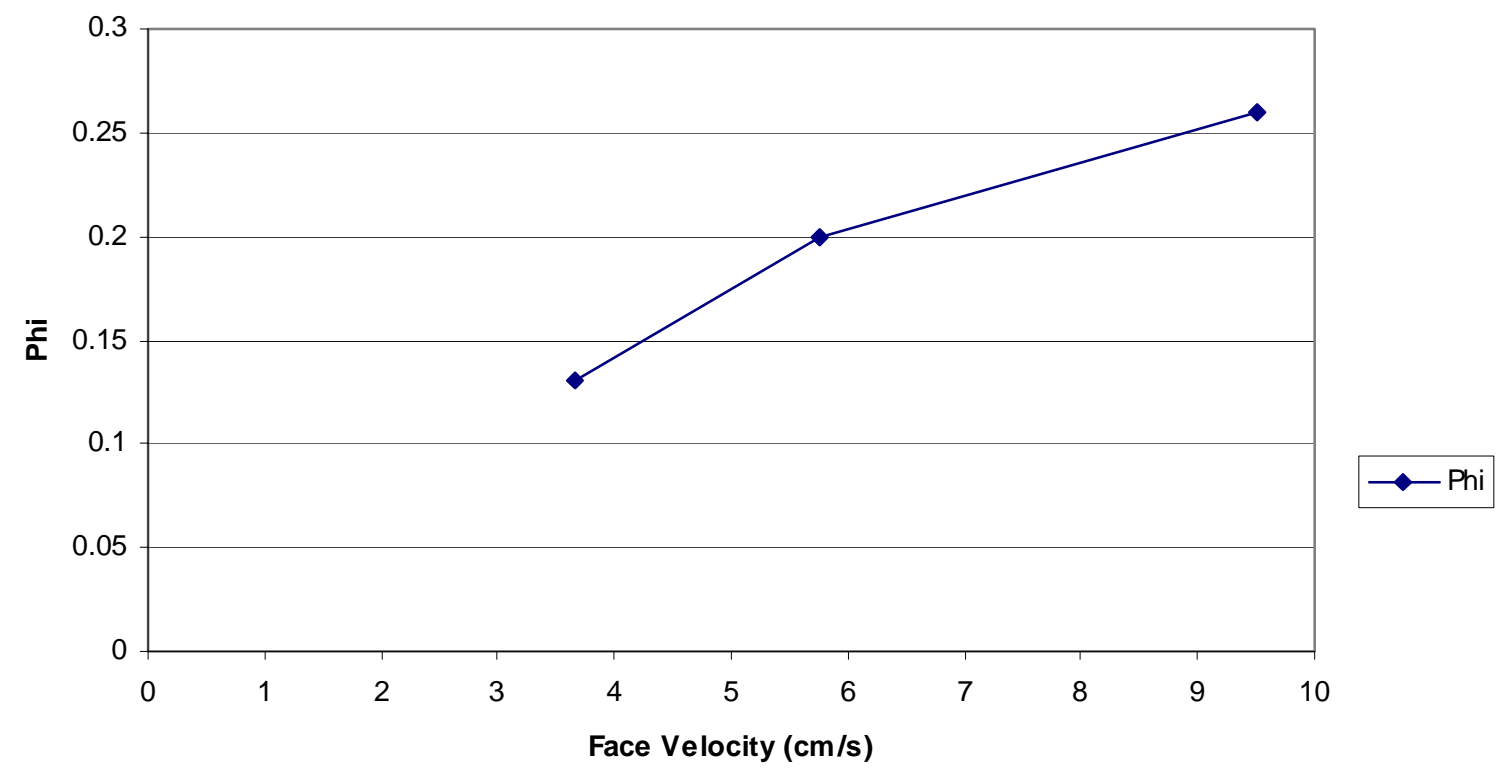

Figure 4.4.10

Graph of Phi vs. Face Velocity for Reservoir Pressure of $1000 \mathrm{kPa}$

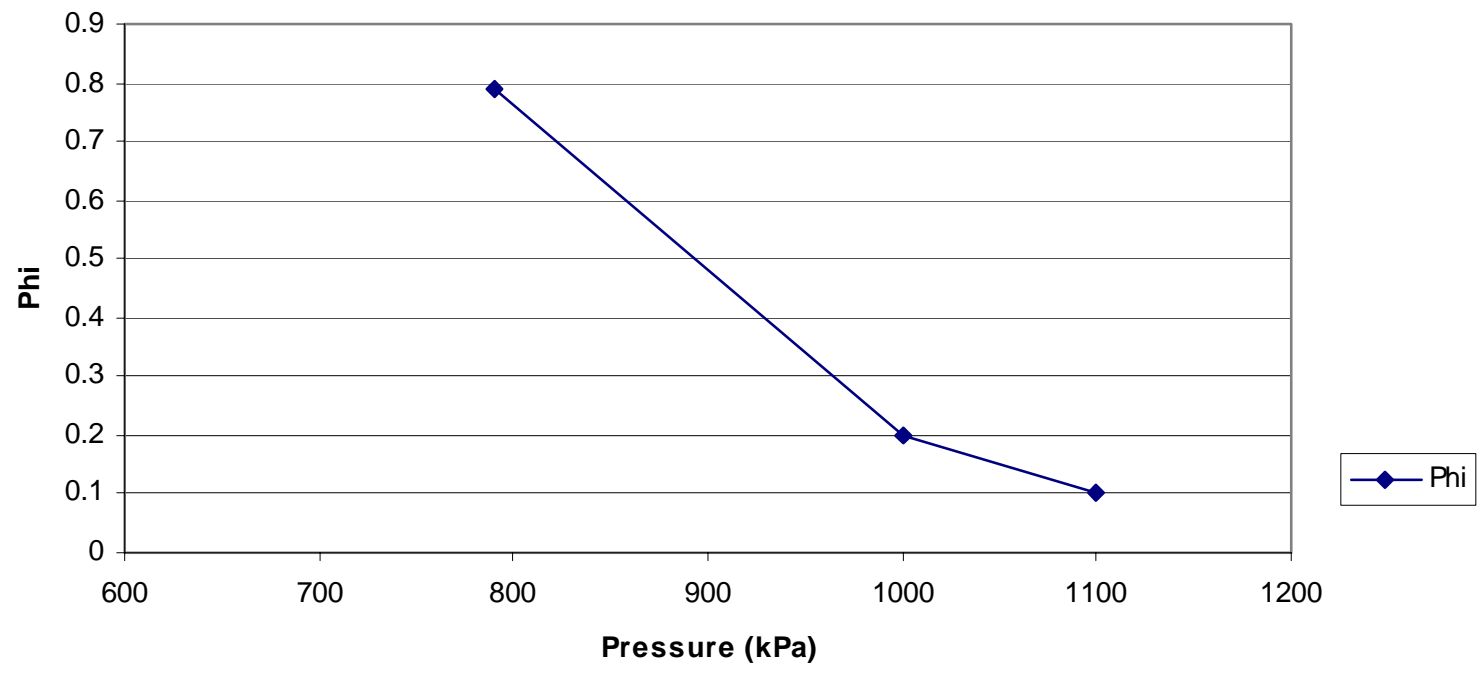

Figure 4.4.11

Graph of Phi vs. Reservoir Pressure for Face Velocity of $5.75 \mathrm{~cm} / \mathrm{s}$ 


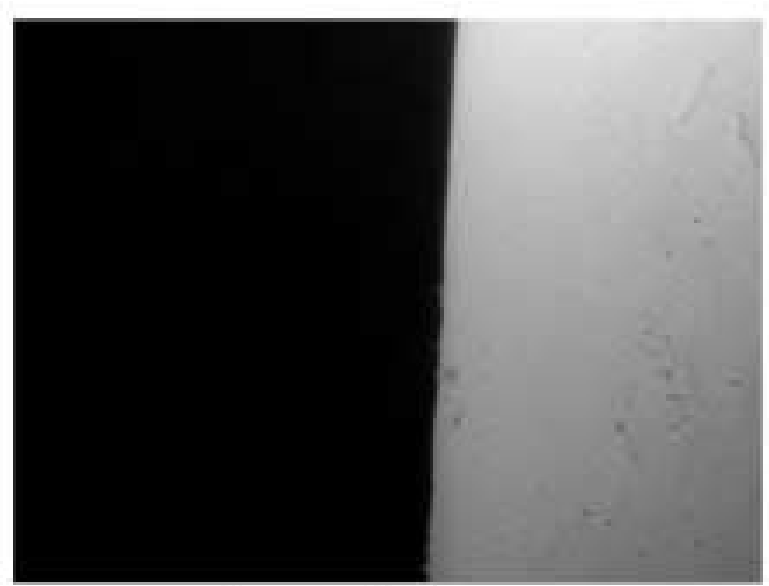

$$
\mathrm{t}=0.167 \mathrm{sec}
$$

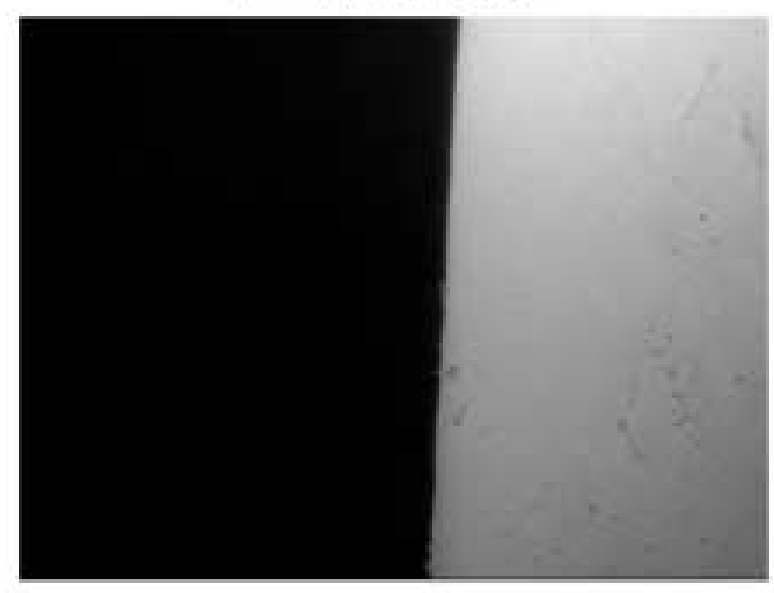

$\mathrm{t}=0.183 \mathrm{sec}$

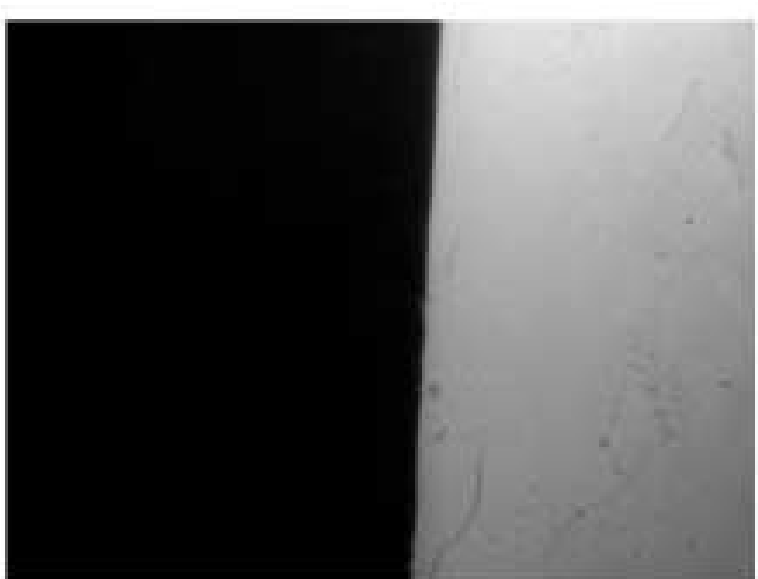

$$
\mathrm{t}=0.200 \mathrm{sec}
$$

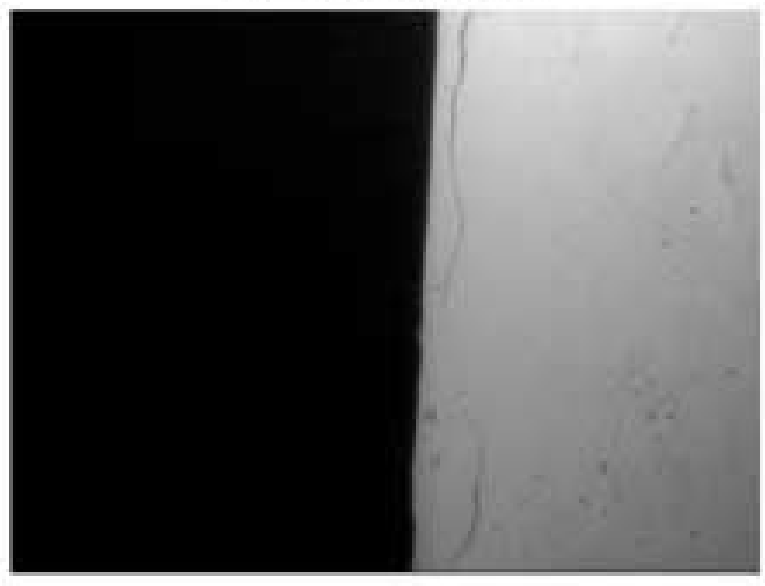

$$
\mathrm{t}=0.217 \mathrm{sec}
$$

Figure 4.5.1a Regeneration for a Thick Ash at $5.75 \mathrm{~cm} / \mathrm{s}$ Face Velocity and $1000 \mathrm{kPa}$ Reservoir Pressure 


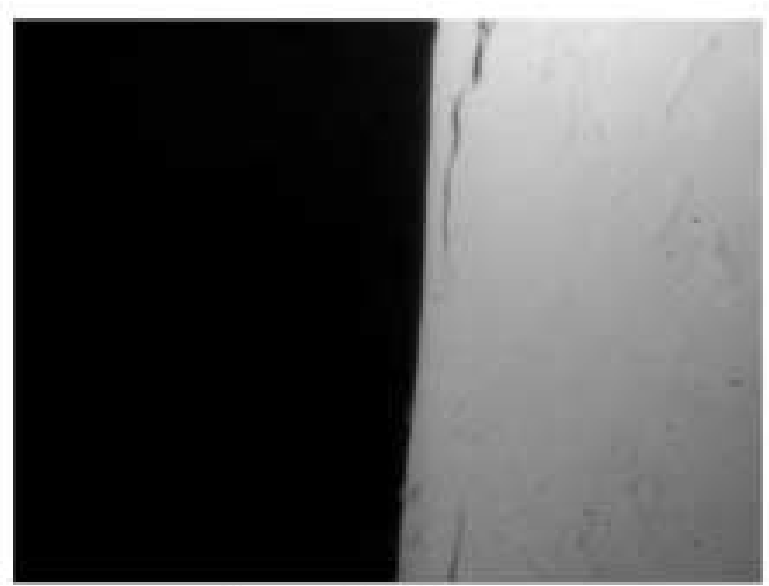

$$
\mathrm{t}=0.233 \mathrm{sec}
$$

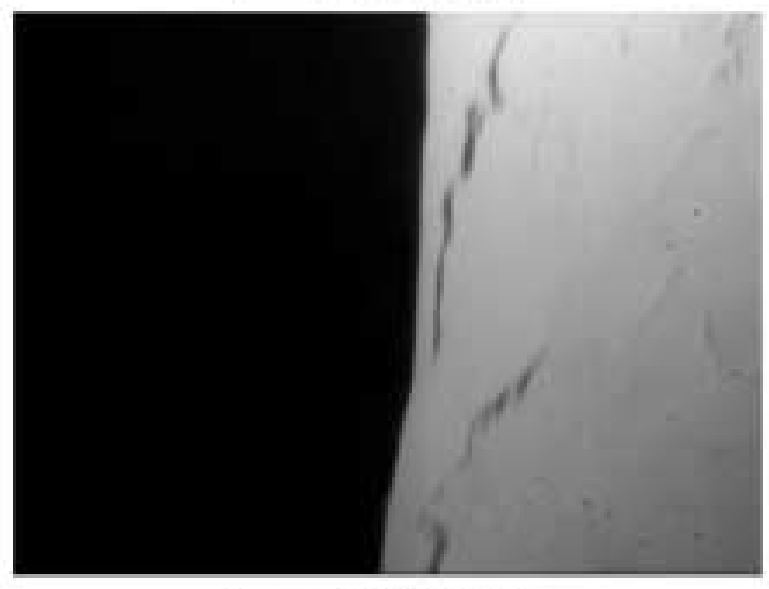

$\mathrm{t}=0.250 \mathrm{sec}$

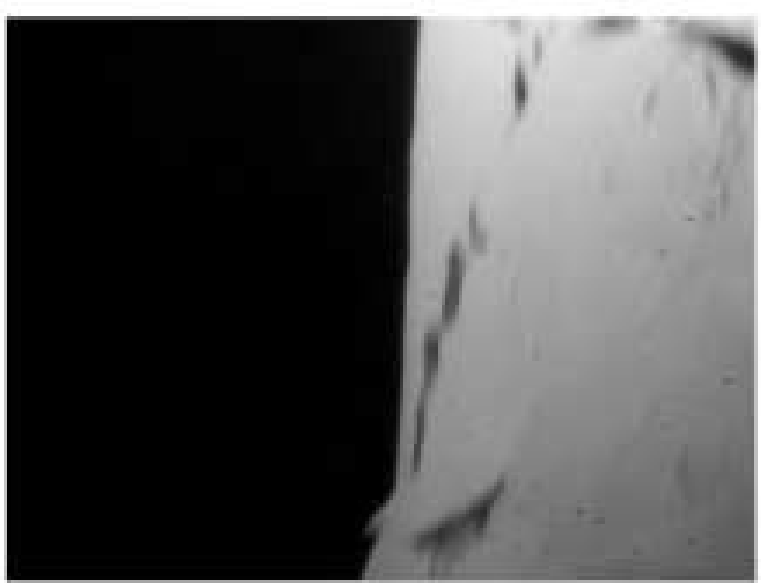

$$
\mathrm{t}=0.267 \mathrm{sec}
$$

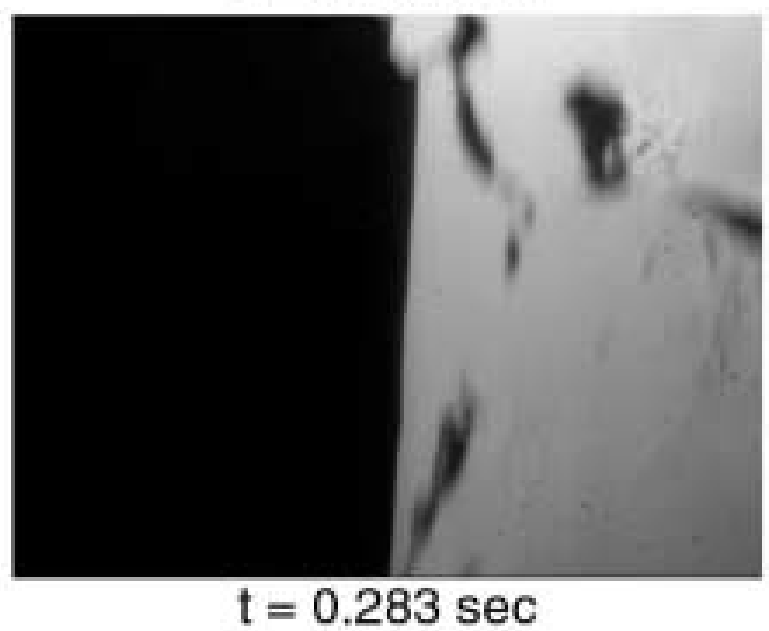

$t=0.283 \mathrm{sec}$

Figure 4.5.1b Regeneration for a Thick Ash at $5.75 \mathrm{~cm} / \mathrm{s}$ Face Velocity and $1000 \mathrm{kPa}$ Reservoir Pressure 


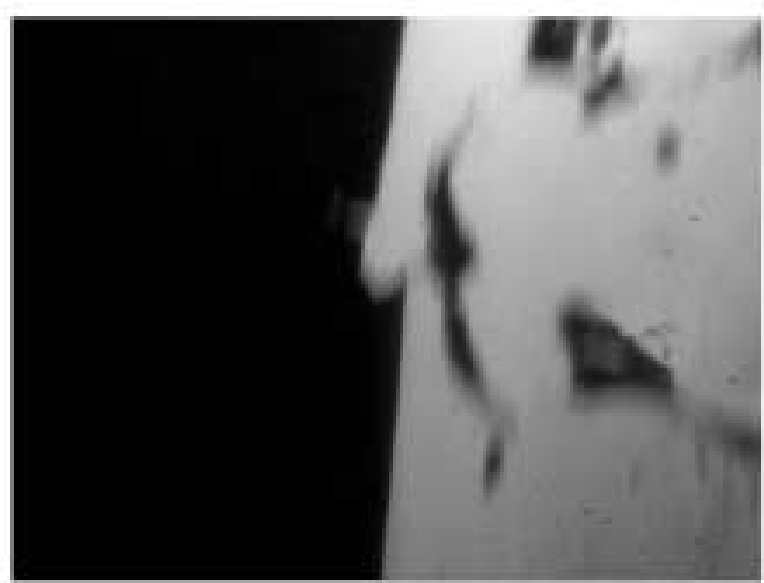

$$
\mathrm{t}=0.300 \mathrm{sec}
$$

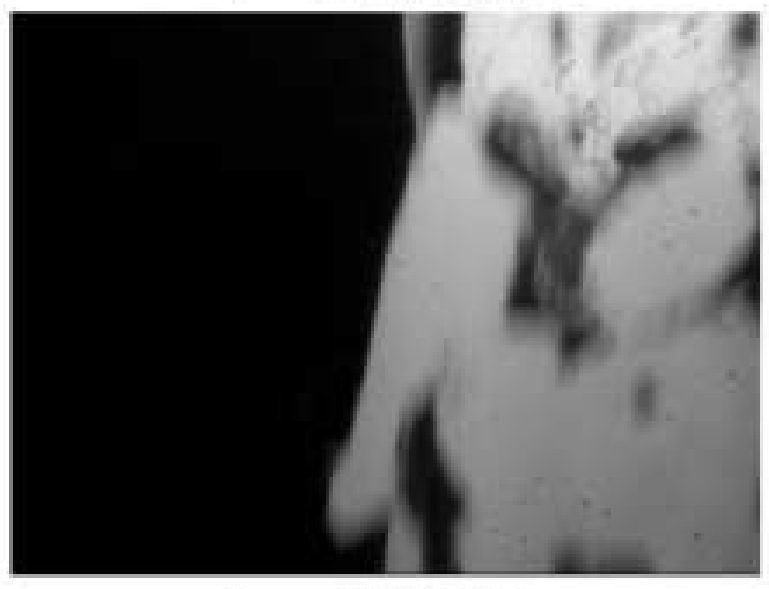

$\mathrm{t}=0.317 \mathrm{sec}$

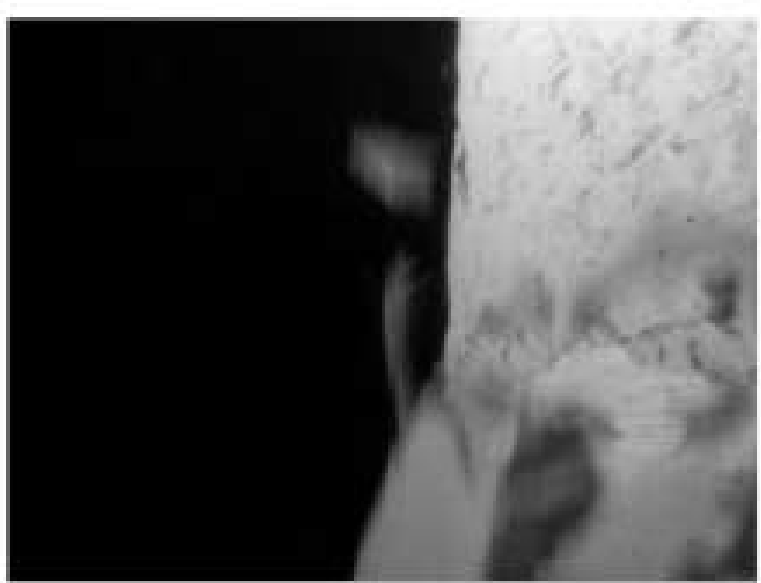

$$
\mathrm{t}=0.333 \mathrm{sec}
$$

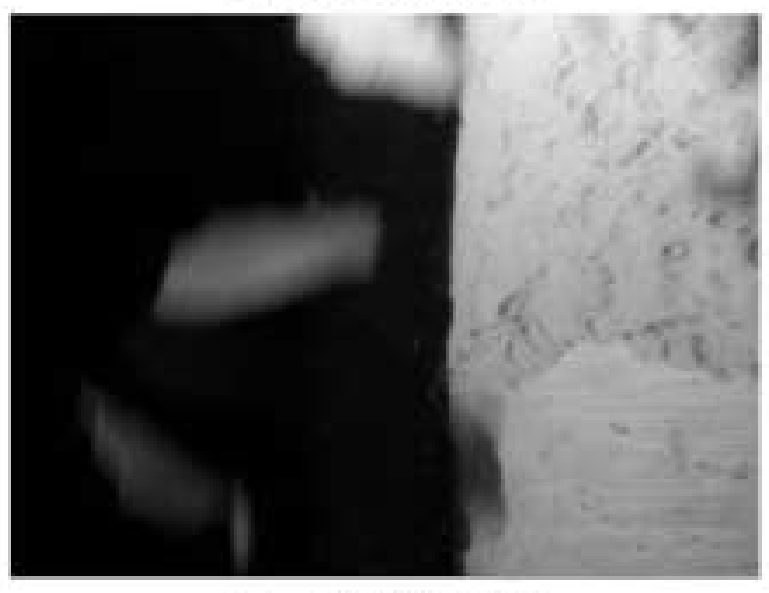

$\mathrm{t}=0.367 \mathrm{sec}$

Figure 4.5.1c Regeneration for a Thick Ash at $5.75 \mathrm{~cm} / \mathrm{s}$ Face Velocity and $1000 \mathrm{kPa}$ Reservoir Pressure 


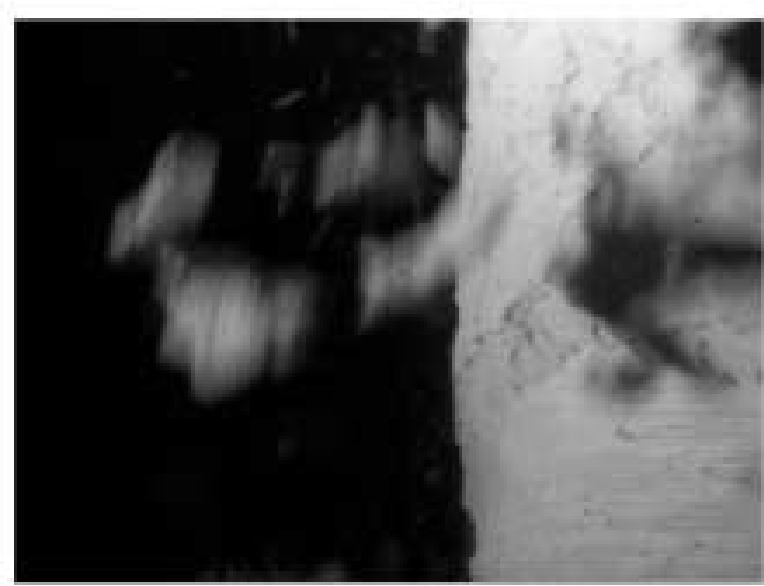

$\mathrm{t}=0.400 \mathrm{sec}$

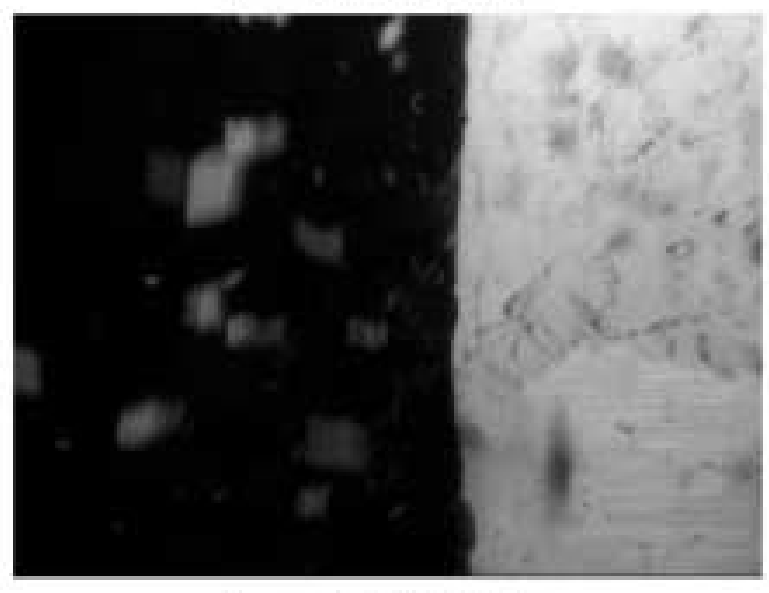

$\mathrm{t}=0.450 \mathrm{sec}$

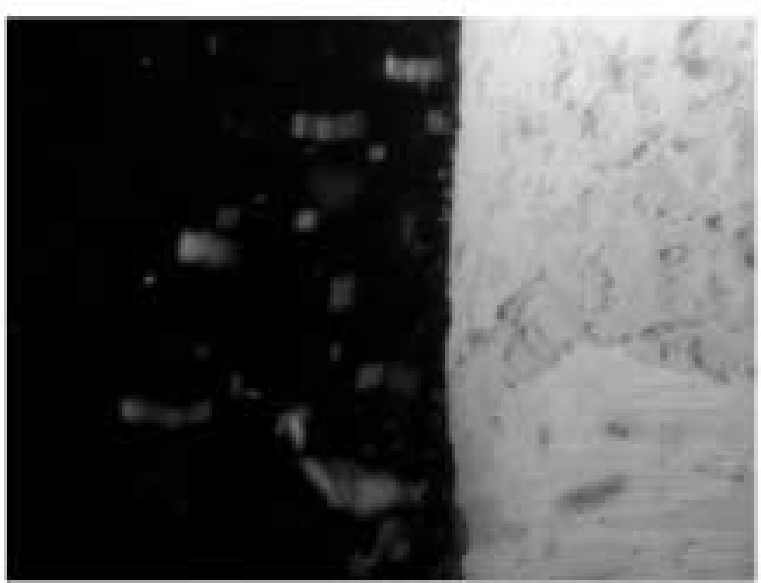

$\mathrm{t}=0.500 \mathrm{sec}$

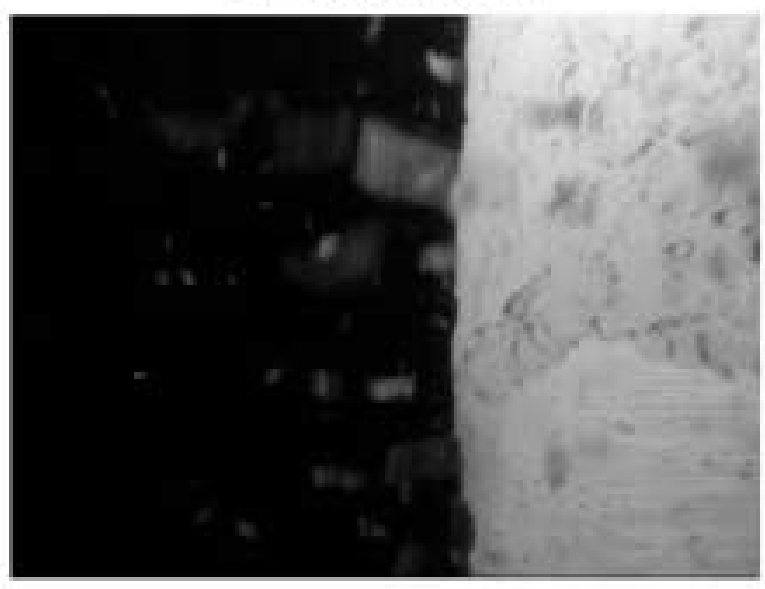

$\mathrm{t}=0.550 \mathrm{sec}$

Figure 4.5.1d Regeneration for a Thick Ash at $5.75 \mathrm{~cm} / \mathrm{s}$ Face Velocity and $1000 \mathrm{kPa}$ Reservoir Pressure 


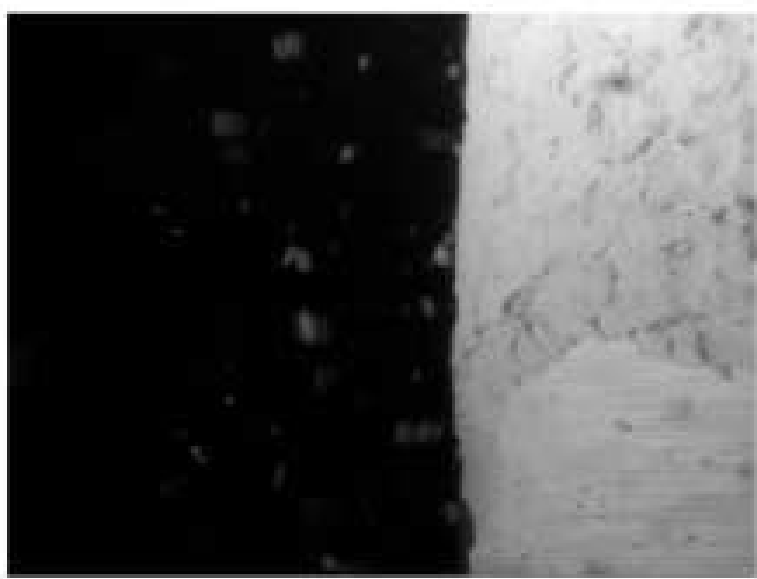

$t=0.600 \mathrm{sec}$

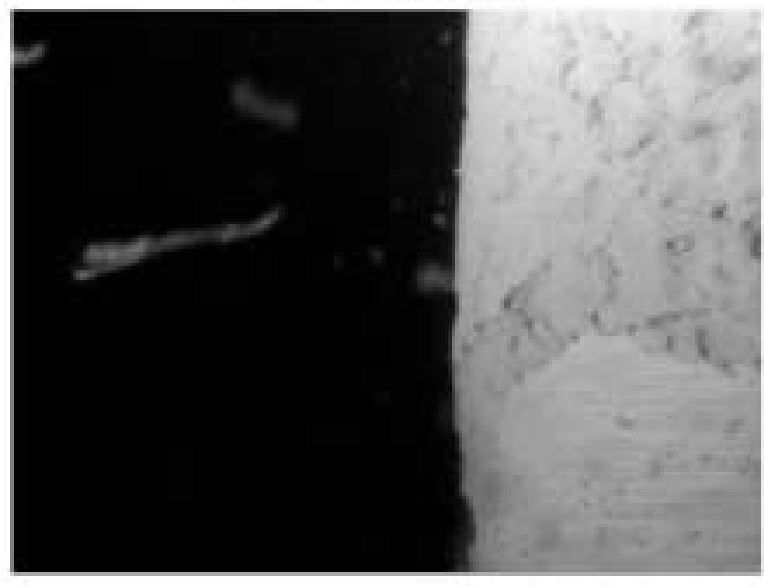

$\mathrm{t}=0.700 \mathrm{sec}$

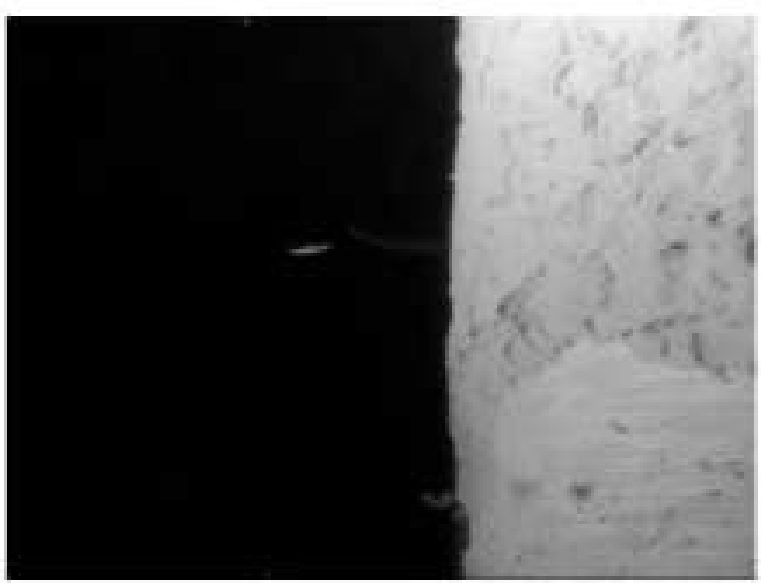

$\mathrm{t}=1.000 \mathrm{sec}$

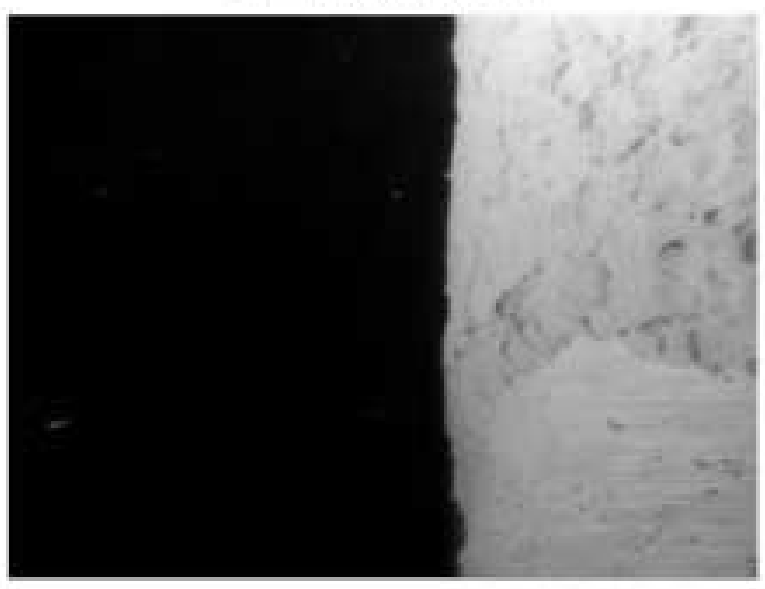

$\mathrm{t}=1.300 \mathrm{sec}$

Figure 4.5.1e Regeneration for a Thick Ash at $5.75 \mathrm{~cm} / \mathrm{s}$ Face Velocity and $1000 \mathrm{kPa}$ Reservoir Pressure 


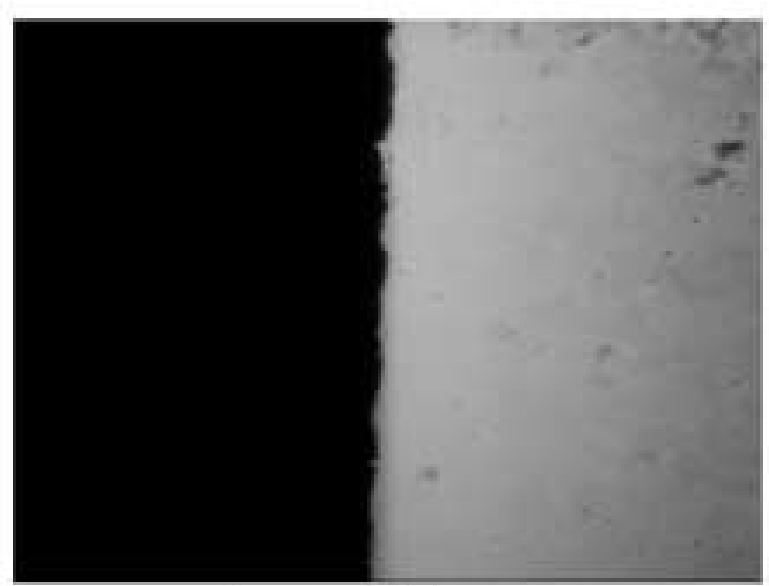

$$
\mathrm{t}=0.117 \mathrm{sec}
$$

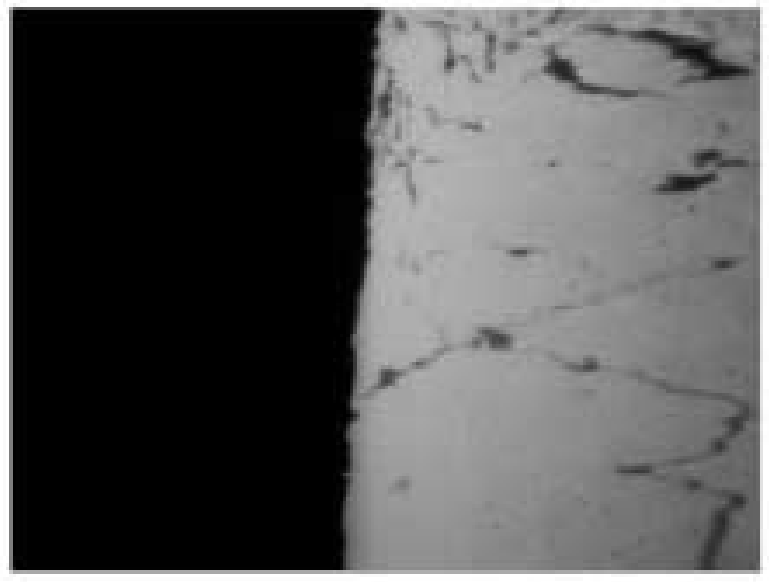

$\mathrm{t}=0.133 \mathrm{sec}$

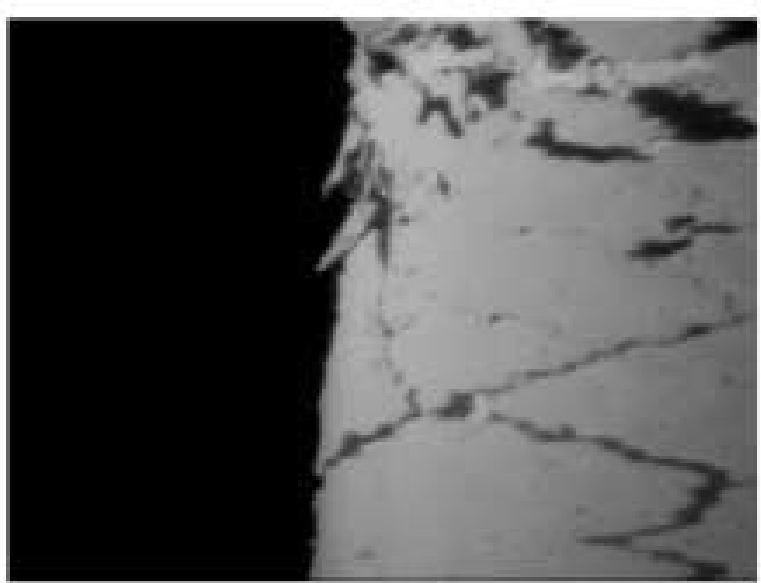

$$
\mathrm{t}=0.150 \mathrm{sec}
$$

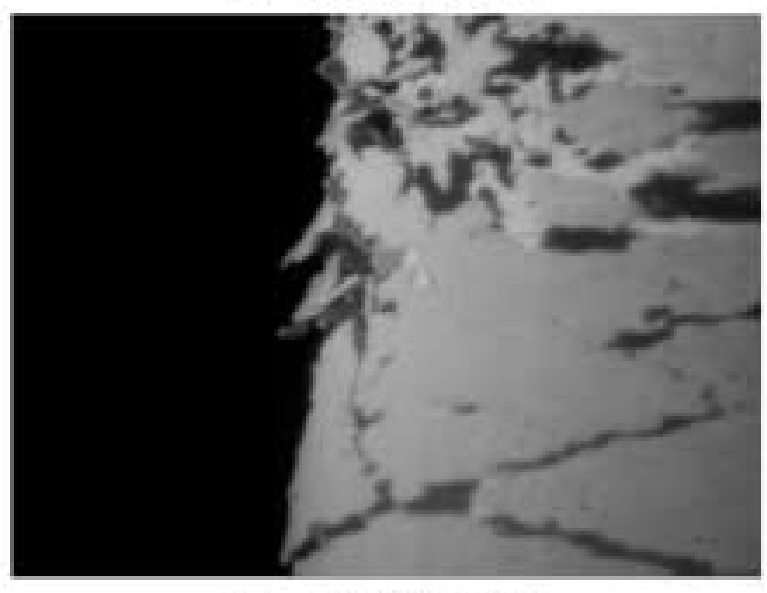

$\mathrm{t}=0.167 \mathrm{sec}$

Figure 4.5.2a Regeneration for a Thin Ash at $5.75 \mathrm{~cm} / \mathrm{s}$ Face Velocity and $1000 \mathrm{kPa}$ Reservoir Pressure 


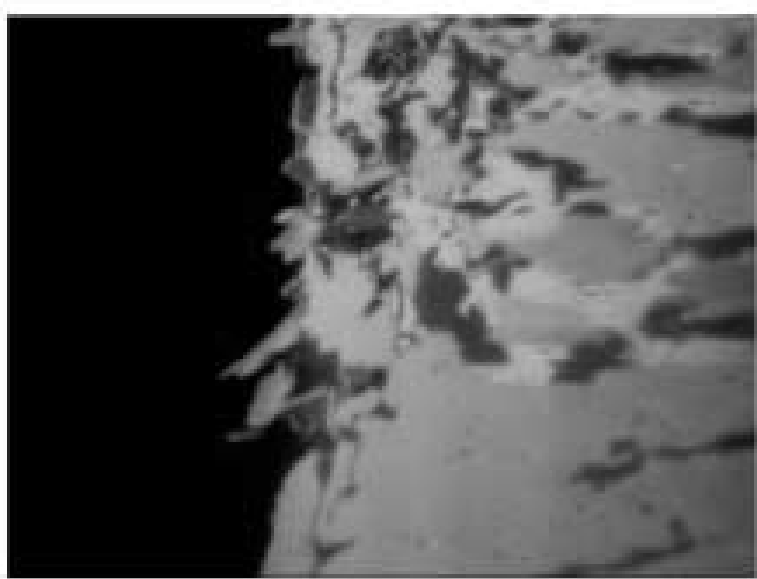

$\mathrm{t}=0.183 \mathrm{sec}$

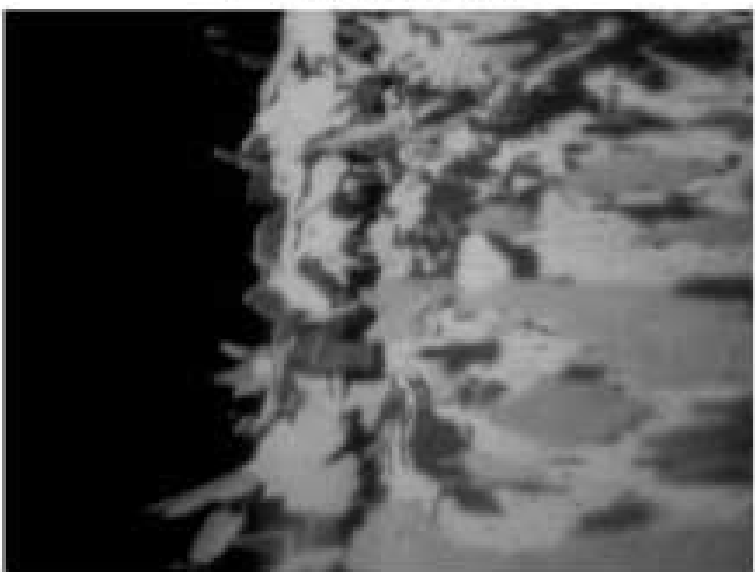

$\mathrm{t}=0.200 \mathrm{sec}$

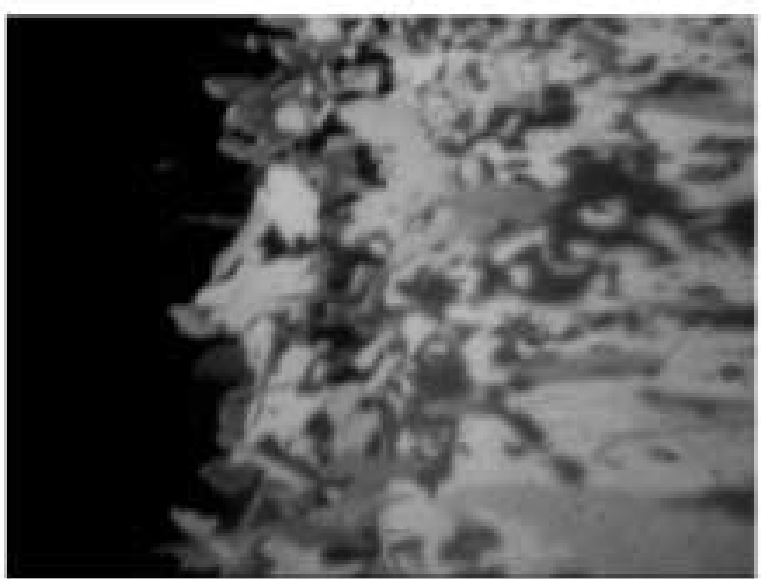

$\mathrm{t}=0.217 \mathrm{sec}$

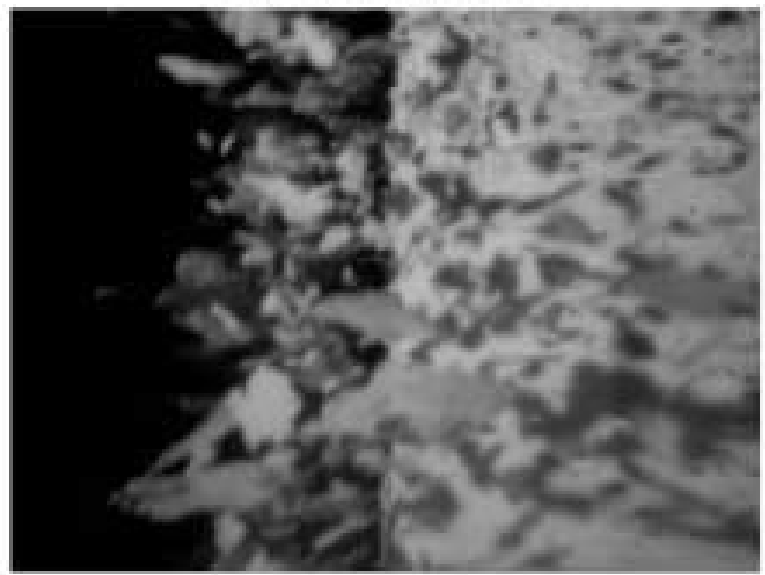

$\mathrm{t}=0.233 \mathrm{sec}$

Figure 4.5.2b Regeneration for a Thin Ash at $5.75 \mathrm{~cm} / \mathrm{s}$ Face Velocity and $1000 \mathrm{kPa}$ Reservoir Pressure 


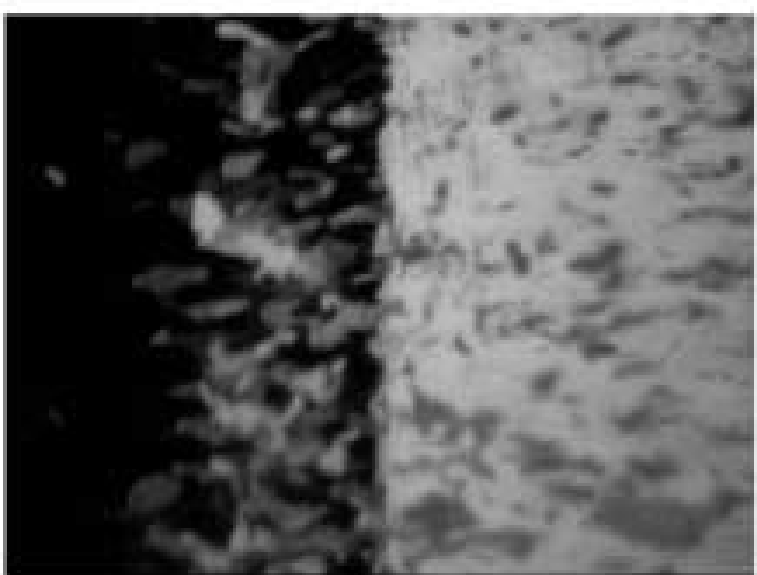

$\mathrm{t}=0.250 \mathrm{sec}$

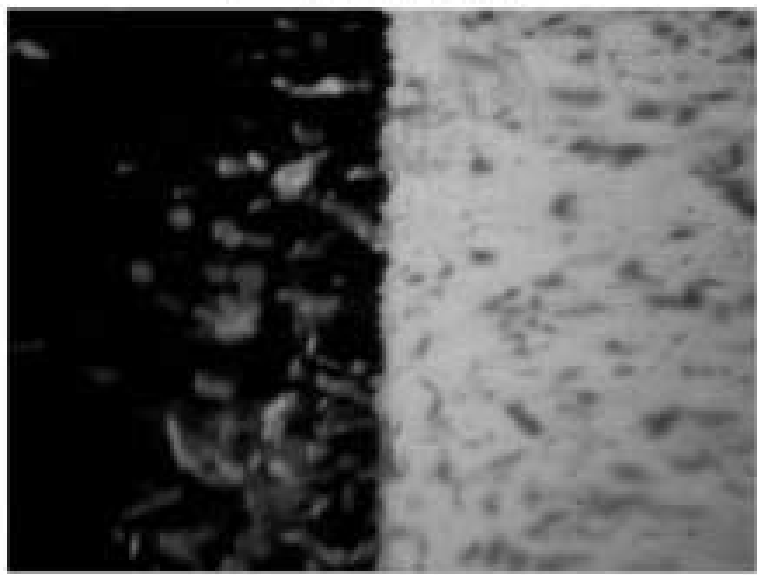

$\mathrm{t}=0.267 \mathrm{sec}$

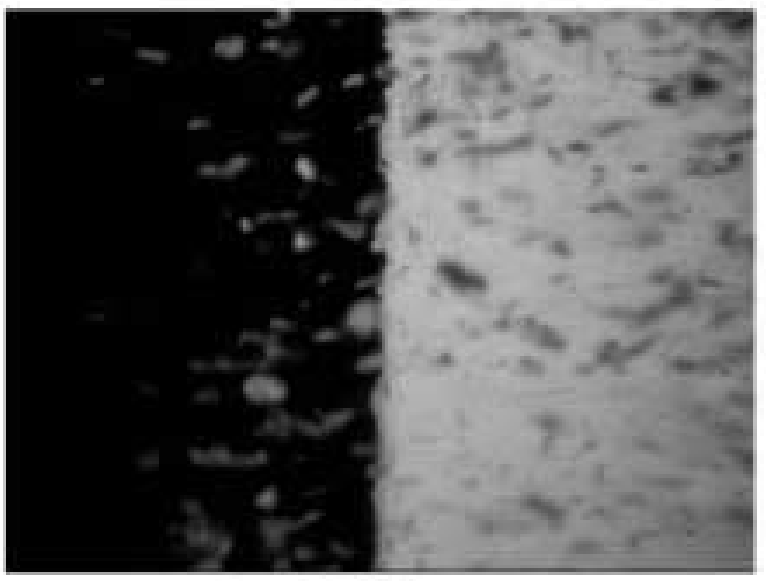

$\mathrm{t}=0.283 \mathrm{sec}$

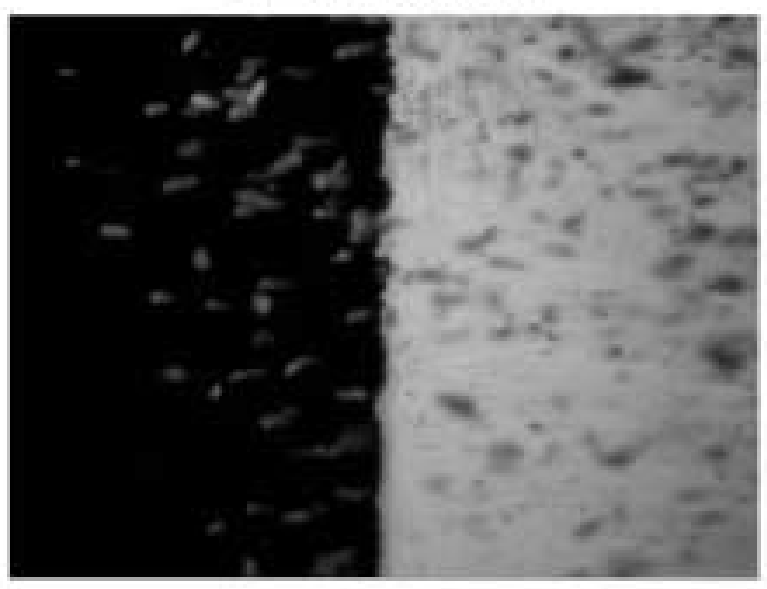

$\mathrm{t}=0.300 \mathrm{sec}$

Figure 4.5.2c Regeneration for a Thin Ash at $5.75 \mathrm{~cm} / \mathrm{s}$ Face Velocity and $1000 \mathrm{kPa}$ Reservoir Pressure 


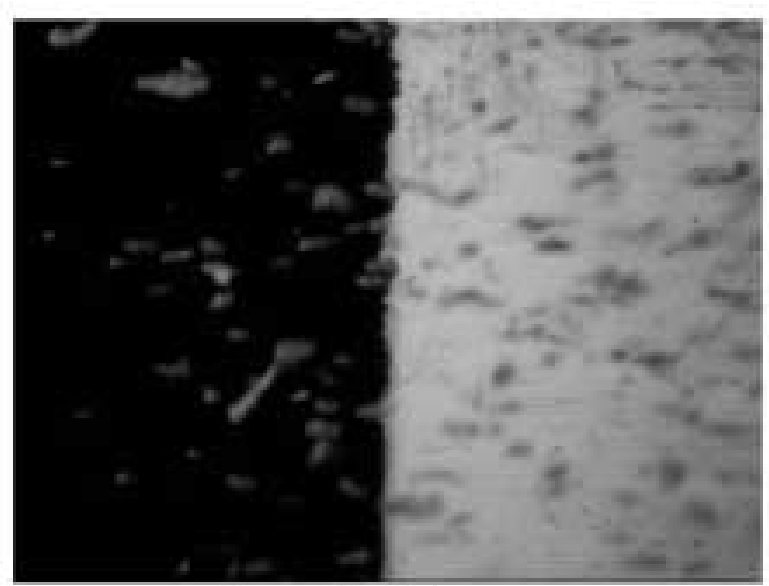

$$
\mathrm{t}=0.317 \mathrm{sec}
$$

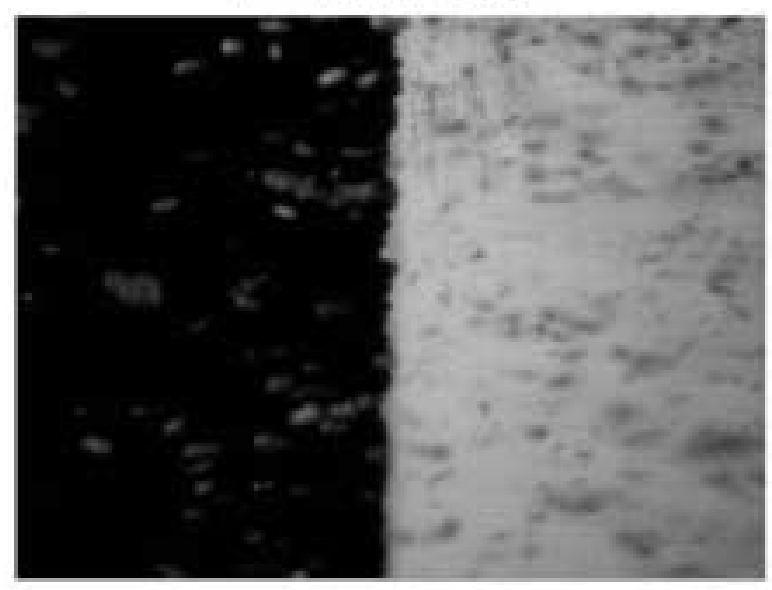

$\mathrm{t}=0.333 \mathrm{sec}$

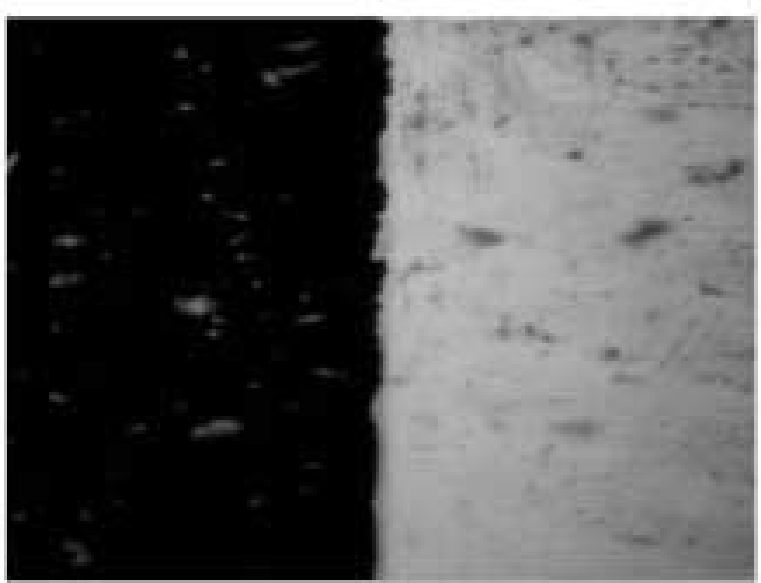

$\mathrm{t}=0.500 \mathrm{sec}$

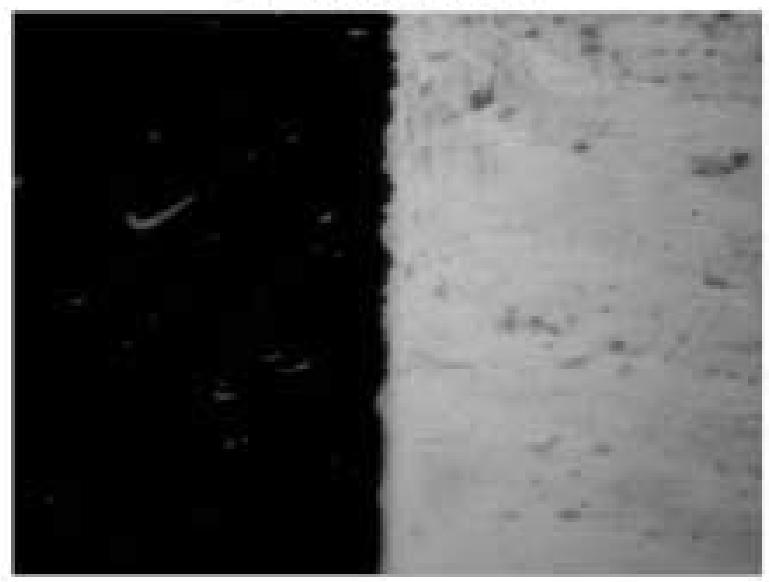

$\mathrm{t}=0.700 \mathrm{sec}$

Figure 4.5.2d Regeneration for a Thin Ash at $5.75 \mathrm{~cm} / \mathrm{s}$ Face Velocity and $1000 \mathrm{kPa}$ Reservoir Pressure 


\section{Chapter 5}

\section{Conclusions and Recommendations}

\subsection{Conclusions}

As stated before, this research project is only a stepping stone to developing a high temperature test facility. The specific objective of this effort is to develop the instrumentation necessary to investigate the surface regeneration process at high temperatures in a room temperature test facility (RTTF). The changes brought about by this effort have given the researcher the ability to control many of the important variables such as the face velocity, reservoir pressure, time period for pulse regeneration, frequency of surface regeneration, and the ability to change the filter. These concepts will now be incorporated in the high temperature test facility.

It has been demonstrated that the chamber along with its pressure transducers can measure the pressure drop across the filter for the length of the regeneration process. Using the pressure histories, surface regeneration efficiencies can be calculated to see how well the candle filter was cleaned. Using the pictures taken, the time of crack initiation may be estimated, the pressure drop at the time of initiation can be estimated for any given test as long as the pictures show the crack initiation. These important characteristics of the regeneration process will lead to a better understanding of high temperature gas cleaning and hopefully help to improve the performance of power plants everywhere.

The recorded data showed that as the face velocity increases, the regeneration process becomes more difficult. It also showed that as the reservoir pressure increases, 
the surface regeneration process becomes easier. A thicker ash also makes regeneration more difficult.

\subsection{Recommendations for the Future}

Several improvements and additions can be made to the experiment to give more information. The variable of time for the pressure pulse period may be added. The only thing that would need to be changed in the present system to accomplish this would be the computer program.

Another possible improvement would be to find a method of either keeping the windows clean or cleaning the windows without taking them off or entering the system. This will be a necessity for a high temperature system because it will be impossible to reach into the chamber to clean the windows or to remove the windows at $1500^{\circ} \mathrm{F}$.

Adding a pressure transducer to measure the pressure between the cap and the chamber might add information to the tests since the cap pressure appears to be very similar to the filter pressure.

The face velocity of the gas coming out of the filter can also be measured during regeneration for a clean filter. A thin film anemometer could accomplish this. 


\section{References}

Berbner, Stefan, and Lofler, Friedrich, "Pulse Jet Cleaning of Rigid Filter Elements at High Temperatures", Gas Cleaning at High Temperatures, Chapman and Hall, 1993, pp. 225-243.

Chiang, Ta-Kuan, "Regeneration Characteristics of a Rigid Barrier Filter", Symposium on High Temperature Particulate Cleanup for Advanced Coal-Based Power Systems, DOE/EPRI, Birmingham, AL, April 20-23, 1998

Cicero Daniel C., Dennis, Richard A., Geiling, Donald W., and Schmidt, Dale K., "Hotgas cleanup for coal-based gas turbines", Mechanical Engineering, September, 1994, pp. 70-75.

Dennis R., McMahon, T., Dorchak, T., and Chaing, T., “U.S. Department of Energy's High-Temperature and High-Pressure Particulate Cleanup Program for Advanced Coal-Based Power Systems", High Temperature Gas Cleaning Volume II, 1999, G. Braun ems GmbH, pp. 303-314.

Krein, J., "LLB Candle Filter for the ELCOGAS IGCC Power Plant Puertollano/Spain", High Temperature Gas Cleaning Volume II, 1999, G. Braun ems GmbH, pp. 253260.

Laux, S., Giernoth, B., Bulak, H., Renz, U., "Aspects of Pulse-Jet Cleaning of Ceramic Filter Elements", Gas Cleaning at High Temperatures, Chapman and Hall, 1993, pp. 203-224.

Lippert, T.E. [1], et. al., "Development of Hot Gas Cleaning Systems for Advanced, Coal-Based Gas Turbine Cycles", Journal of Engineering for Gas Turbines and Power, Vol. 115, July 1993, pp. 658-664.

Lippert, T.E. [2], et. al., "Hot Gas Filter Development for Advanced Power Systems" High Temperature Gas Cleaning Volume II, 1999, G. Braun ems GmbH, pp. 291302 .

Natesan, K., "Materials Performance in Advanced Combustion Systems", Journal of Engineering for Gas Turbines and Power, April 1994, Vol. 116, pp. 331-337.

Newby, R. A., Bannister, R. L., "Advanced Hot Gas Cleaning System for Coal Gasification Processes", Journal of Engineering for Gas Turbines and Power, Vol. 116, April 1994, pp. 338-344.

Quimby, Jay M. and Kumar, K. Sam, "Hot Gas Cleanup for Advanced Power Generation System", Gas Cleaning at High Temperatures, Chapman and Hall, 1993, pp. 6685. 
Sasatsu, Hiroshi, Misawa, Nobuhiro, Abe, Rikiya, and Mochida, Isao, "Prediction for Pressure Drop Across CTF at Wakamatsu 71 Mwe PFBC Combined Cycle Power Plant", High Temperature Gas Cleaning Volume II, 1999, G. Braun ems GmbH, pp. 261-275.

Stringer, J., Leitch, A. J., "Ceramic Candle Filter Performance at the Grimethorpe (UK) Pressurized Fluikized Bed Combustor", Journal of Engineering for Gas Turbines and Power, April 1992, Vol. 114, pp. 371-379. 


\section{Appendix A}

First a brief explanation of DAPL. The DAPL language uses subroutines that must be called before the subroutines are performed. Very few commands are left outside of the subroutines. Most of the commands outside of the subroutines are definitions. In reading or sending out signals it uses pipes to keep the data organized.

DAPL program for collecting build-up data, Calib.dap:

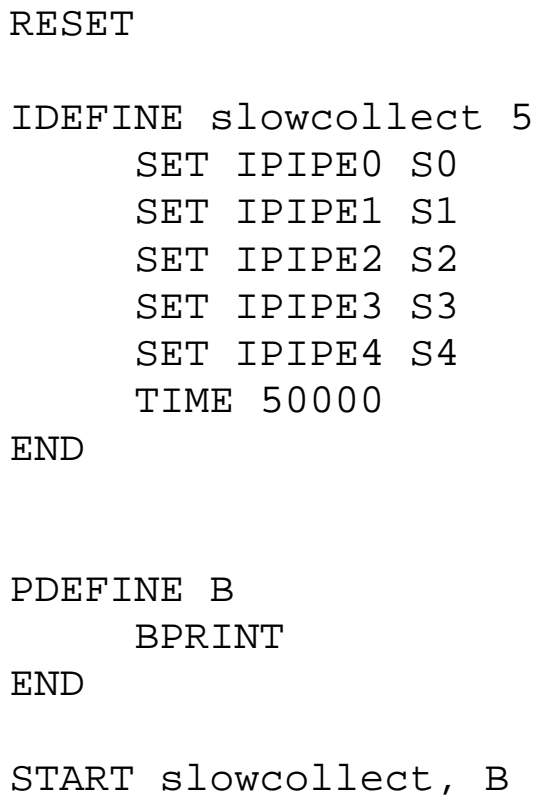

IDEFINE is a command that creates and initializes the input configuration.

"slowcollect" is the title of the "subroutine". The "5" sets the number of channel pipes at five. This means that the board is prepared to accept five channels of input. The "SET IPIPE0 SO" sets the first input pipe to read the data from the S0 channel. "SET IPIPE1 S1" and the others are similar. "TIME 50000" sets the time (in microseconds) that the board waits in between each operation in that subroutine. In this case 50,000 microseconds (.05 seconds) is the delay in between the acquisition of each voltage read. 
So with 5 channels there is a delay of .25 seconds ( 5 channels multiplied by .05 seconds) in between the reading of each signal. So every 0.25 seconds one reading is taken for each channel.

The next subroutine sends the data that is taken in the first subroutine to the computer. PDEFINE creates a processing procedure. BPRINT sends the raw data to the computer with no processing in the data acquisition processor. This subroutine is titled "B".

"START SLOWCOLLECT, B" starts the subroutines.

DAPL program for collecting regeneration data, "Fastack.dap":

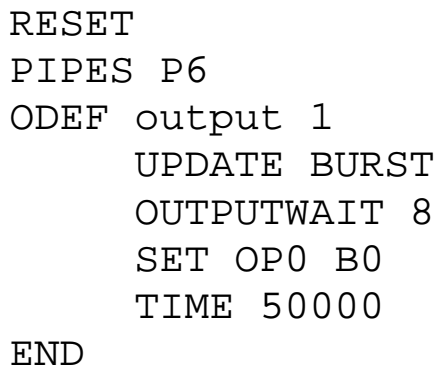

FILL P $\quad \$ 0001 \$ 0006 \$ 0006 \$ 0006 \$ 0006 \$ 0006 \$ 0006 \$ 0000$

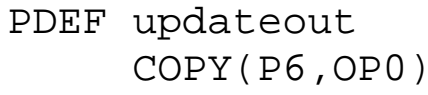




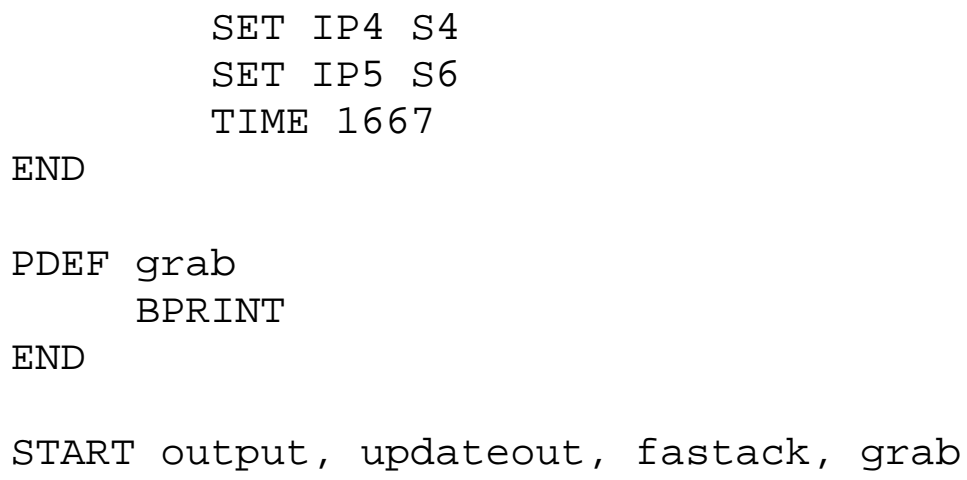

This program is more complicated than the first one. "PIPES P6" creates a pipe called P6. This pipe will be used for the digital output signal. ODEF begins an output updating configuration. "output" is the title of the subroutine. The " 1 " sets the number of channel pipes at one. The UPDATE command selects the output configuration. The output configuration is set to BURST. "OUTPUTWAIT 8" sets the number of samples for the output channel pipe. "SET OP0 B0" sets the outpipe3 (OP3) to the binary output. "TIME 50000" sets the time (in microseconds) that the board waits in between each update in the pipe.

"FILL P6" fills pipe 6 with the digital output. The first signal is set to "0001". This means channel 0 is high and the others are low. "0006" sets channel 0 low, channel 1 high, channel 2 high, and the others are low. The camera trigger reads a drop in the signal, so it is triggered when channel 0 goes low. The solenoid valve is triggered by a high signal and is connected to channel 1. Channel 2 is connected to an analog input channel so that the person looking at the data collected will know how long the solenoid valve was open. For all of the tests this thesis the solenoid valve was open for 0.3 seconds, which is what is programmed here. 
"PDEF updateout" starts a new subroutine called updateout. "COPY (P6,OP0)" copies pipe 6 to output pipe 0 . "PIPES P0, P1, P2, P3, P4, P5" creates six new pipes. "IDEF fastack 6" starts another subroutine titled fastack that is prepared to accept six input signals. . The "SET IPIPE0 SO" sets the first input pipe to read the data from the S0 channel. "SET IPIPE1 S1" and the others are similar. "TIME 1667" sets the time (in microseconds) that the board waits in between each operation in that subroutine. In this case 1,667microseconds (.001667 seconds) is the delay in between the acquisition of each voltage read. So with 6 channels there is a delay of .01 seconds ( 6 channels multiplied by .001667 seconds) in between the reading of each signal. So every 0.01 seconds one reading is taken for each channel.

The next subroutine sends the data that is taken in the first subroutine to the computer. PDEF creates a processing procedure. BPRINT sends the raw data to the computer with no processing in the data acquisition processor. This subroutine is titled "grab".

"START output, updateout, fastack, grab" starts the subroutines. 


\section{Appendix B}

In this appendix an equation for the mass flow in terms of radii, pressures and permeabilities will be derived. For the flow through a porous media the equations of continuity and motion can be written as:

$$
\varepsilon \frac{\delta \rho}{\delta t}=-(\nabla \cdot \rho v)
$$

B.1

where,

$$
\begin{aligned}
& \varepsilon=\text { Porosity } \\
& \rho=\text { Density } \\
& v=\text { velocity } \\
& t=\text { time }
\end{aligned}
$$

Also using Darcy's Law:

$$
\mathrm{v}=-\frac{\mathrm{k}}{\mu}(\nabla P)
$$

Where,

$$
\begin{aligned}
& \mathrm{k}=\text { permeability } \\
& \mu=\text { viscosity } \\
& \mathrm{P}=\text { pressure }
\end{aligned}
$$

Using $\mathrm{p}=\rho \mathrm{RT}$ yields with $\mathrm{T}$ as a constant:

$$
P=\rho\left(\frac{P_{0}}{\rho_{0}}\right)
$$


Note that $\beta=\mathrm{P}_{0} / \rho_{0}$. So,

Substituting B. 2 and B. 3 into B.1 yields:

$$
\rho=\frac{P}{\beta}
$$

B.3

Which simplifies to

$$
\frac{\varepsilon}{\beta} \frac{\delta \mathrm{P}}{\delta \mathrm{t}}=-\nabla \cdot\left(\frac{\mathrm{P}}{\beta}\left[-\frac{\mathrm{k}}{\mu} \nabla \mathrm{P}\right]\right)
$$

$$
\varepsilon \frac{\delta \mathrm{P}}{\delta \mathrm{t}}=\frac{\mathrm{k}}{2 \mu} \nabla^{2} \mathrm{P}^{2}
$$

Assuming Steady-State

$$
\nabla^{2} \mathrm{P}^{2}=0
$$

B.6

In polar coordinates, assuming an axis-symmetric model that is constant along the length of the filter:

$$
\frac{1}{\mathrm{r}} \frac{\delta}{\delta \mathrm{r}}\left(\mathrm{r} \frac{\delta \mathrm{P}^{2}}{\delta \mathrm{r}}\right)=0
$$

The solution for this equation is $\mathrm{P}^{2}=\mathrm{C}_{1} \ln \mathrm{r}+\mathrm{C}_{2}$. Note that $\mathrm{C}_{1}$ and $\mathrm{C}_{2}$ are constants.

Using the notation used in Figure B.1 and algebraic manipulation yields:

$$
\frac{\mathrm{P}^{2}-\mathrm{P}_{2}^{2}}{\mathrm{P}_{1}^{2}-\mathrm{P}_{2}^{2}}=\frac{\ln \left(\frac{\mathrm{r}}{\mathrm{r}_{2}}\right)}{\ln \left(\frac{\mathrm{r}_{1}}{\mathrm{r}_{2}}\right)}
$$

Taking the derivative of $\mathrm{P}$ with respect to $\mathrm{r}$ and using the product rule gives: 


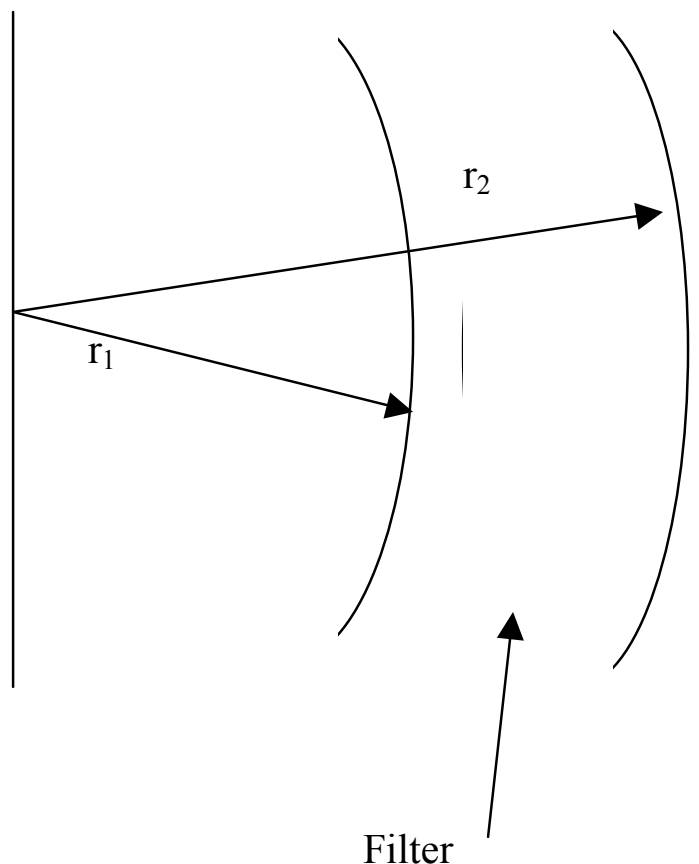

Figure B.1

Schematic of Filter and Radii

$$
\left(\frac{\delta \mathrm{P}}{\delta \mathrm{r}}\right)_{\mathrm{r}_{1}}=\frac{\mathrm{P}_{1}^{2}-\mathrm{P}_{2}^{2}}{2 \mathrm{P}_{1} \ln \left(\frac{\mathrm{r}_{1}}{\mathrm{r}_{2}}\right)} \frac{1}{\mathrm{r}}
$$

Substituting into B.2, the solution of the pressure derivative yields: 


$$
\mathrm{v}=\frac{\mathrm{k}}{\mu} \frac{1}{2 \rho \mathrm{RT}}\left[\frac{\mathrm{P}_{1}^{2}-\mathrm{P}_{2}^{2}}{\ln \left(\frac{\mathrm{r}_{2}}{\mathrm{r}_{1}}\right)}\right]
$$

This shows that the velocity should be proportional to the difference of the squares of the pressures across the filter. Now let $\mathrm{P}_{2}=\mathrm{P}_{1}+\Delta \mathrm{P}$. Ignoring the $\Delta \mathrm{P}^{2}$ term because it is small gives:

$$
\mathrm{v}=\frac{\mathrm{k}}{\mu} \frac{1}{2 \rho \mathrm{RT}}\left[\frac{-2 \Delta \mathrm{P}}{\ln \left(\frac{\mathrm{r}_{2}}{\mathrm{r}_{1}}\right)}\right]
$$




\section{Appendix C}

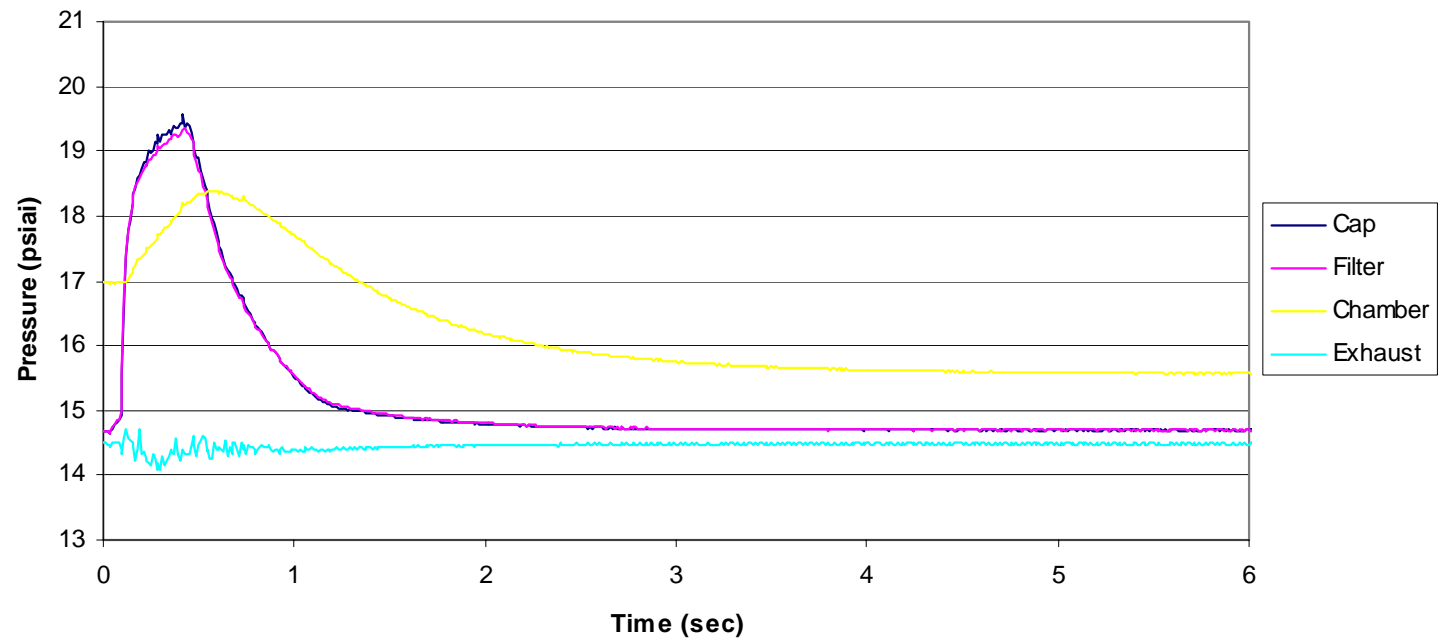

Figure C.1

Graph of Pressure vs. Time for Thick Ash, 145 psia Reservoir Pressure, and $3.65 \mathrm{~cm} / \mathrm{s}$ Face Velocity

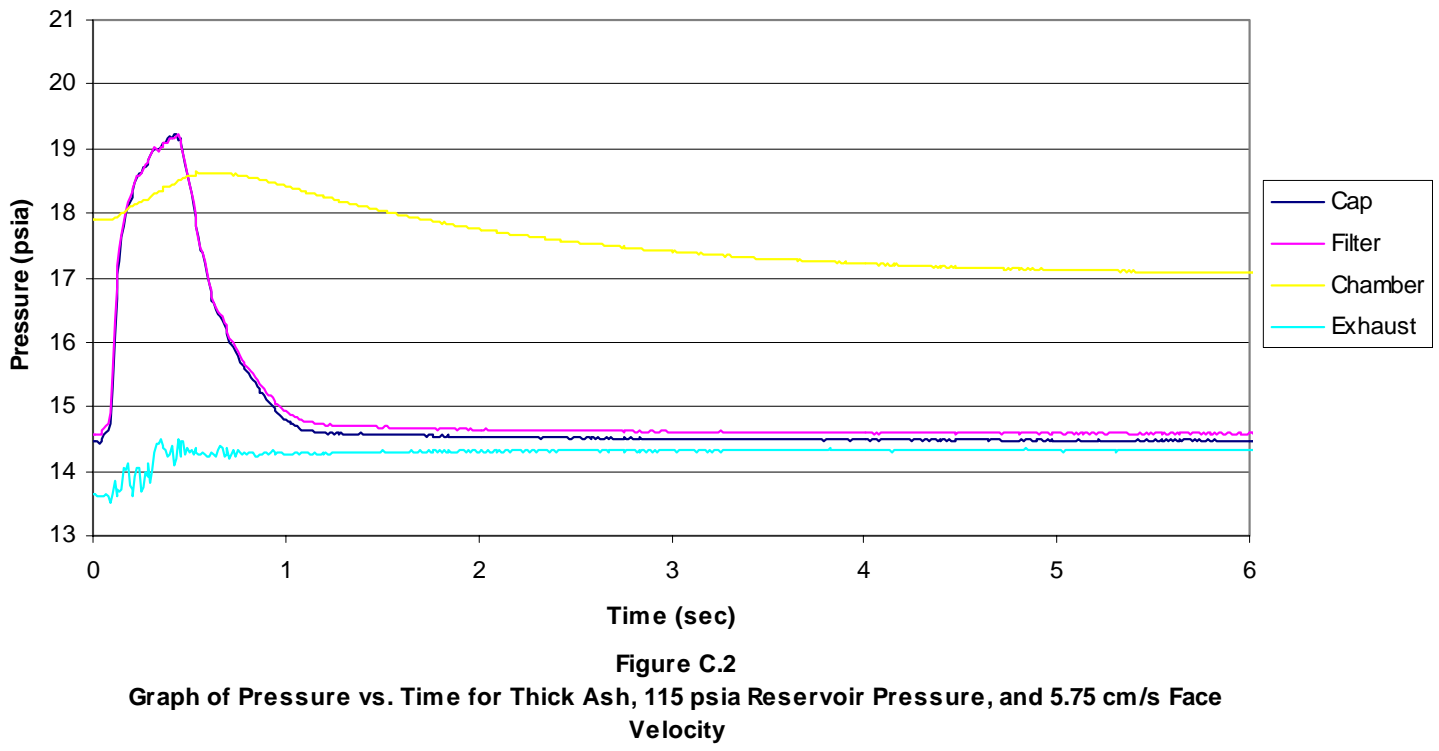



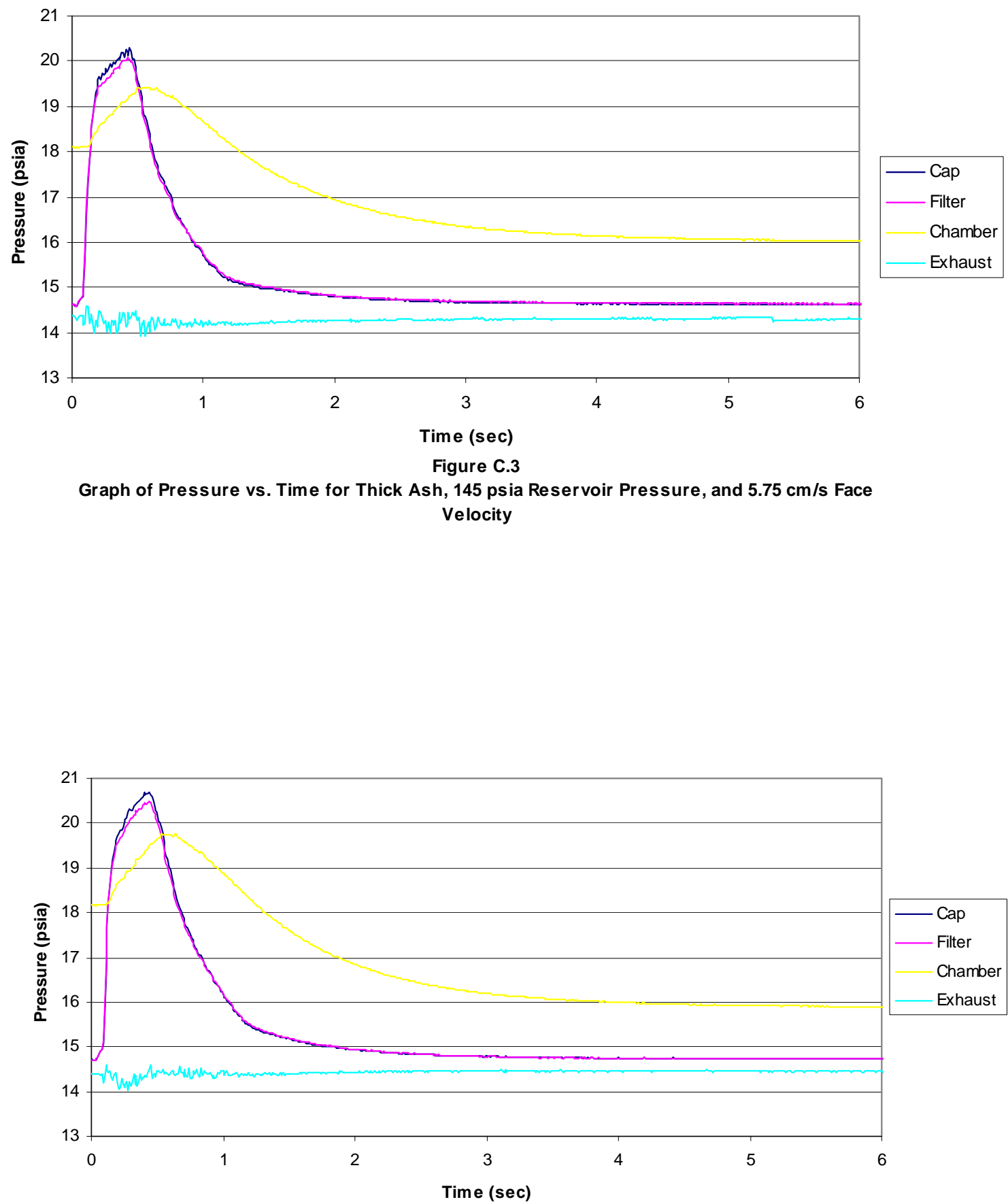

Figure C.4

Graph of Pressure vs. Time for Thick Ash, 145 psia Reservoir Pressure, and $5.75 \mathrm{~cm} / \mathrm{s}$ Face Velocity 

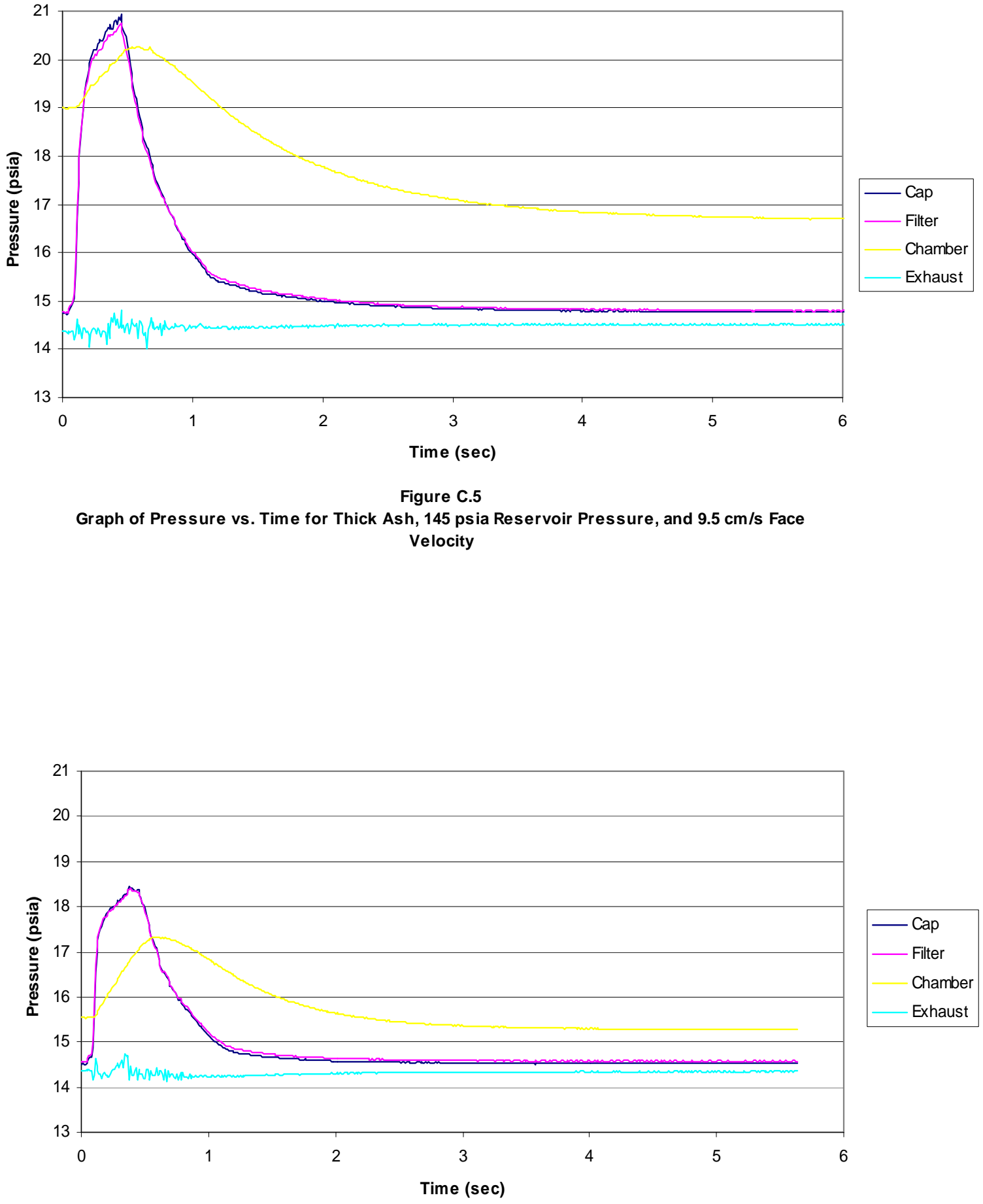

Figure C. 6

Graph of Pressure vs. Time for Thin Ash, 145 psia Reservoir Pressure, and $3.65 \mathrm{~cm} / \mathrm{s}$ Face Velocity 

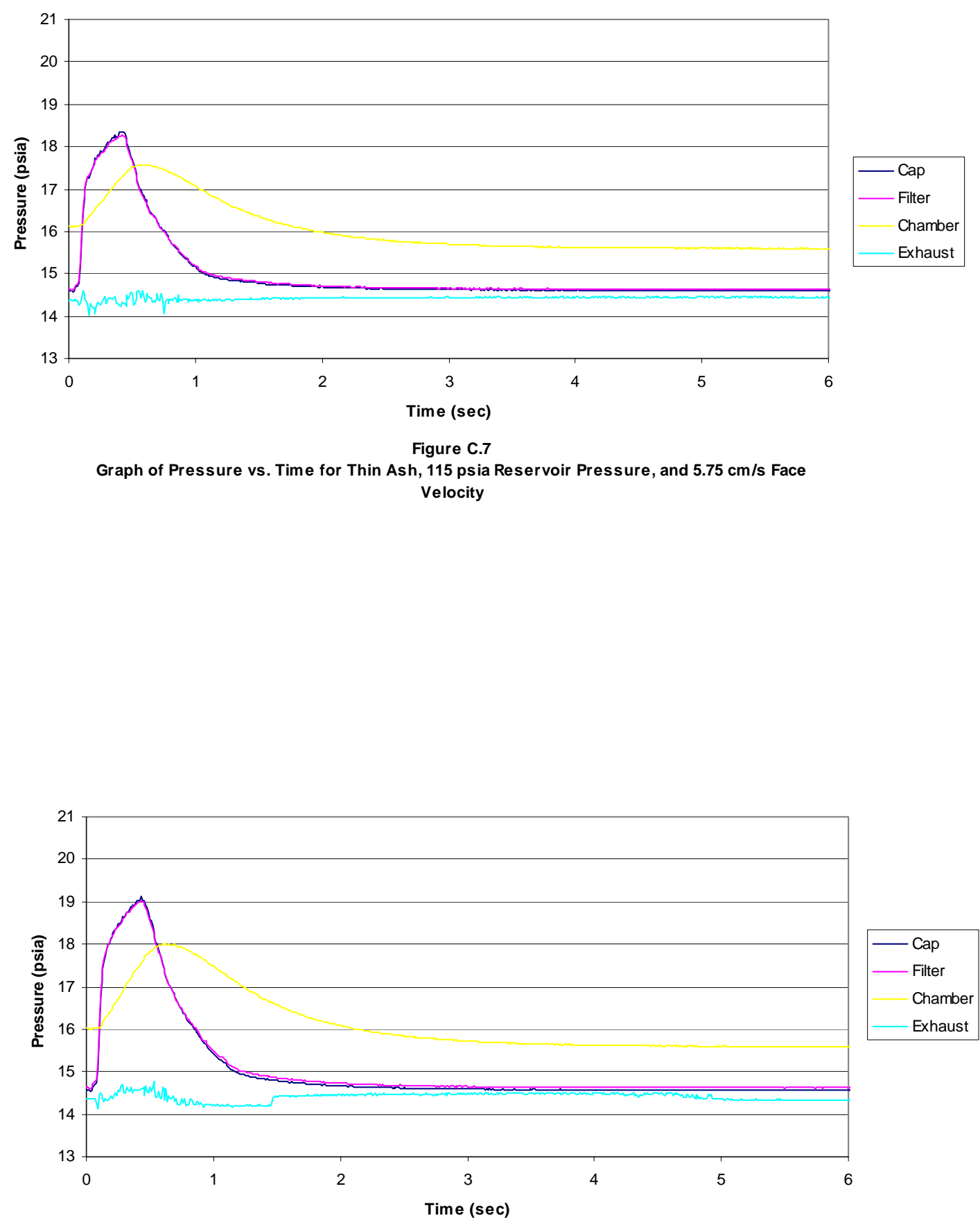

Figure C.8

Graph of Pressure vs. Time for Thin Ash, 145 psia Reservoir Pressure, and $5.75 \mathrm{~cm} / \mathrm{s}$ Face Velocity 


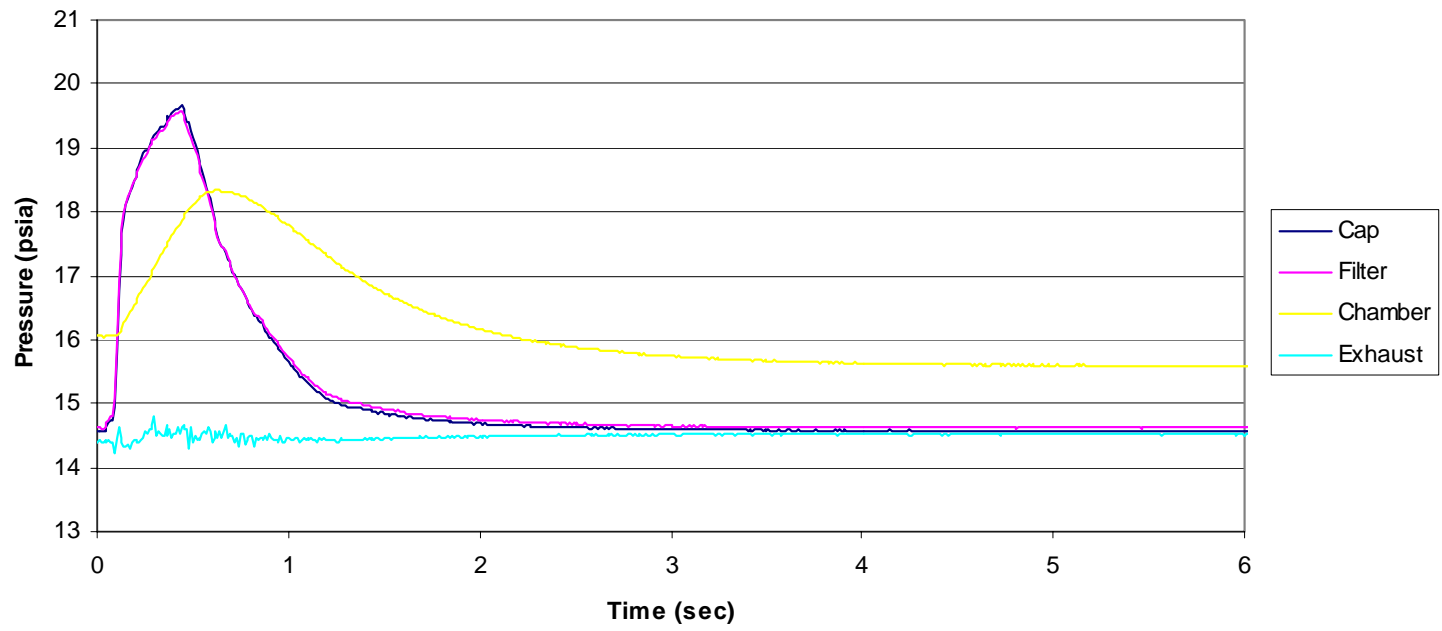

Figure C.9

Graph of Pressure vs. Time for Thin Ash, 160 psia Reservoir Pressure, and $5.75 \mathrm{~cm} / \mathrm{s}$ Face Velocity

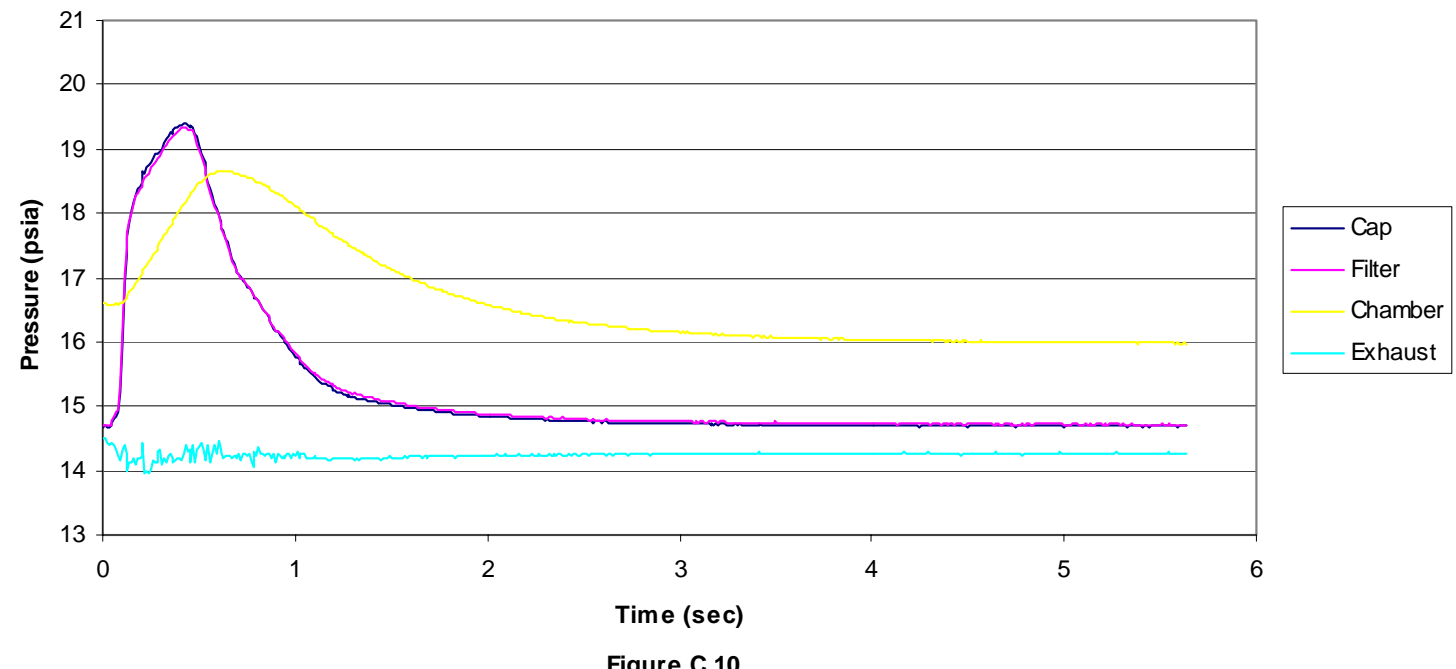

Graph of Pressure vs. Time for Thick Ash, $145 \mathrm{psia}$ Reservoir Pressure, and $9.5 \mathrm{~cm} / \mathrm{s}$ Face Velocity 


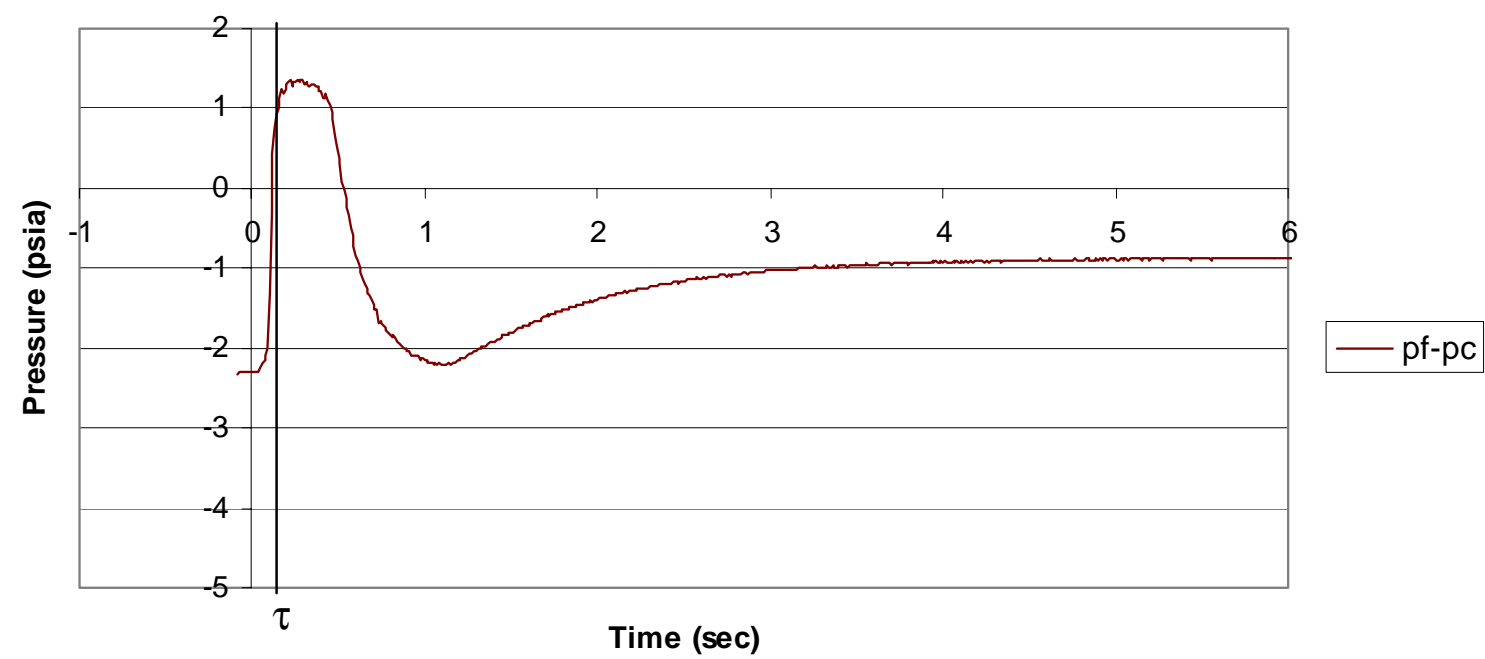

Figure C.11

Graph of Pressure Drop for Thick Ash, 145 psia Reservoir Pressure, and $3.65 \mathrm{~cm} / \mathrm{s}$ Face Velocity

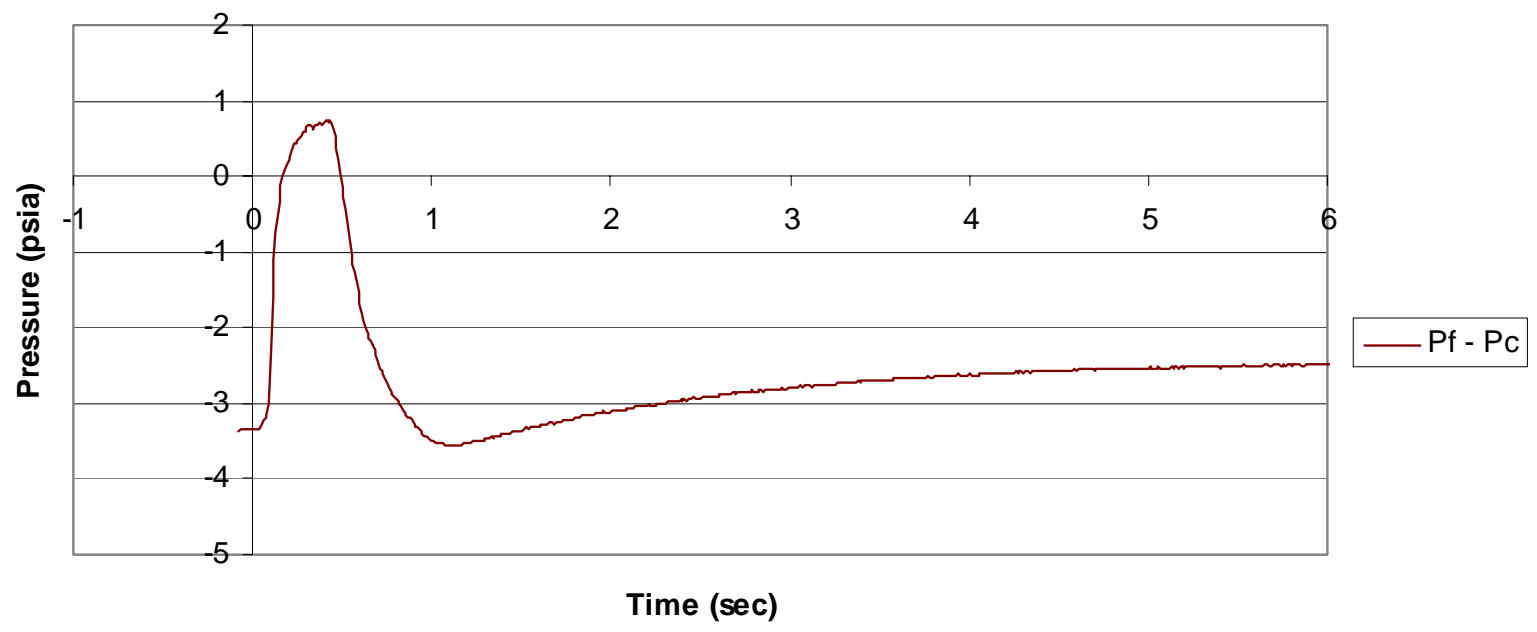

Figure C.12

Graph of Pressure Drop for Thick Ash, 115 psia Reservoir Pressure, and $5.75 \mathrm{~cm} / \mathrm{s}$ Face Velocity 


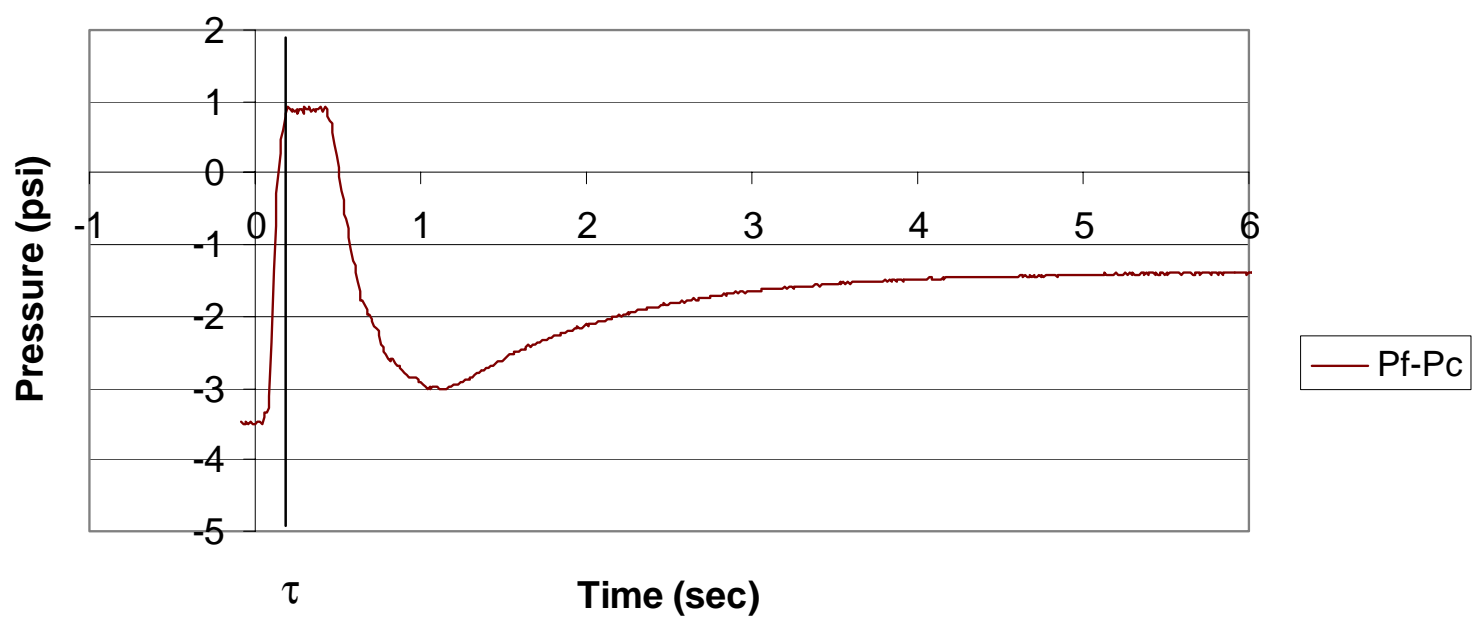

Figure C.13

Graph of Pressure Drop for Thick Ash,145 psia Reservoir Pressure, and 5.75 $\mathrm{cm} / \mathrm{s}$ Face Velocity.

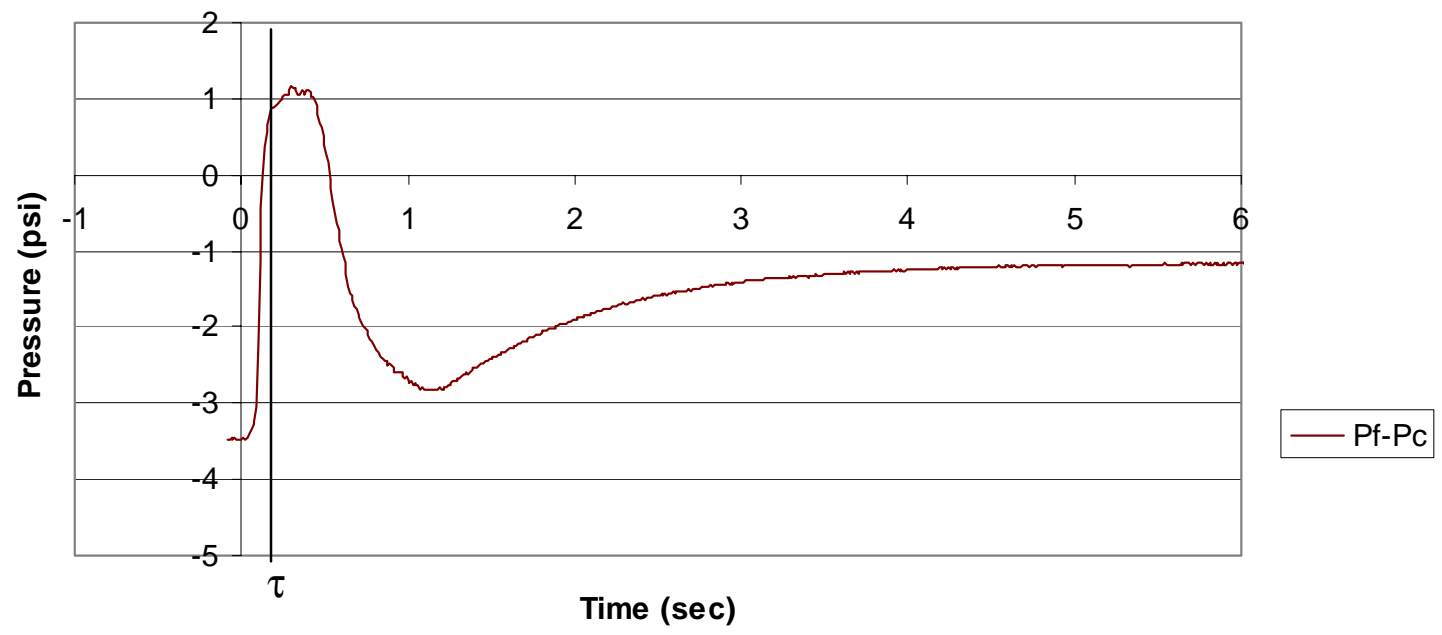

Figure C.14

Graph of Pressure Drop for Thick Ash, 160 psia Reservoir Pressure, and $5.75 \mathrm{~cm} / \mathrm{s}$ Face Velocity 


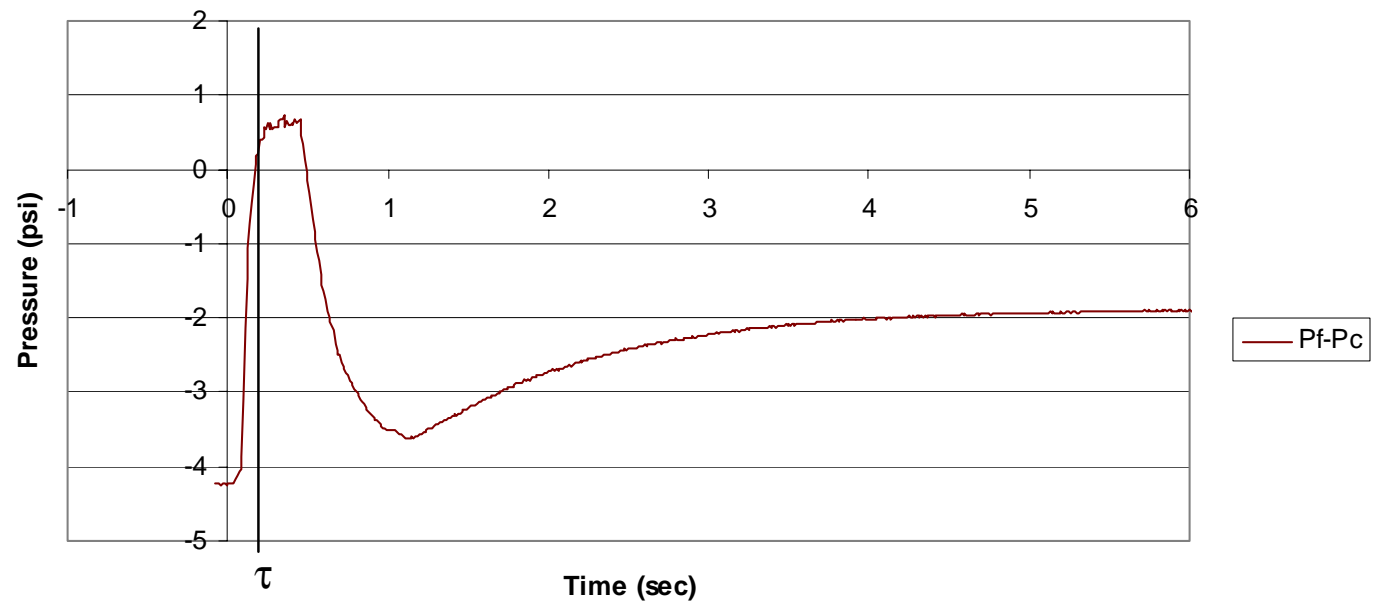

Figure C.15

Graph of Pressure vs. Time for Thick Ash, 145 psia Reservoir Pressure, and $9.5 \mathrm{~cm} / \mathrm{s}$ Face Velocity

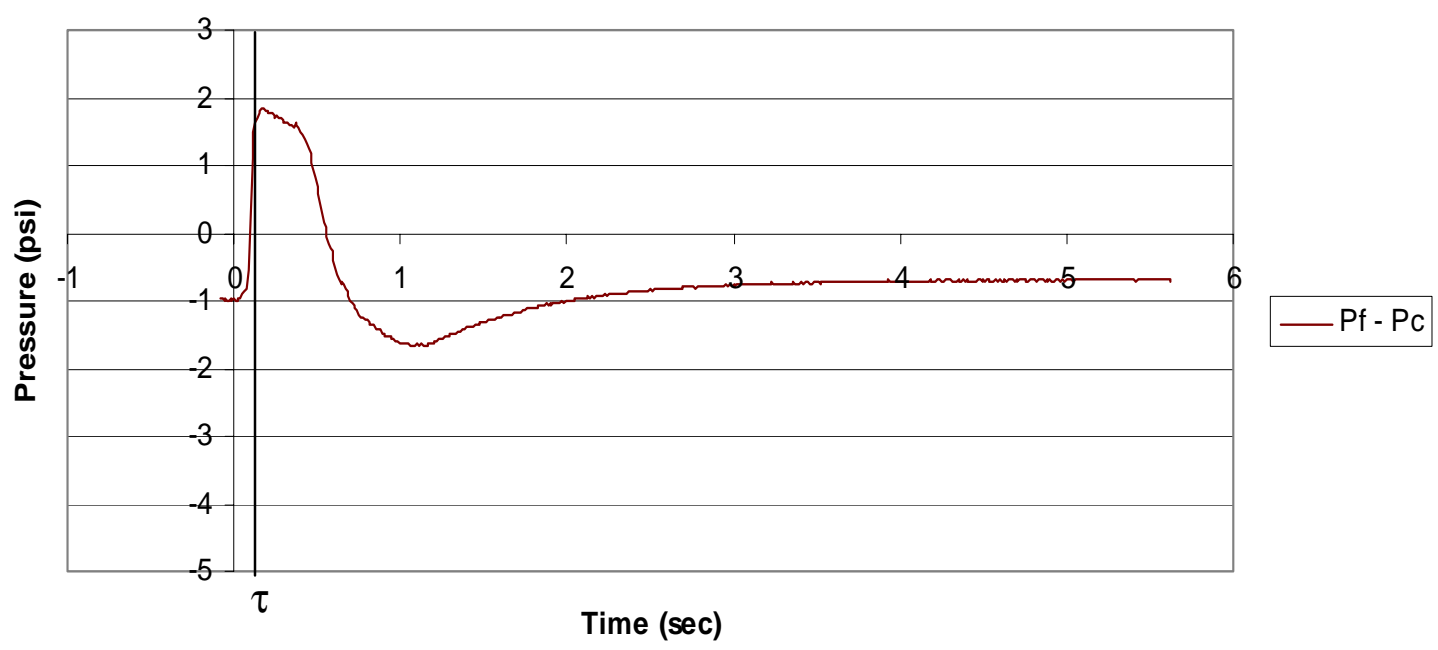

Figure C.16

Graph of Pressure Drop for Thin Ash, 145 psia Reservoir Pressure, and $3.65 \mathrm{~cm} / \mathrm{s}$ Face Velocity 


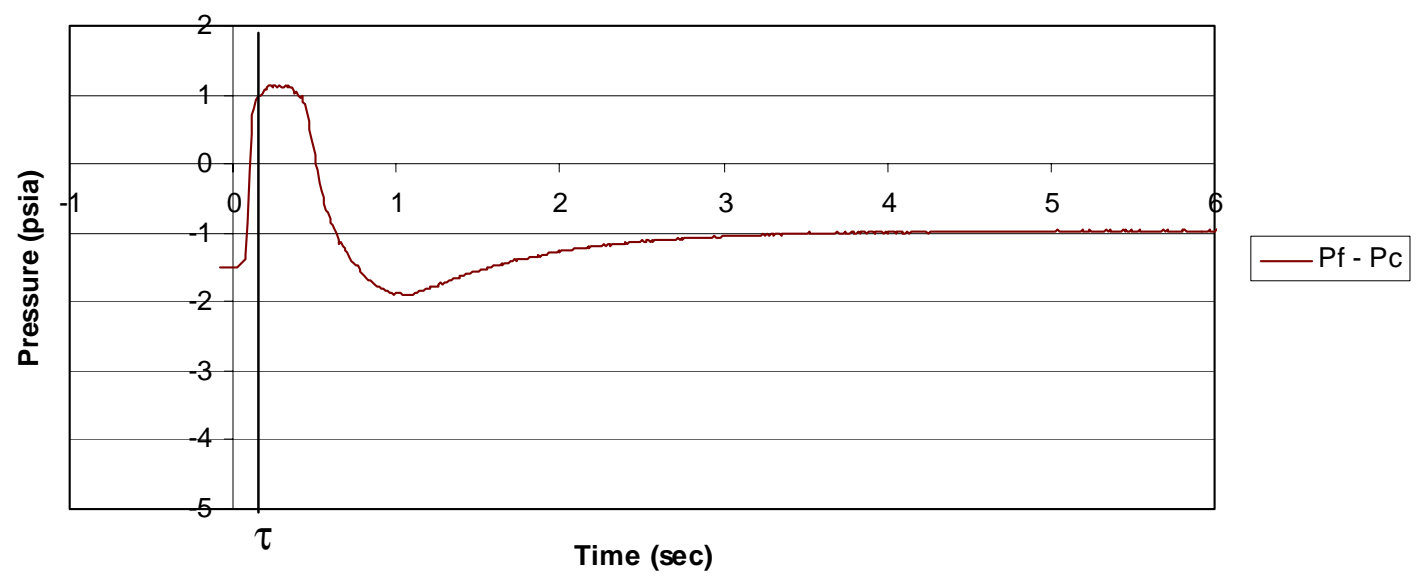

Figure C.17

Graph of Pressure Drop for Thin Ash, 115 psia Reservoir Pressure, and $5.75 \mathrm{~cm} / \mathrm{s}$ Face Velocity

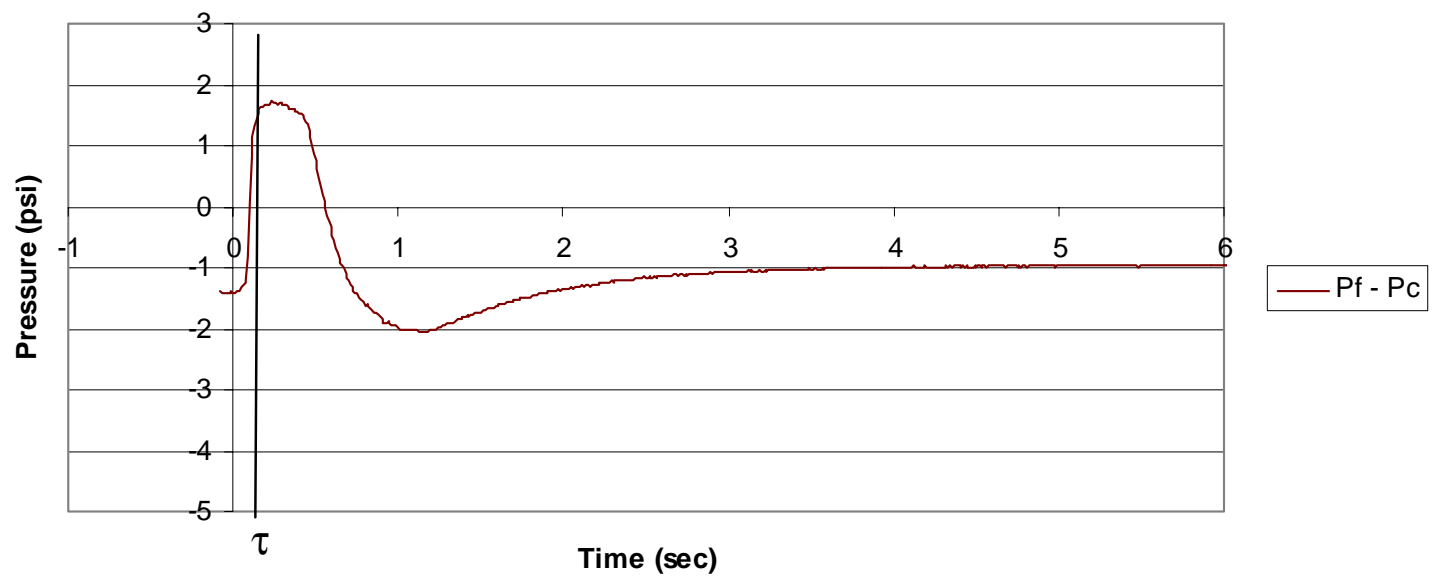

Figure C.18

Graph of Pressure Drop for Thin Ash, 145 psia Reservoir Pressure, and $5.75 \mathrm{~cm} / \mathrm{s}$ Face Velocity 


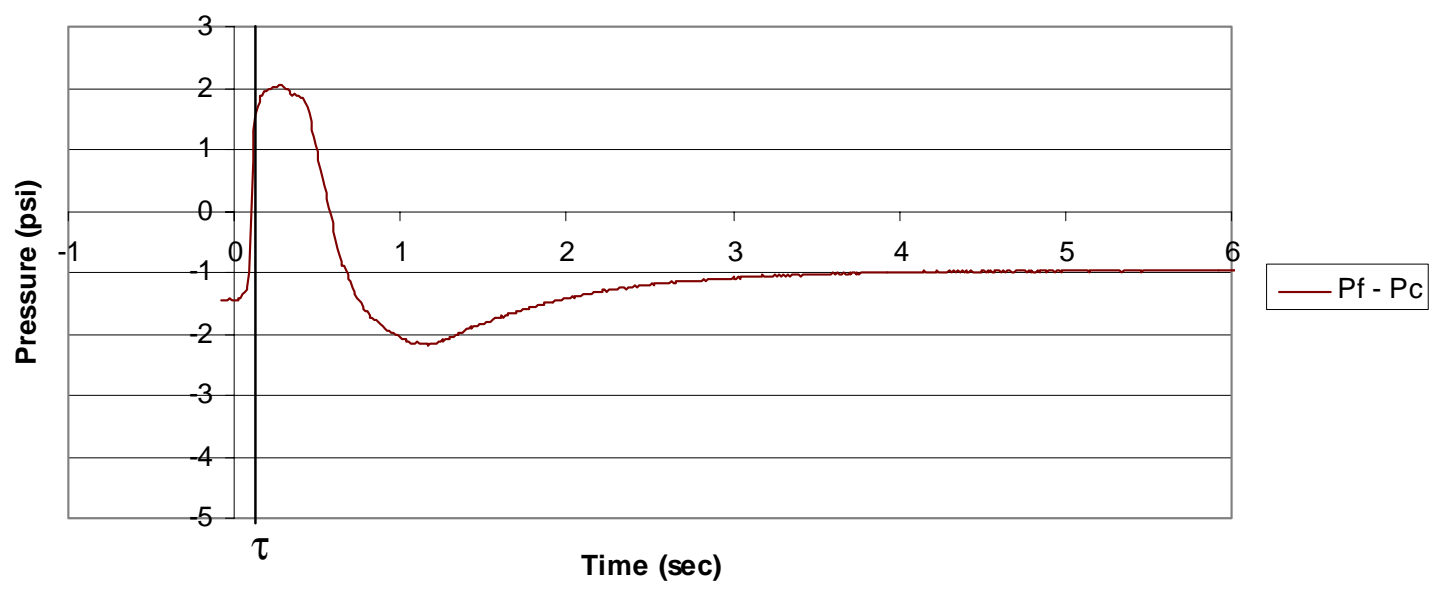

Figure C.19

Graph of Pressure Drop for Thin Ash, 160 psia Reservoir Pressure, and $5.75 \mathrm{~cm} / \mathrm{s}$ Face Velocity

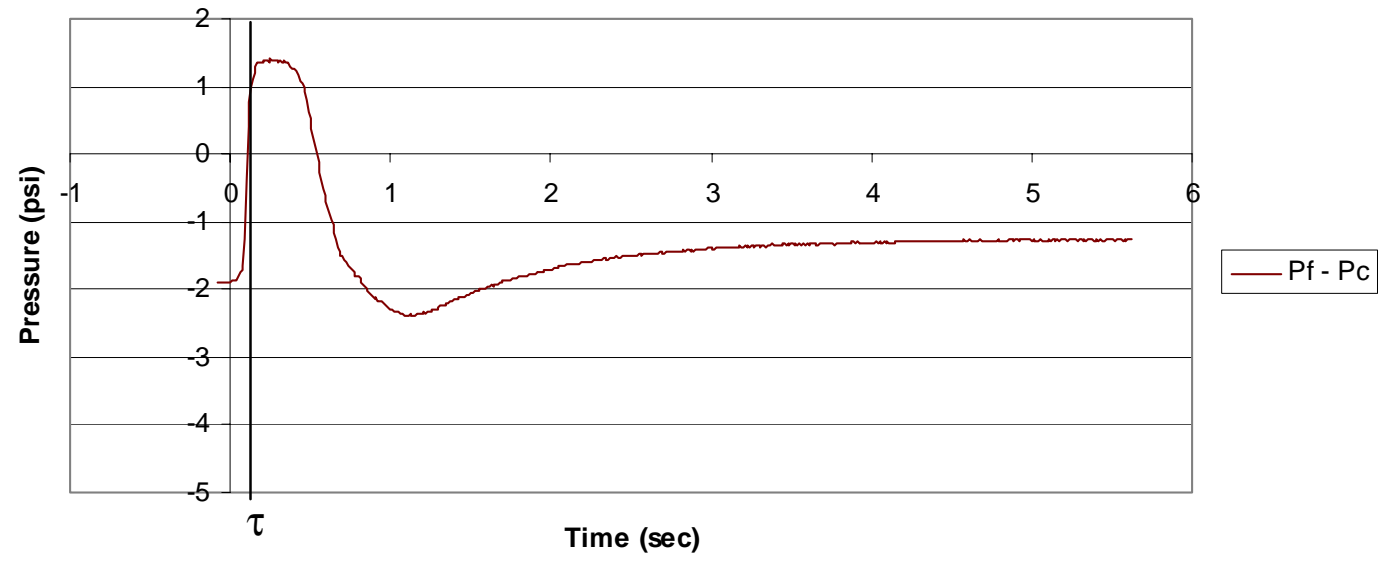

Figure C.20

Graph of Pressure Drop for Thin Ash, 145 psia Reservoir Pressure, and $9.5 \mathrm{~cm} / \mathrm{s}$ Face Velocity 


\section{Appendix D}

This appendix graphs and lists the data used for the reference curve, Figure 4.3.1.

Listed are the maximum and the minimum pressures found in the data. For the face velocity calculations the possible operator error in reading the pressure gage and the flow meter are taken into account.

\begin{tabular}{|c|c|c|c|c|c|}
\hline Minimum & Used & Maximum & Minimum & Used & Maximum \\
\hline 1.34 & 1.45 & 1.59 & 0.08 & 0.11 & 0.13 \\
\hline 1.73 & 1.85 & 1.98 & 0.12 & 0.13 & 0.14 \\
\hline 2.02 & 2.16 & 2.30 & 0.15 & 0.17 & 0.19 \\
\hline 2.42 & 2.57 & 2.71 & 0.16 & 0.19 & 0.21 \\
\hline 2.88 & 2.99 & 3.06 & 0.19 & 0.22 & 0.24 \\
\hline 3.11 & 3.26 & 3.32 & 0.22 & 0.24 & 0.27 \\
\hline 3.48 & 3.65 & 3.82 & 0.24 & 0.273 & 0.29 \\
\hline 3.87 & 4.05 & 4.23 & 0.27 & 0.29 & 0.31 \\
\hline 4.13 & 4.32 & 4.50 & 0.29 & 0.31 & 0.33 \\
\hline 4.31 & 4.50 & 4.69 & 0.31 & 0.33 & 0.35 \\
\hline 4.68 & 4.87 & 5.09 & 0.33 & 0.35 & 0.36 \\
\hline 4.85 & 5.05 & 5.25 & 0.34 & 0.36 & 0.38 \\
\hline 5.19 & 5.40 & 5.60 & 0.37 & 0.39 & 0.40 \\
\hline 5.55 & 5.75 & 5.94 & 0.38 & 0.404 & 0.43 \\
\hline 6.08 & 6.30 & 6.51 & 0.42 & 0.45 & 0.47 \\
\hline 6.44 & 6.67 & 6.90 & 0.43 & 0.46 & 0.48 \\
\hline 6.80 & 7.03 & 7.27 & 0.47 & 0.49 & 0.51 \\
\hline 7.42 & 7.64 & 7.92 & 0.48 & 0.51 & 0.53 \\
\hline 8.24 & 8.50 & 8.76 & 0.53 & 0.55 & 0.58 \\
\hline 9.21 & 9.50 & 9.78 & 0.61 & 0.625 & 0.64 \\
\hline
\end{tabular}

Table D.1

Data and Possible Errors Used in Reference Curve 
Appendix E

\begin{tabular}{|c|c|c|c|c|c|}
\hline $\begin{array}{c}\text { Ash } \\
\text { Thickness }\end{array}$ & $\begin{array}{c}\text { Face } \\
\text { Velocity } \\
(\mathrm{cm} / \mathrm{s})\end{array}$ & $\begin{array}{c}\text { Reservoir } \\
\text { Pressure } \\
\text { (psia) }\end{array}$ & $\begin{array}{l}\text { Time of } \\
\text { Crack } \\
\text { Initiation }\end{array}$ & $\begin{array}{c}\text { Minimum } \\
\Delta \mathrm{P}_{\tau} \\
(\mathrm{psi})\end{array}$ & $\begin{array}{c}\text { Maximum } \\
\Delta \mathrm{P}_{\tau} \\
(\mathrm{psi})\end{array}$ \\
\hline Thick & 3.65 & 145 & 0.133 & 0.76 & 1.02 \\
\hline Thick & 5.75 & 115 & & & \\
\hline Thick & 5.75 & 145 & 0.183 & 0.78 & 0.91 \\
\hline Thick & 5.75 & 160 & 0.200 & 0.77 & 0.89 \\
\hline Thick & 9.5 & 145 & 0.167 & 0.40 & 0.42 \\
\hline Thin & 3.65 & 145 & 0.117 & 1.41 & 1.63 \\
\hline Thin & 5.75 & 115 & 0.133 & 0.80 & 0.98 \\
\hline Thin & 5.75 & 145 & 0.133 & 1.13 & 1.32 \\
\hline Thin & 5.75 & 160 & 0.117 & 1.32 & 1.55 \\
\hline Thin & 9.5 & 145 & 0.133 & 1.19 & 0.98 \\
\hline
\end{tabular}

Table E.1

Data for Time Interval of Crack Initiation 


\section{VITA}

\section{Sean Gregory}

Date of Birth: June 23, 1975

Place of Birth: $\quad$ Oakland, Maryland

Education:

MS in Mechanical Engineering, West Virginia University

Date of Graduation: August 2001

BS in Engineering Physics/Economics, West Virginia Wesleyan College

Date of Graduation: May 1997 